Electronic Supporting Information For:

Developing Backbone-Modified Mor-DalPhos Ligand Variants for use in PalladiumCatalyzed C-N and C-C Cross-coupling

Mark A. MacLean, Craig A. Wheaton and Mark Stradiotto*

Department of Chemistry, Dalhousie University, 6274 Coburg Road, P.O. Box 15000, Halifax, Nova Scotia, Canada B3H 4R2

Contents:

- NMR spectra (p. S1)

- Information regarding deposited CIF data (p. S66) 
Figure S1. ${ }^{1} \mathrm{H}$ NMR Spectrum of $\mathbf{1}\left(\mathrm{CDCl}_{3}, 500.1 \mathrm{MHz}, 300 \mathrm{~K}\right)$
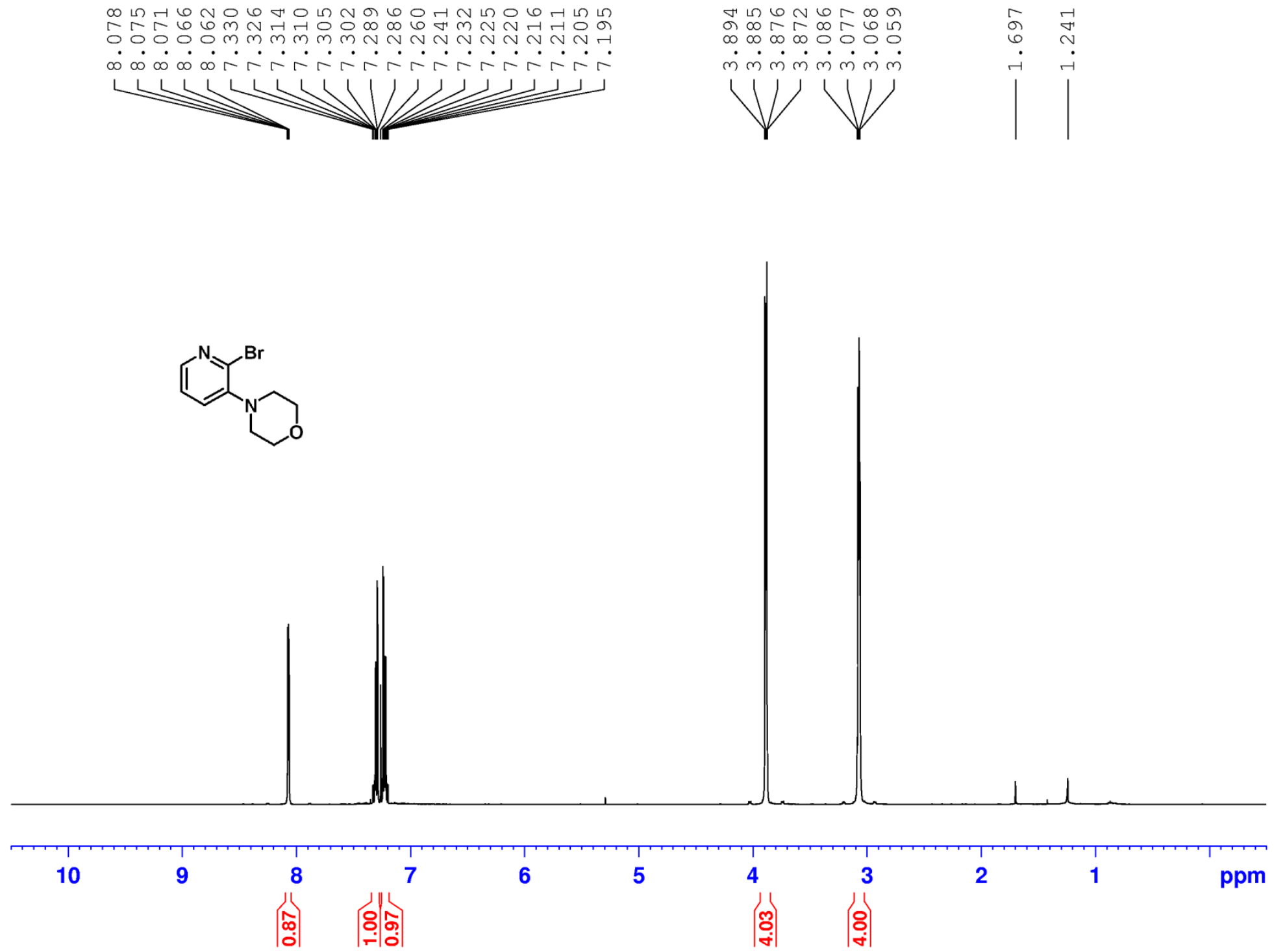
Figure S2. ${ }^{13} \mathrm{C}\left\{{ }^{1} \mathrm{H}\right\}$ NMR Spectrum of $\mathbf{1}\left(\mathrm{CDCl}_{3}, 125.7 \mathrm{MHz}, 300 \mathrm{~K}\right)$
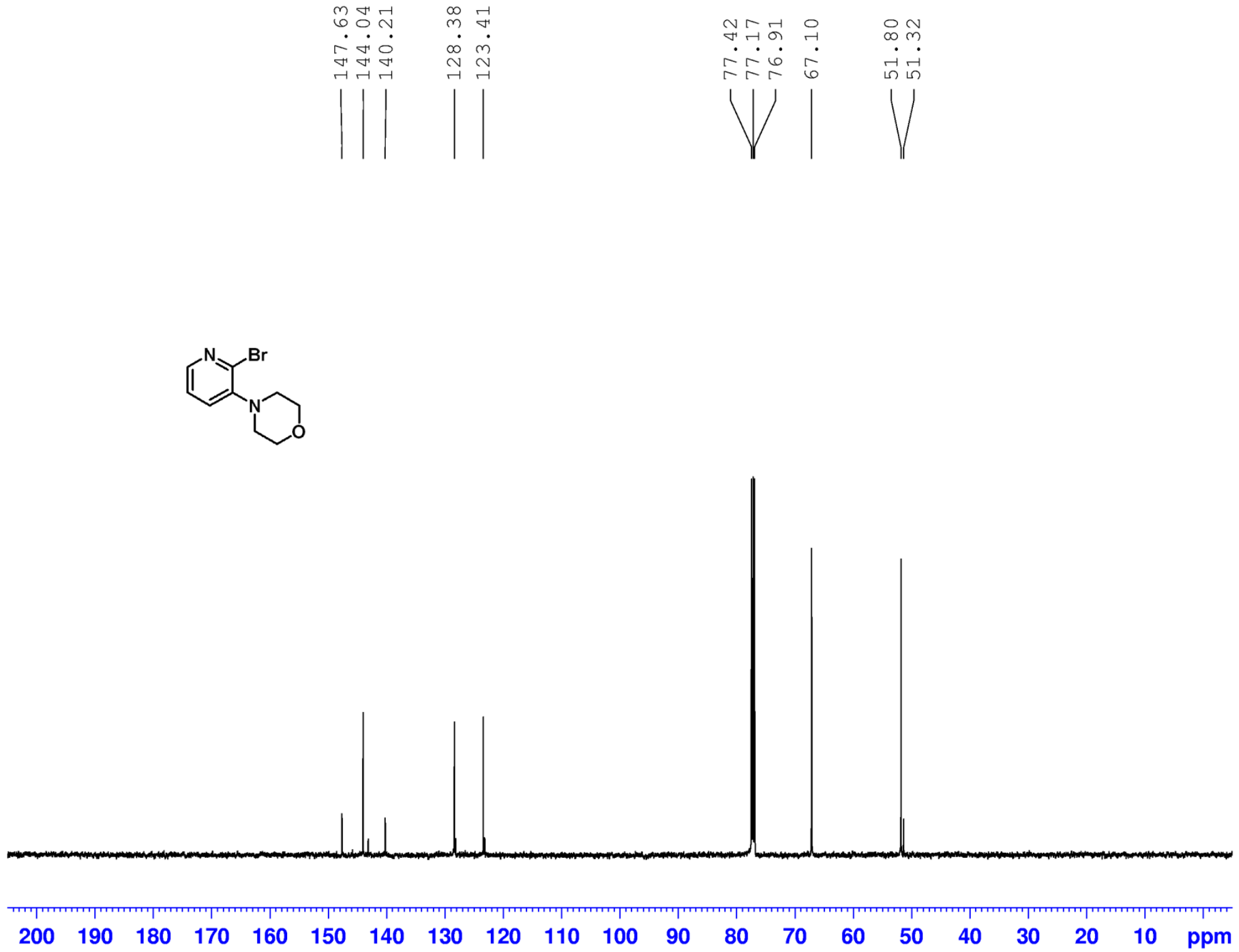
Figure S3. ${ }^{1} \mathrm{H}$ NMR Spectrum of $2\left(\mathrm{CDCl}_{3}, 500.1 \mathrm{MHz}, 300 \mathrm{~K}\right)$

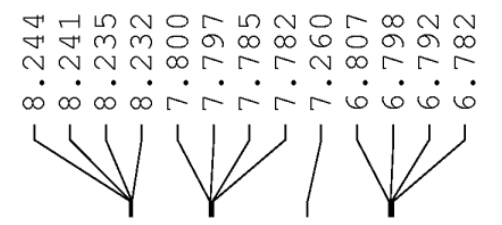

ำ

$\infty \infty \infty \mathrm{mm}$.

mंघंmं

VV
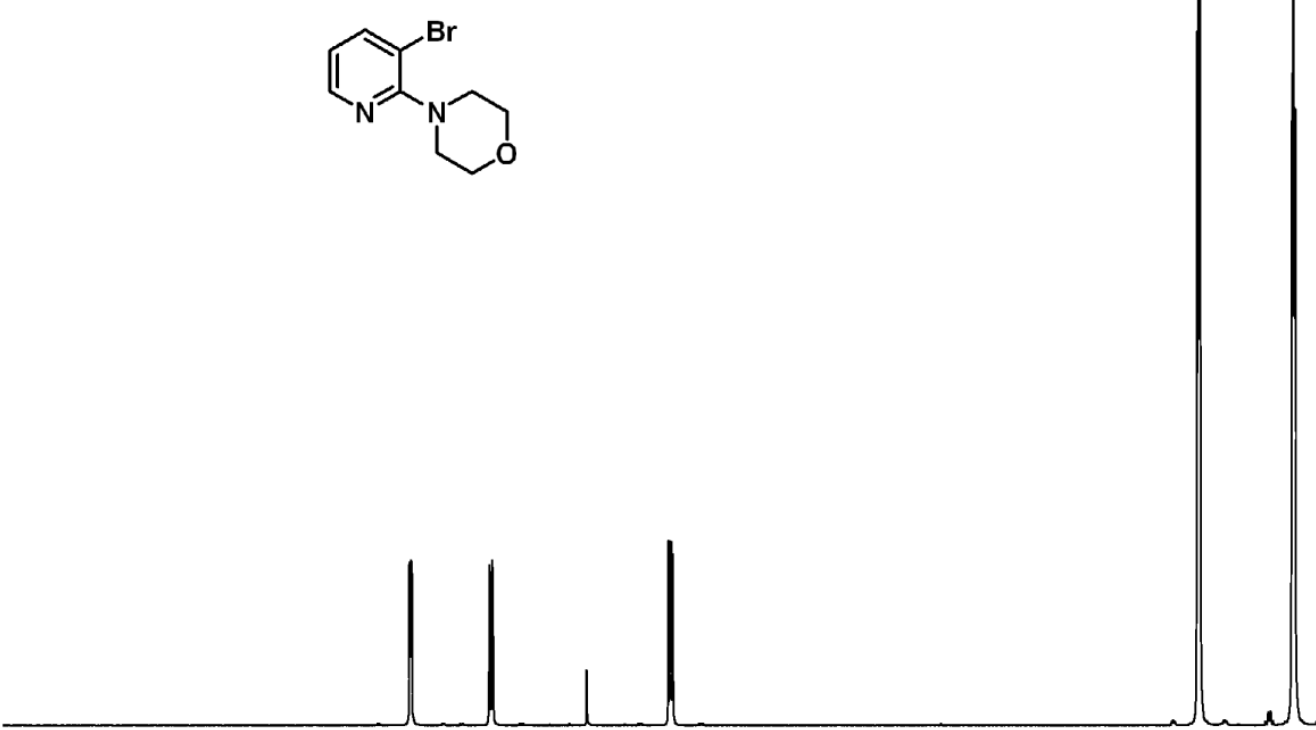

10

9

8

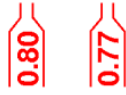

|ำ:

5

4

3

2

ppm

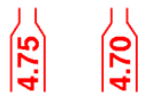


Figure $\mathrm{S} 4 .{ }^{13} \mathrm{C}\left\{{ }^{1} \mathrm{H}\right\}$ NMR Spectrum of $2\left(\mathrm{CDCl}_{3}, 125.7 \mathrm{MHz}, 300 \mathrm{~K}\right)$
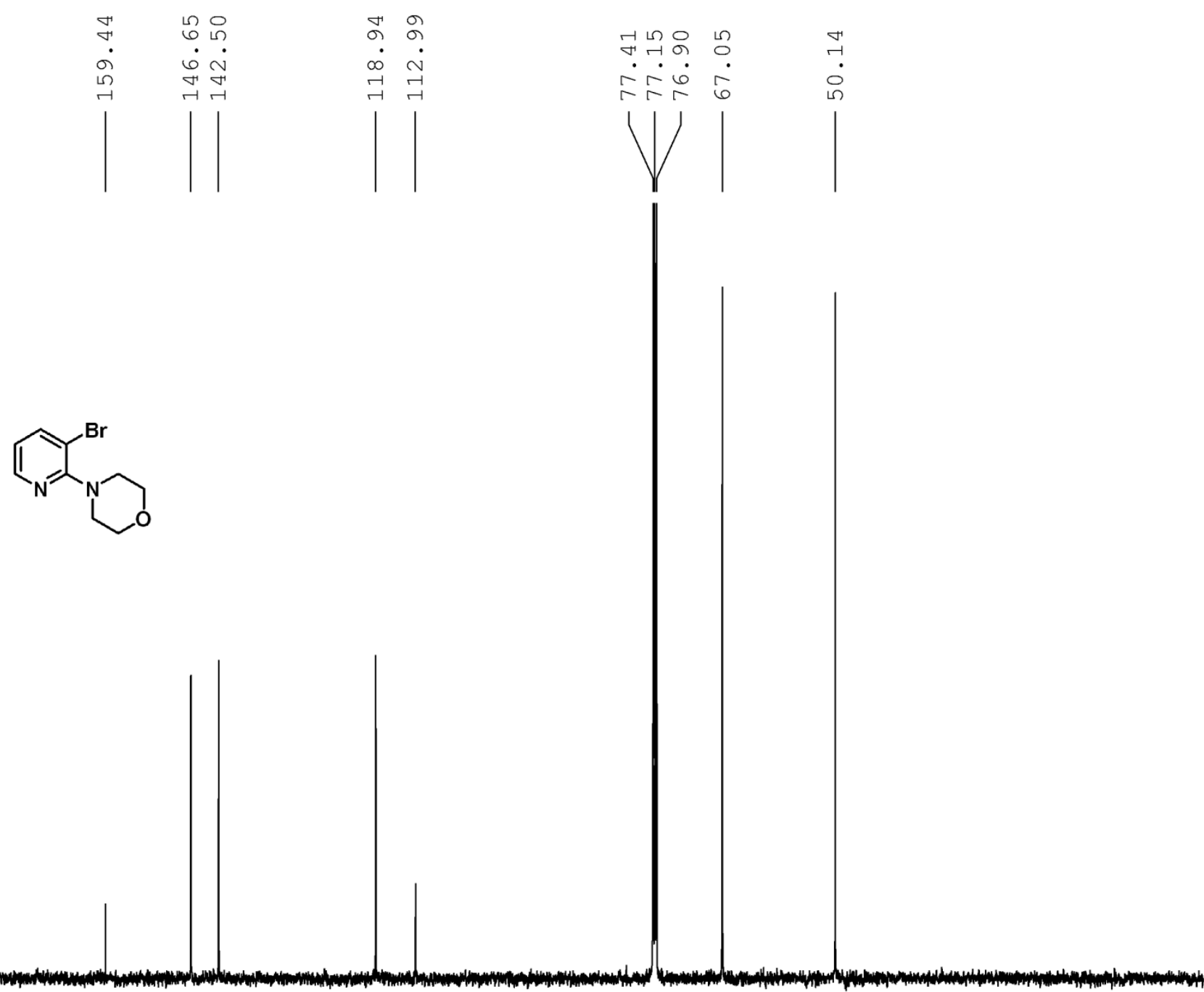

象

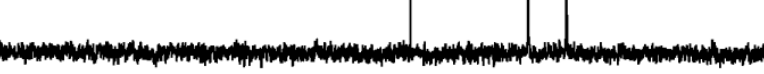

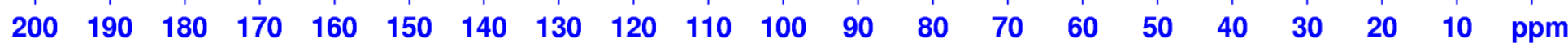


Figure S5. ${ }^{1} \mathrm{H}$ NMR Spectrum of $3^{\prime}\left(\mathrm{CDCl}_{3}, 500.1 \mathrm{MHz}, 300 \mathrm{~K}\right)$
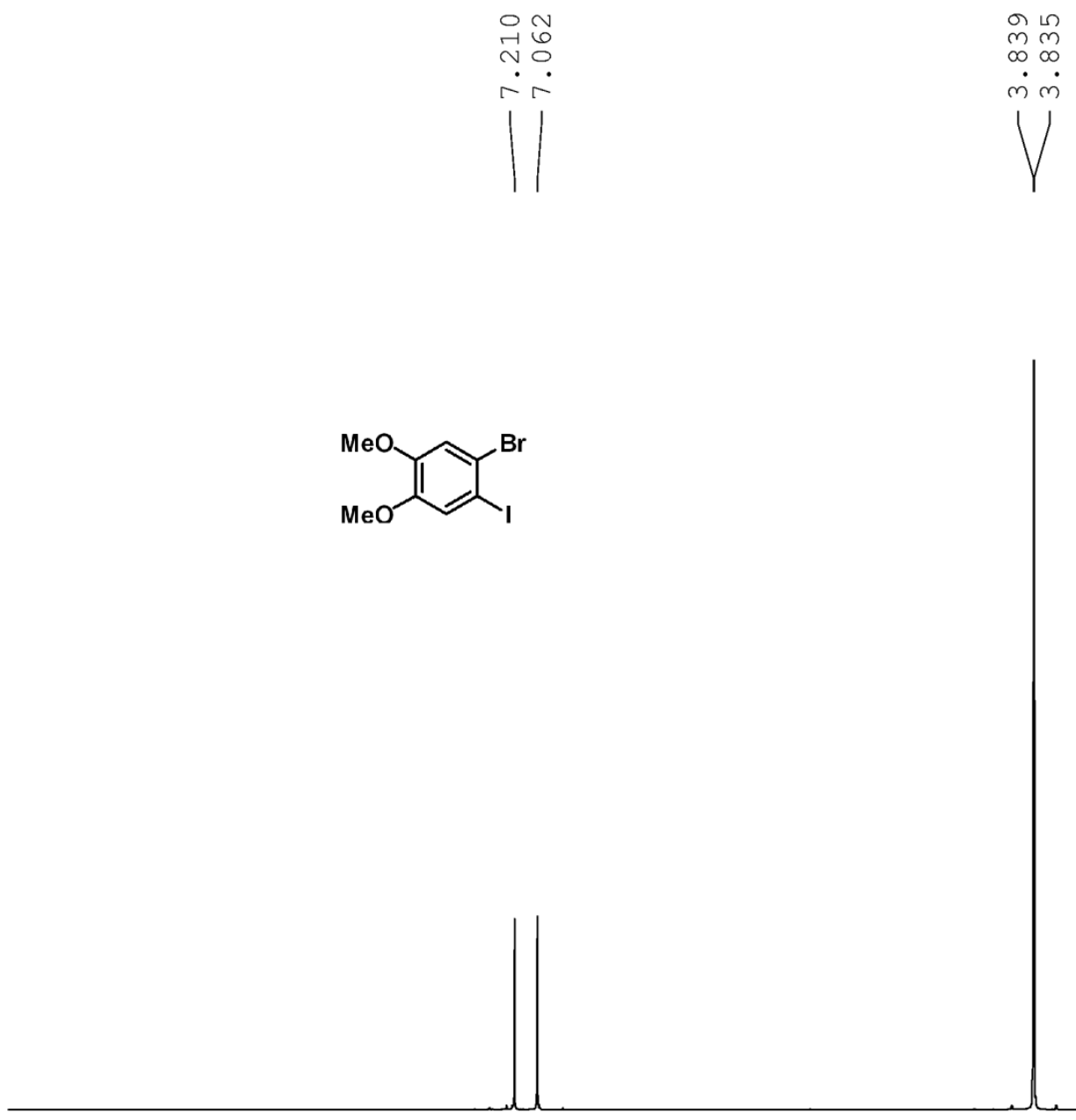
(-) $\mid$ స़่| 
Figure S6. ${ }^{13} \mathrm{C}\left\{{ }^{1} \mathrm{H}\right\}$ NMR Spectrum of $3^{\prime}\left(\mathrm{CDCl}_{3}, 125.7 \mathrm{MHz}, 300 \mathrm{~K}\right)$
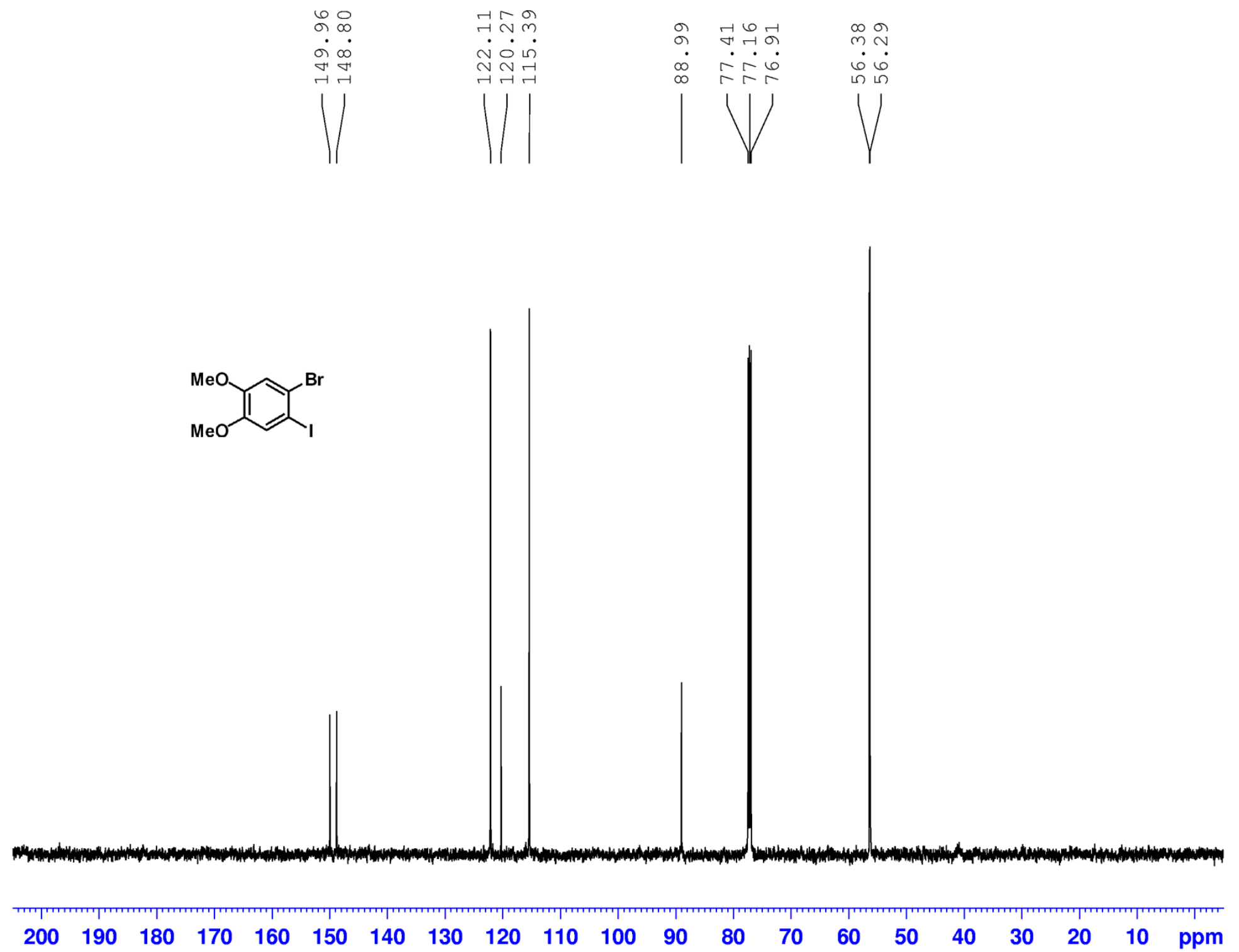
Figure S7. ${ }^{1} \mathrm{H}$ NMR Spectrum of $3\left(\mathrm{CDCl}_{3}, 500.1 \mathrm{MHz}, 300 \mathrm{~K}\right)$
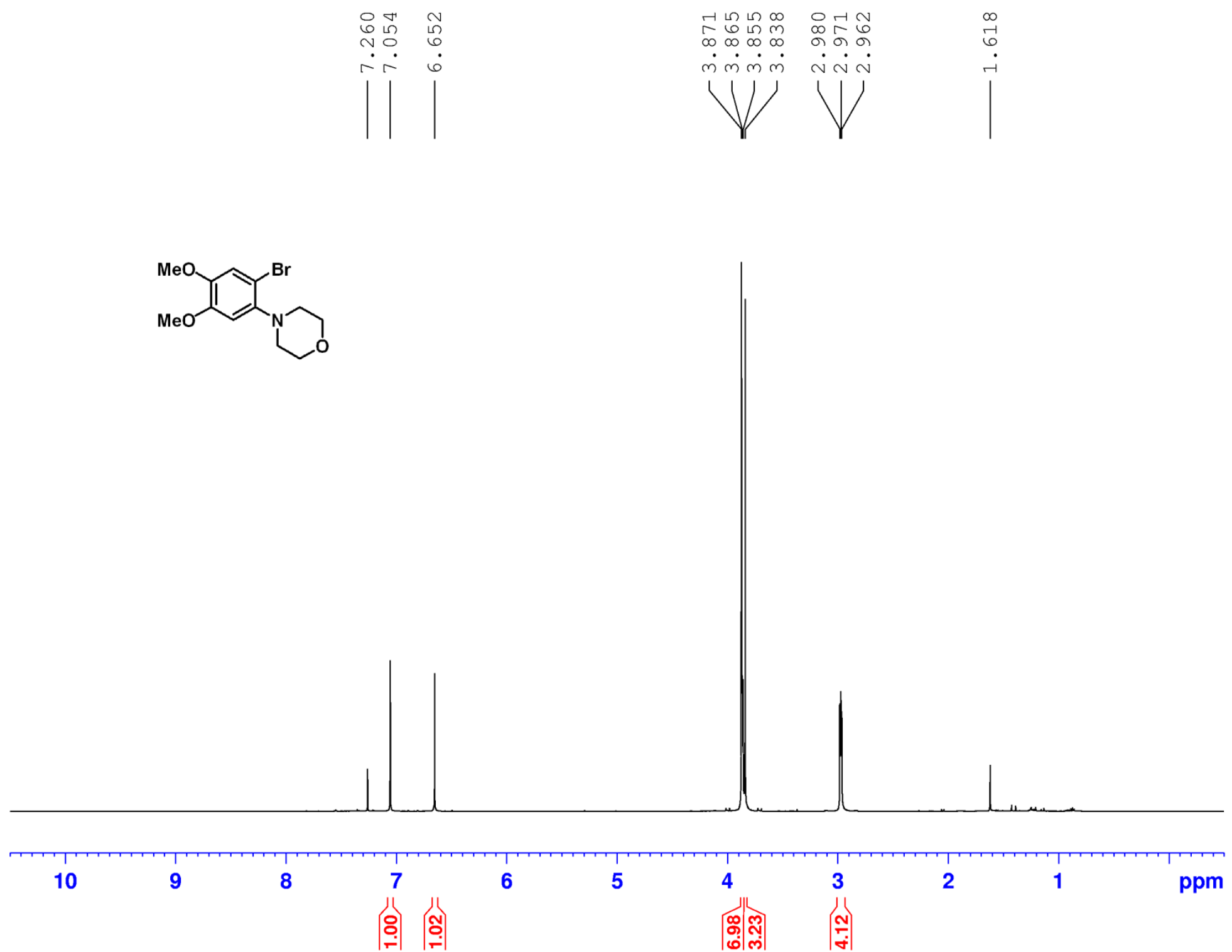
Figure S8. ${ }^{13} \mathrm{C}\left\{{ }^{1} \mathrm{H}\right\}$ NMR Spectrum of 3' $\left(\mathrm{CDCl}_{3}, 125.7 \mathrm{MHz}, 300 \mathrm{~K}\right)$
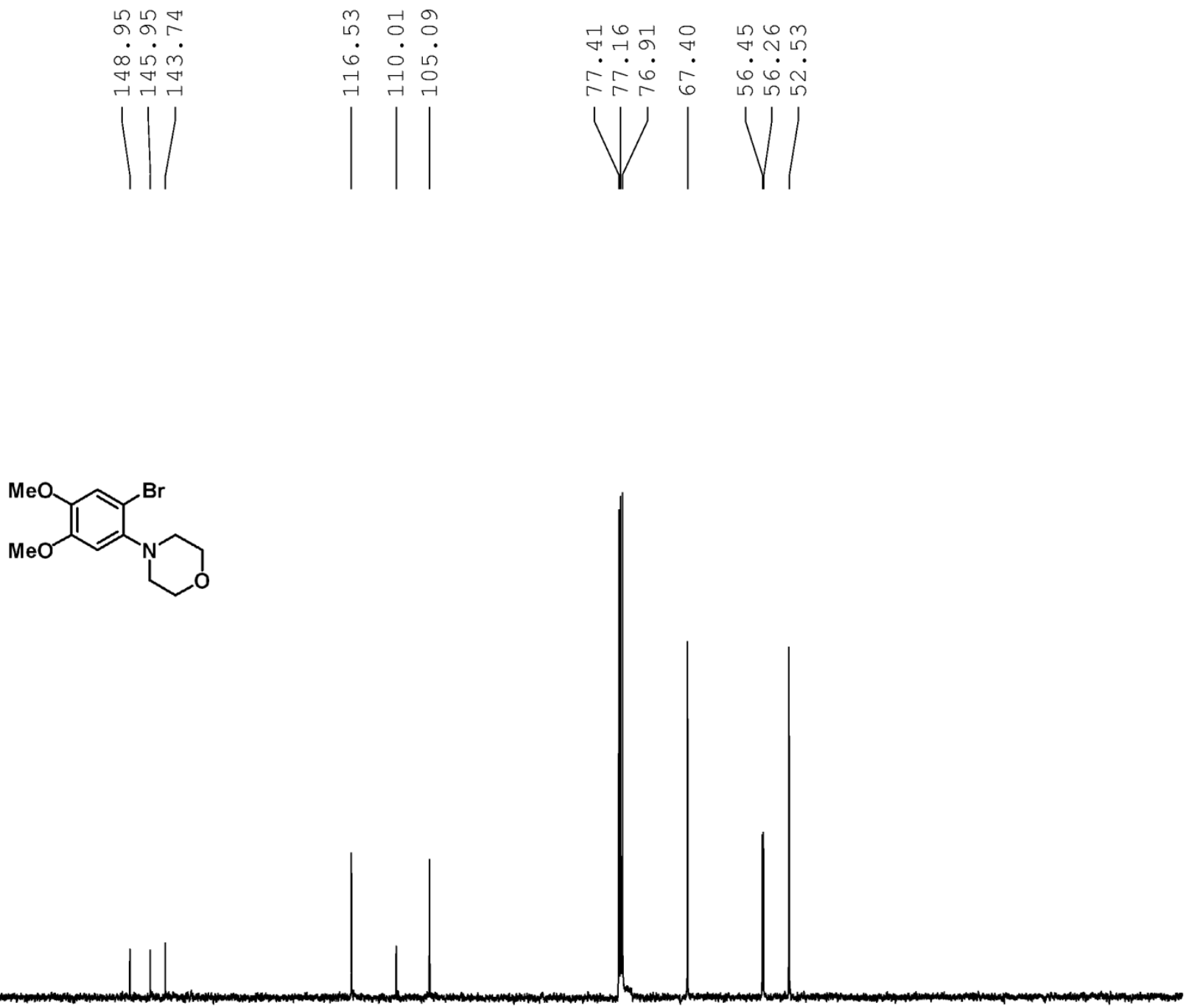
Figure S9. ${ }^{1} \mathrm{H}$ NMR Spectrum of $4\left(\mathrm{CDCl}_{3}, 500.1 \mathrm{MHz}, 300 \mathrm{~K}\right)$
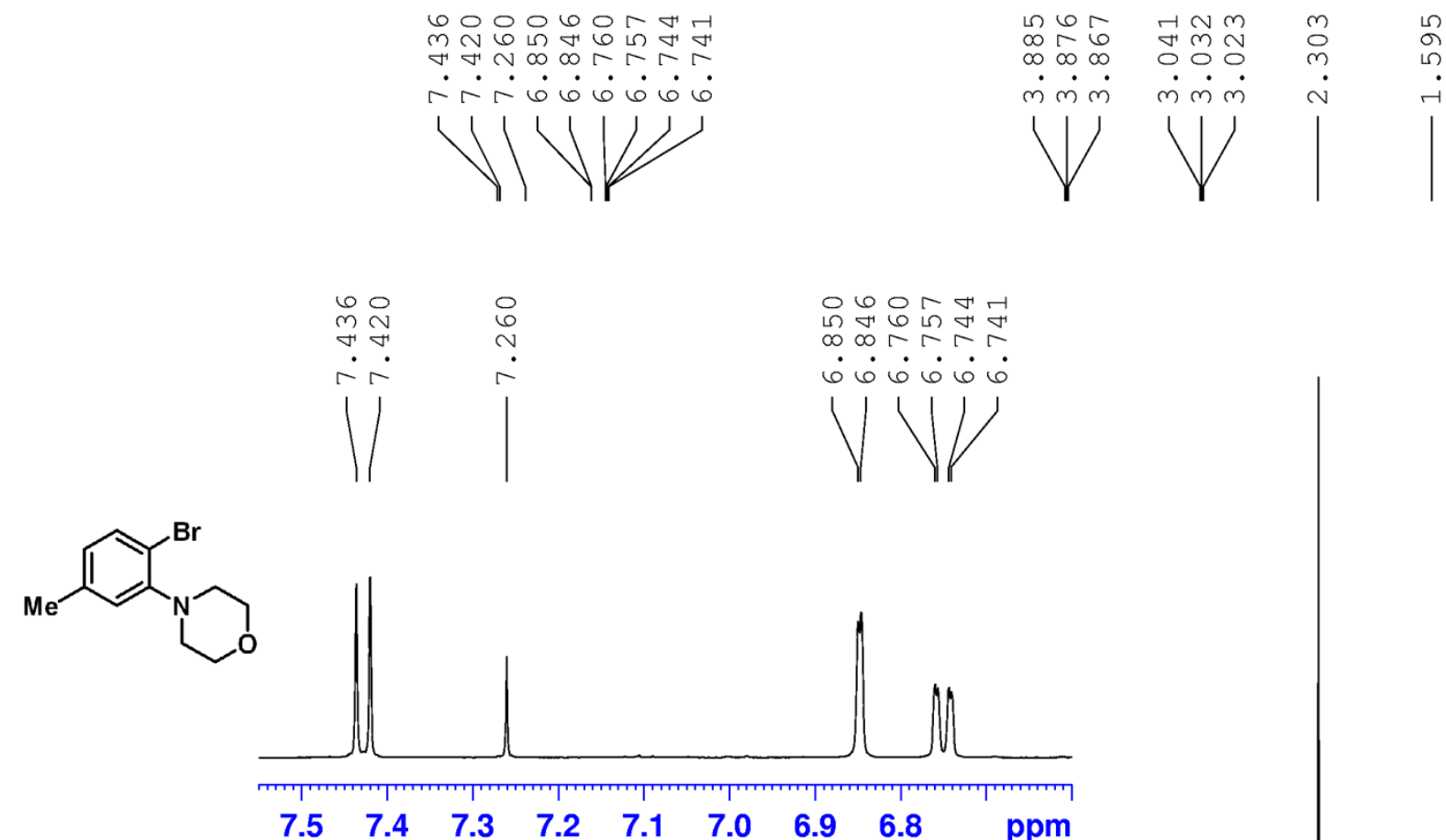

|ํㅜㅇ
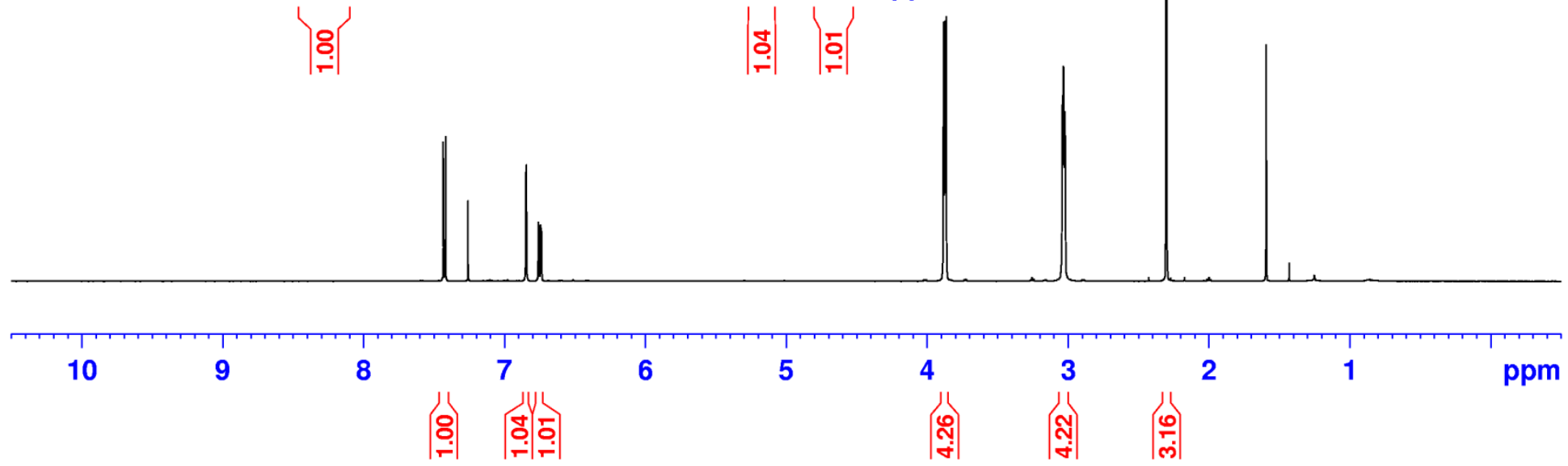
Figure S10. ${ }^{13} \mathrm{C}\left\{{ }^{1} \mathrm{H}\right\}$ NMR Spectrum of $4\left(\mathrm{CDCl}_{3}, 125.7 \mathrm{MHz}, 300 \mathrm{~K}\right)$
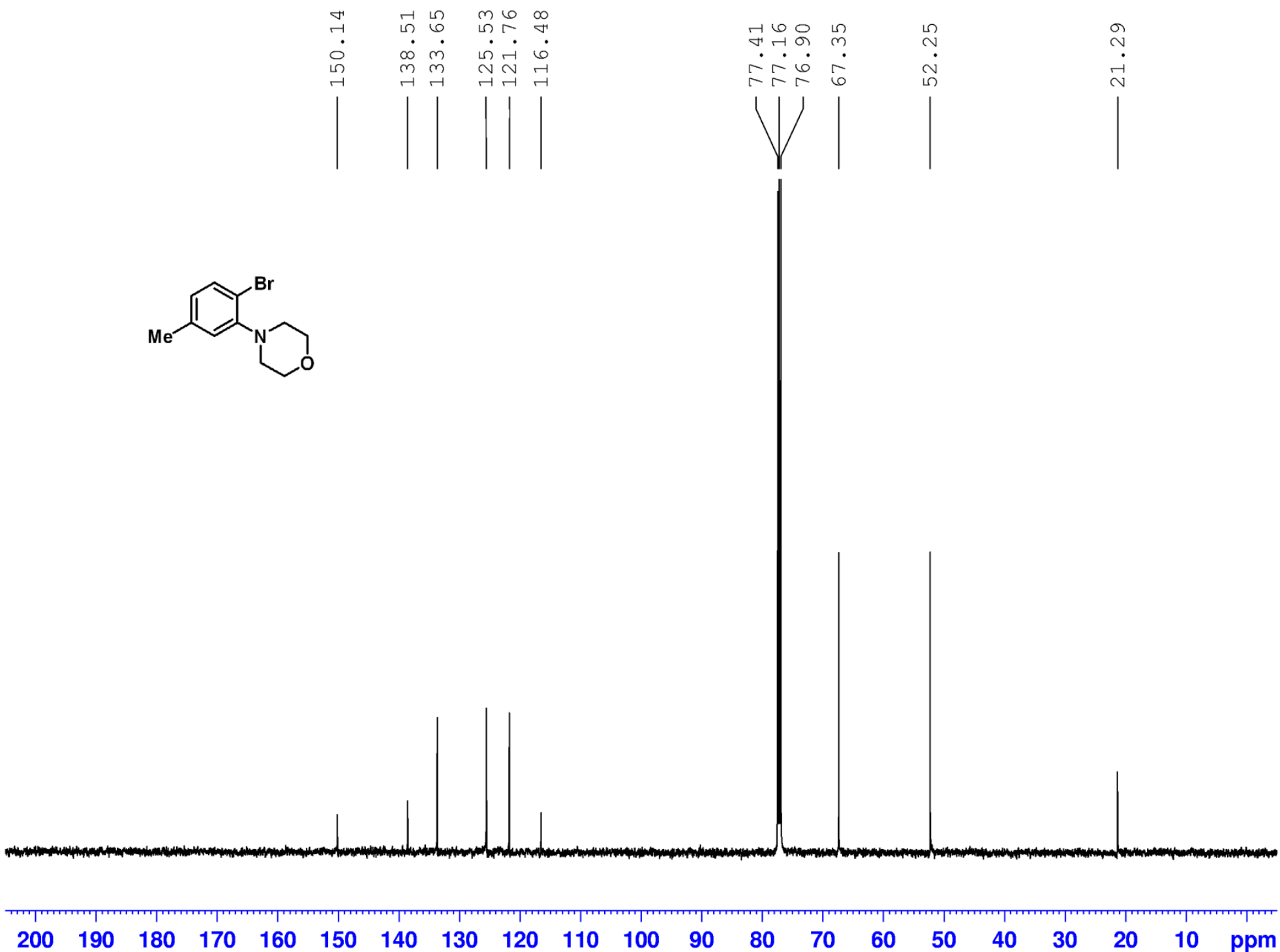
S11

Figure S11. ${ }^{1} \mathrm{H}$ NMR Spectrum of $5\left(\mathrm{CDCl}_{3}, 500.1 \mathrm{MHz}, 300 \mathrm{~K}\right)$
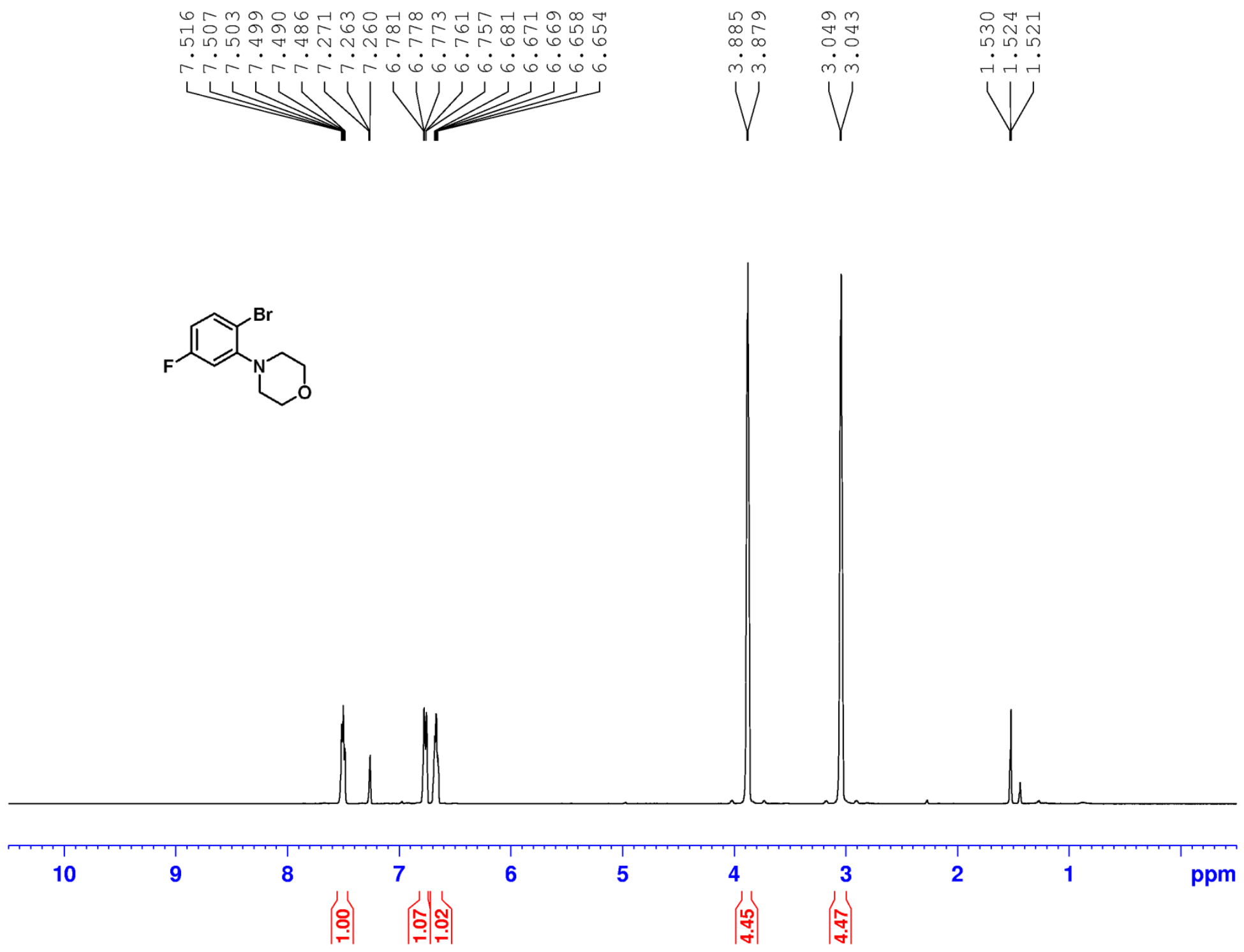
Figure $\mathrm{S} 12 .{ }^{13} \mathrm{C}\left\{{ }^{1} \mathrm{H}\right\}$ NMR Spectrum of $\mathbf{5}\left(\mathrm{CDCl}_{3}, 125.7 \mathrm{MHz}, 300 \mathrm{~K}\right)$
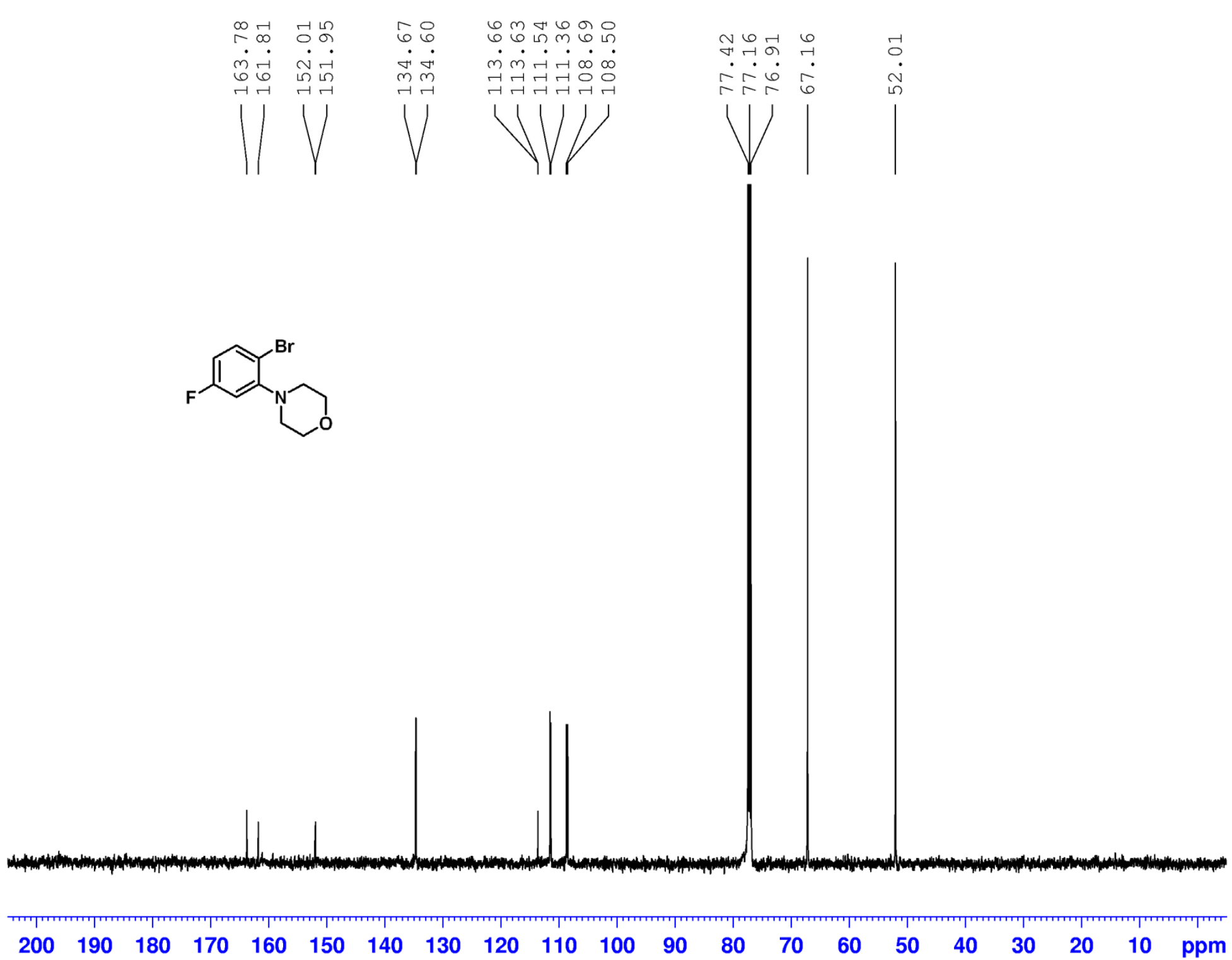
S13

Figure S13. ${ }^{1} \mathrm{H}$ NMR Spectrum of $6\left(\mathrm{CDCl}_{3}, 500.1 \mathrm{MHz}, 300 \mathrm{~K}\right)$
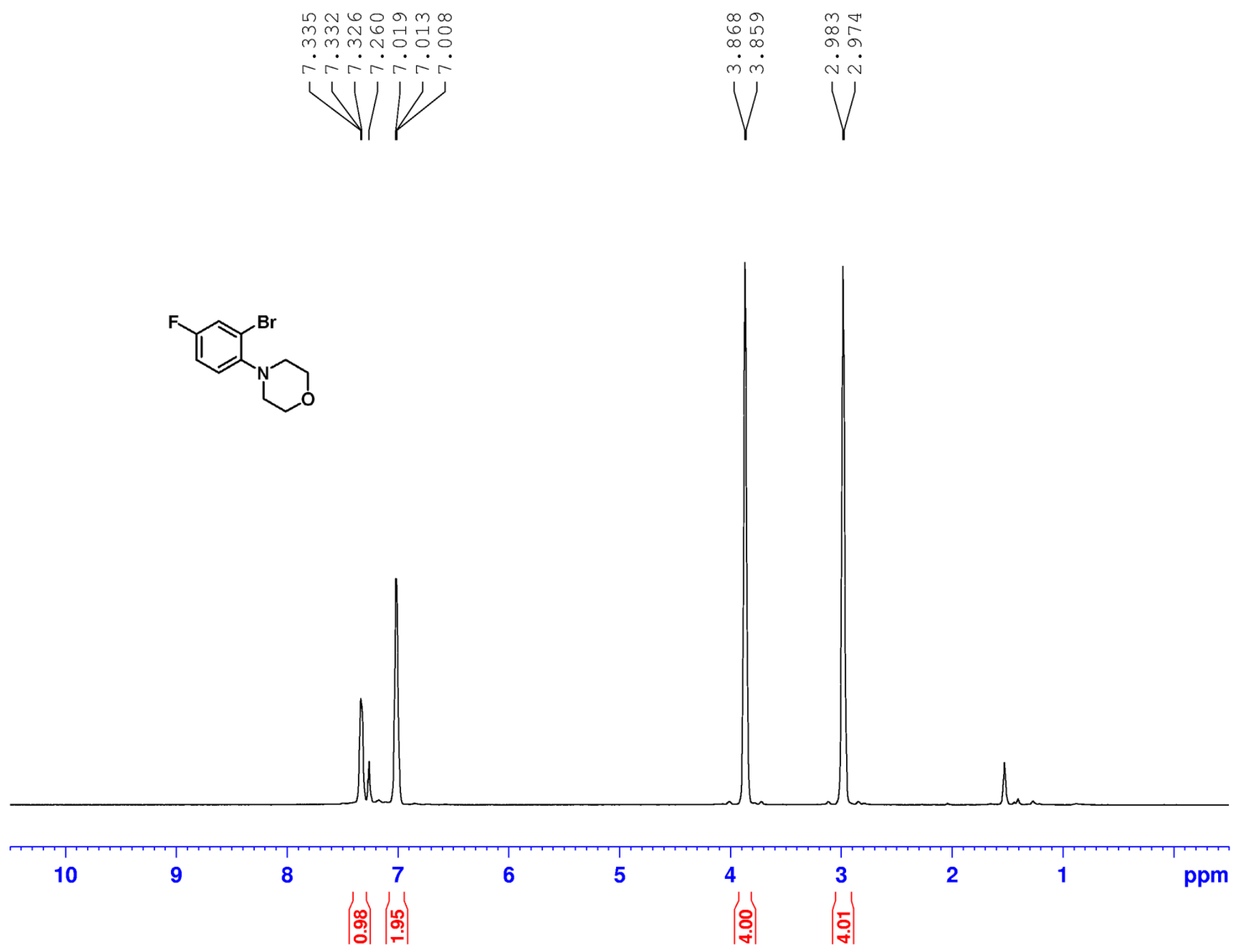
Figure S14. ${ }^{13} \mathrm{C}\left\{{ }^{1} \mathrm{H}\right\}$ NMR Spectrum of $6\left(\mathrm{CDCl}_{3}, 125.7 \mathrm{MHz}, 300 \mathrm{~K}\right)$
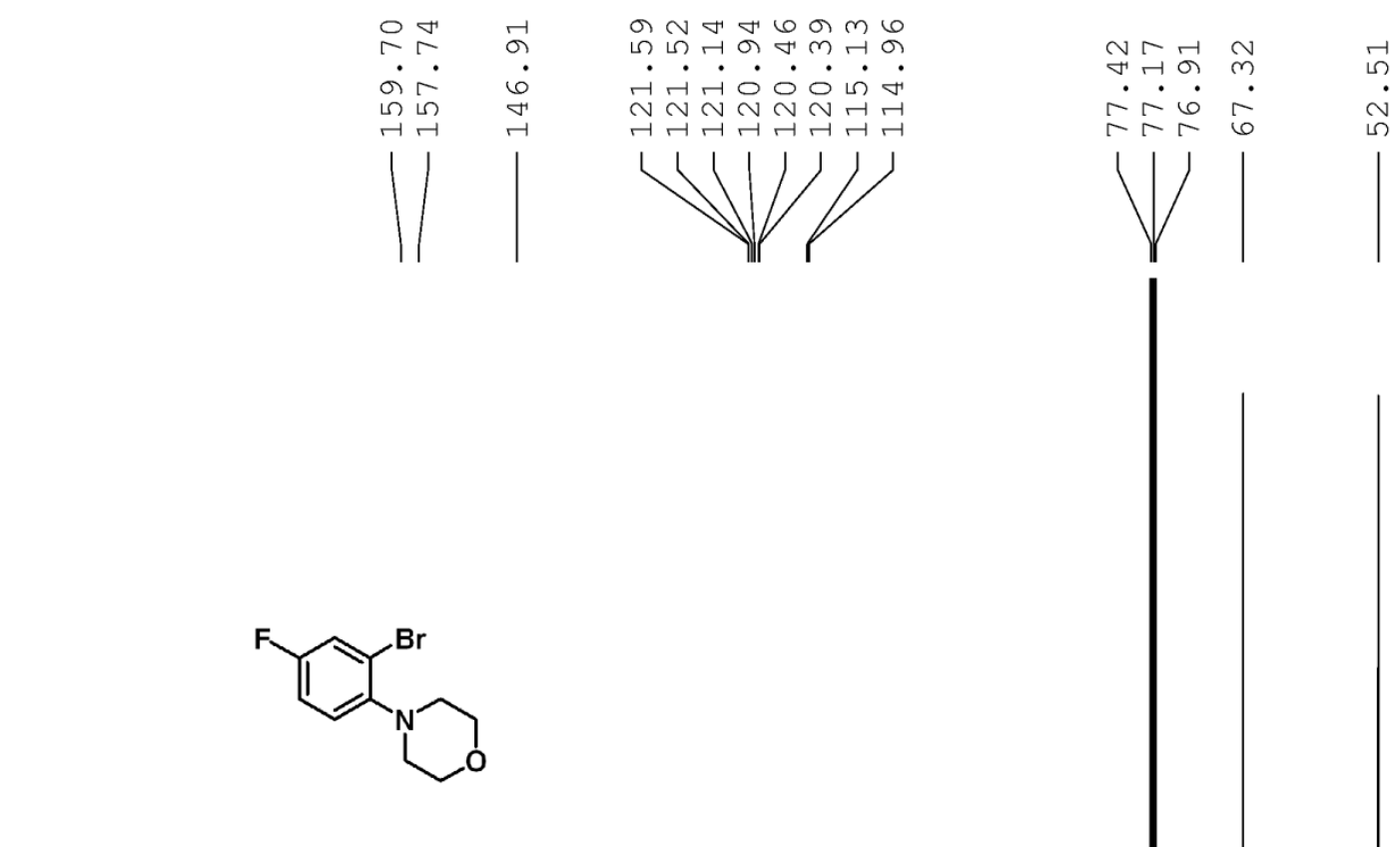

(n)


S15

Figure S15. ${ }^{1} \mathrm{H}$ NMR Spectrum of $7\left(\mathrm{CDCl}_{3}, 500.1 \mathrm{MHz}, 300 \mathrm{~K}\right)$
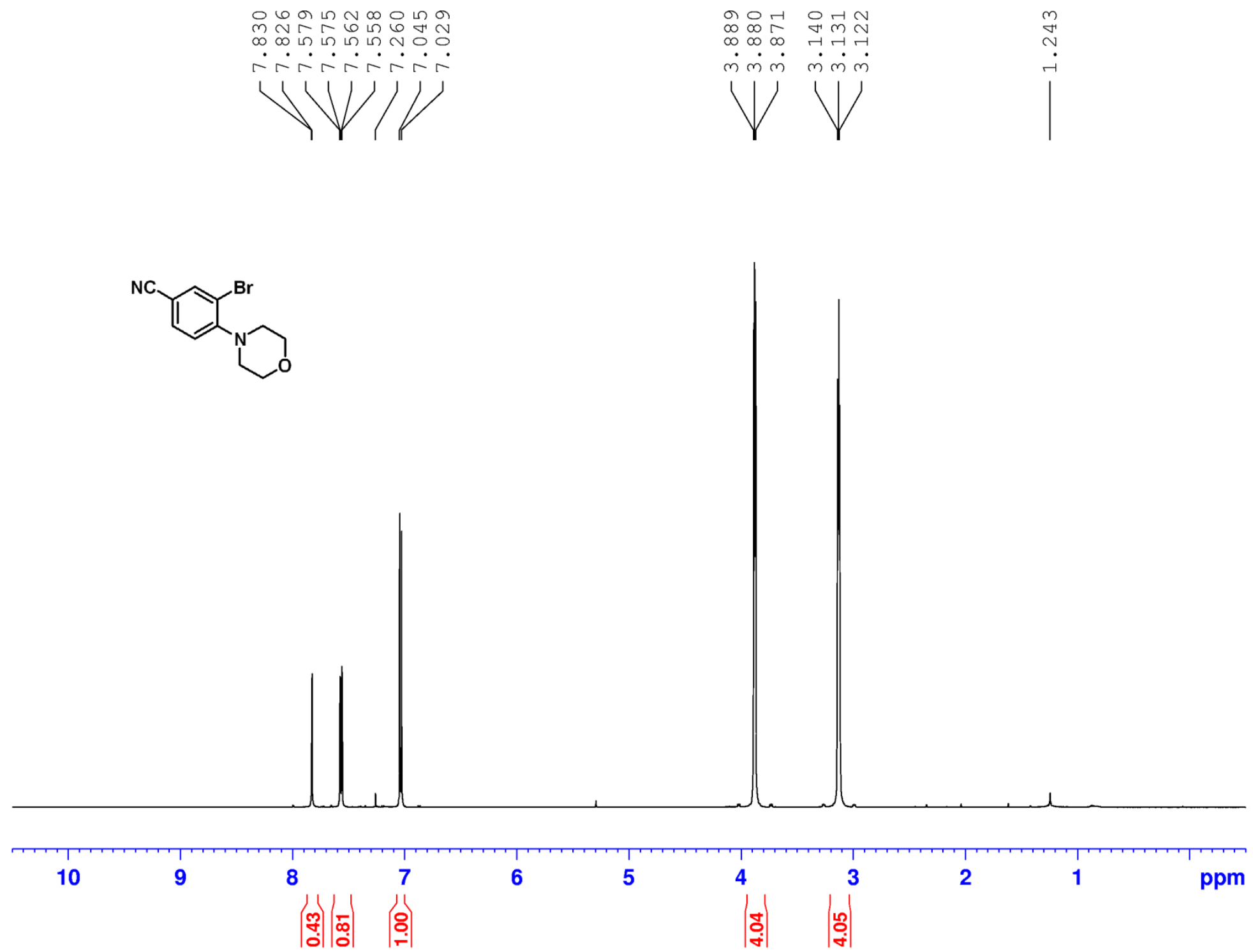
Figure S16. ${ }^{13} \mathrm{C}\left\{{ }^{1} \mathrm{H}\right\}$ NMR Spectrum of $7\left(\mathrm{CDCl}_{3}, 125.7 \mathrm{MHz}, 300 \mathrm{~K}\right)$
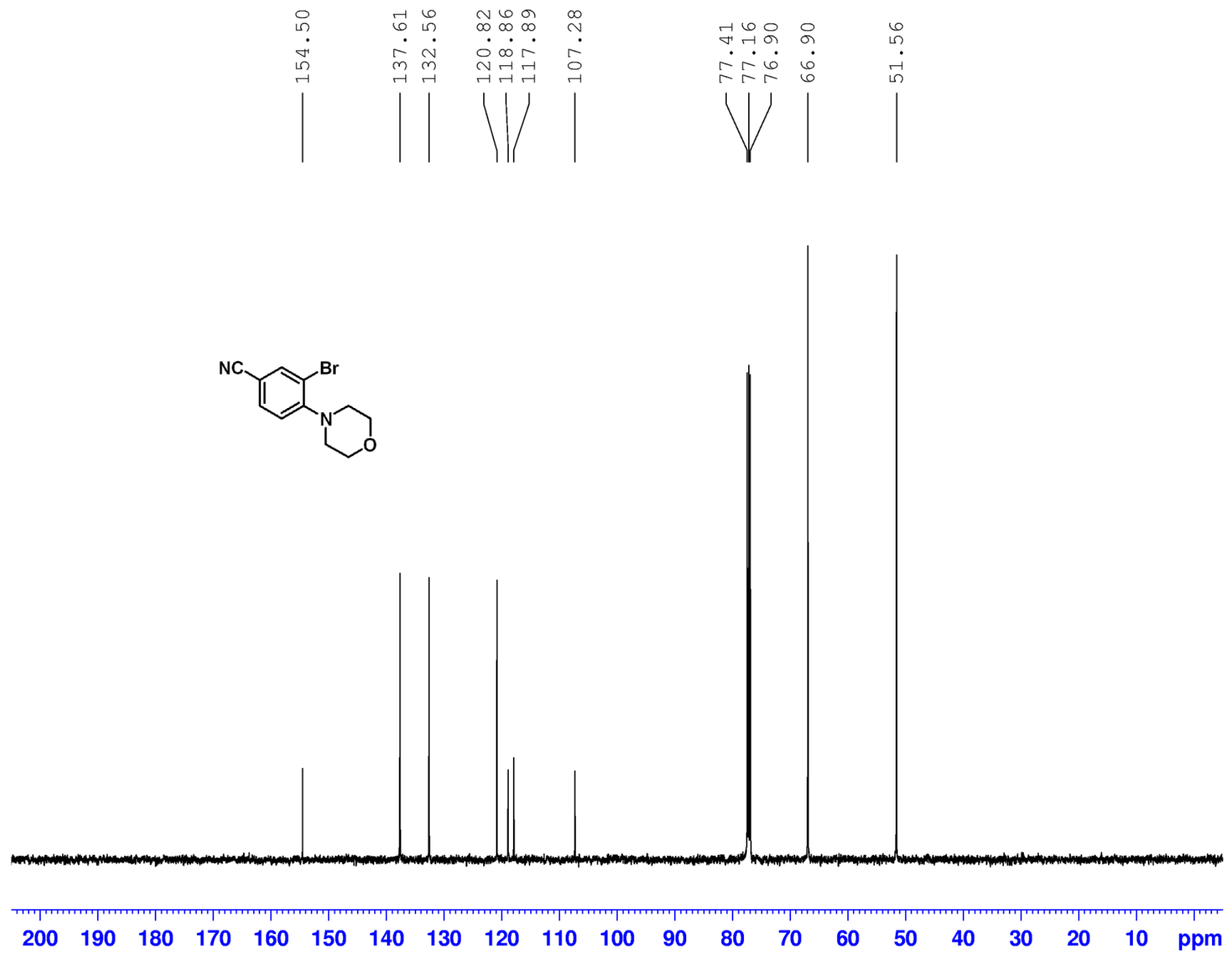
Figure S17. ${ }^{1} \mathrm{H}$ NMR Spectrum of $8\left(\mathrm{CDCl}_{3}, 500.1 \mathrm{MHz}, 300 \mathrm{~K}\right)$
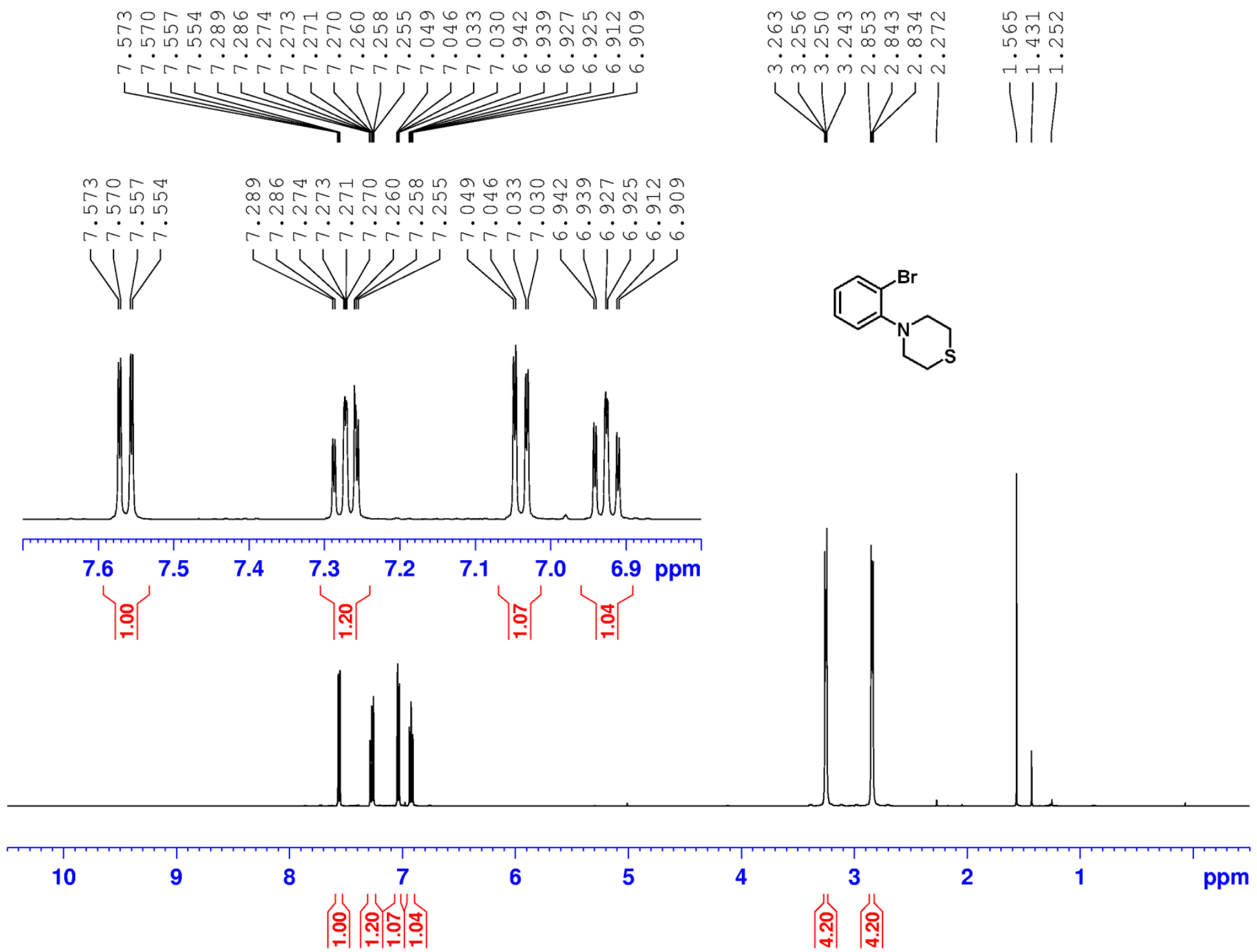
Figure S18. ${ }^{13} \mathrm{C}\left\{{ }^{1} \mathrm{H}\right\}$ NMR Spectrum of $8\left(\mathrm{CDCl}_{3}, 125.7 \mathrm{MHz}, 300 \mathrm{~K}\right)$

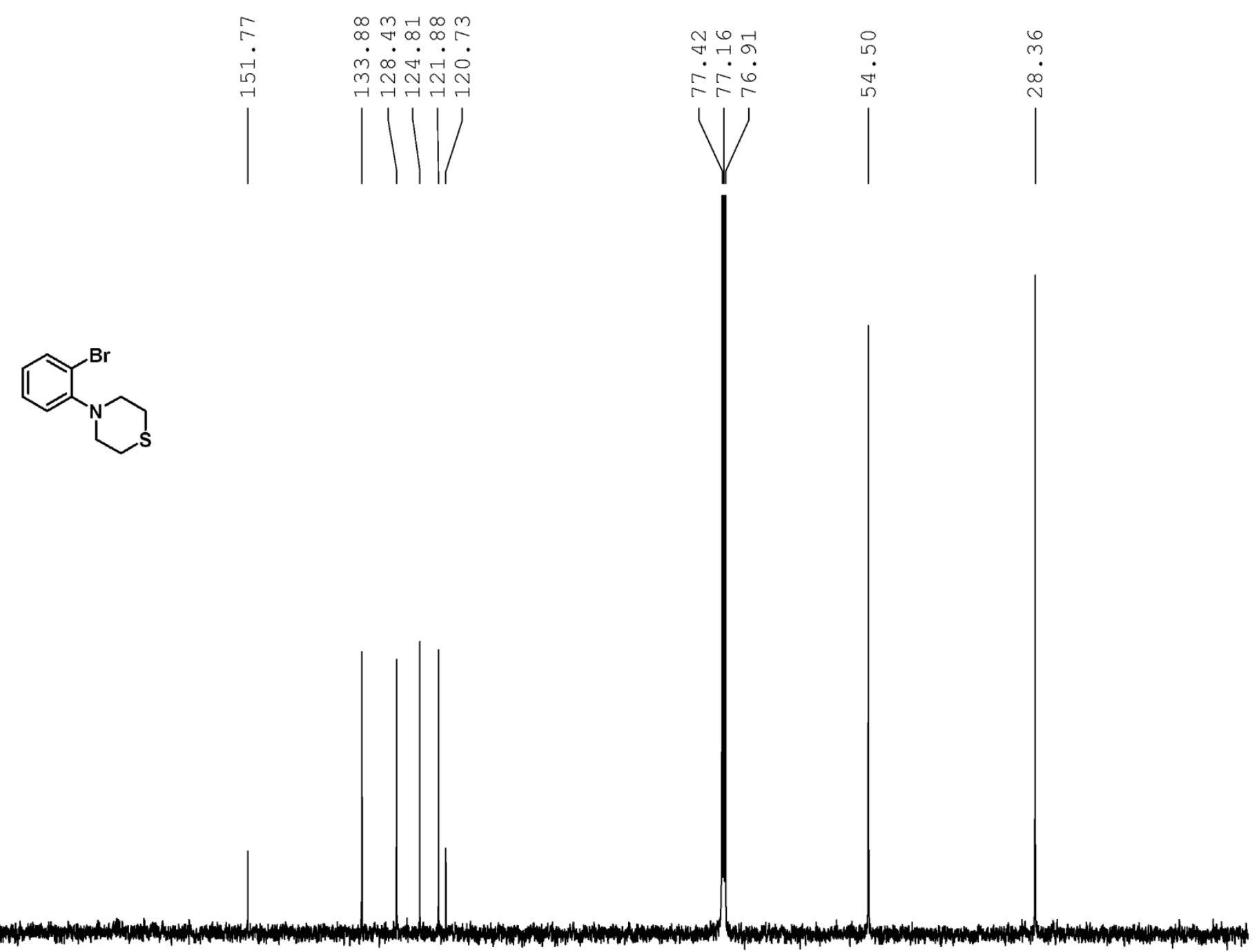

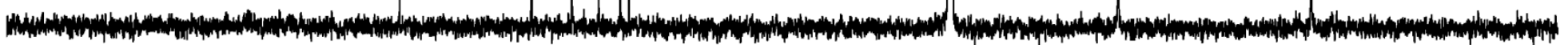

$\begin{array}{lllllllllllllllllllll}200 & 190 & 180 & 170 & 160 & 150 & 140 & 130 & 120 & 110 & 100 & 90 & 80 & 70 & 60 & 50 & 40 & 30 & 20 & 10 & \text { ppm }\end{array}$


Figure S19. ${ }^{1} \mathrm{H}$ NMR Spectrum of $\mathbf{L} 1\left(\mathrm{CDCl}_{3}, 500.1 \mathrm{MHz}, 300 \mathrm{~K}\right)$

ॠ

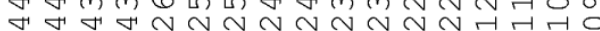

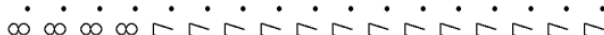

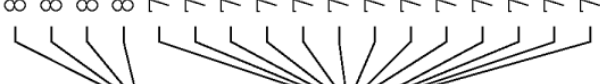

I

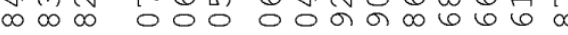

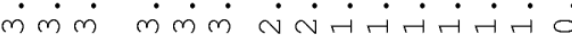

V V WW
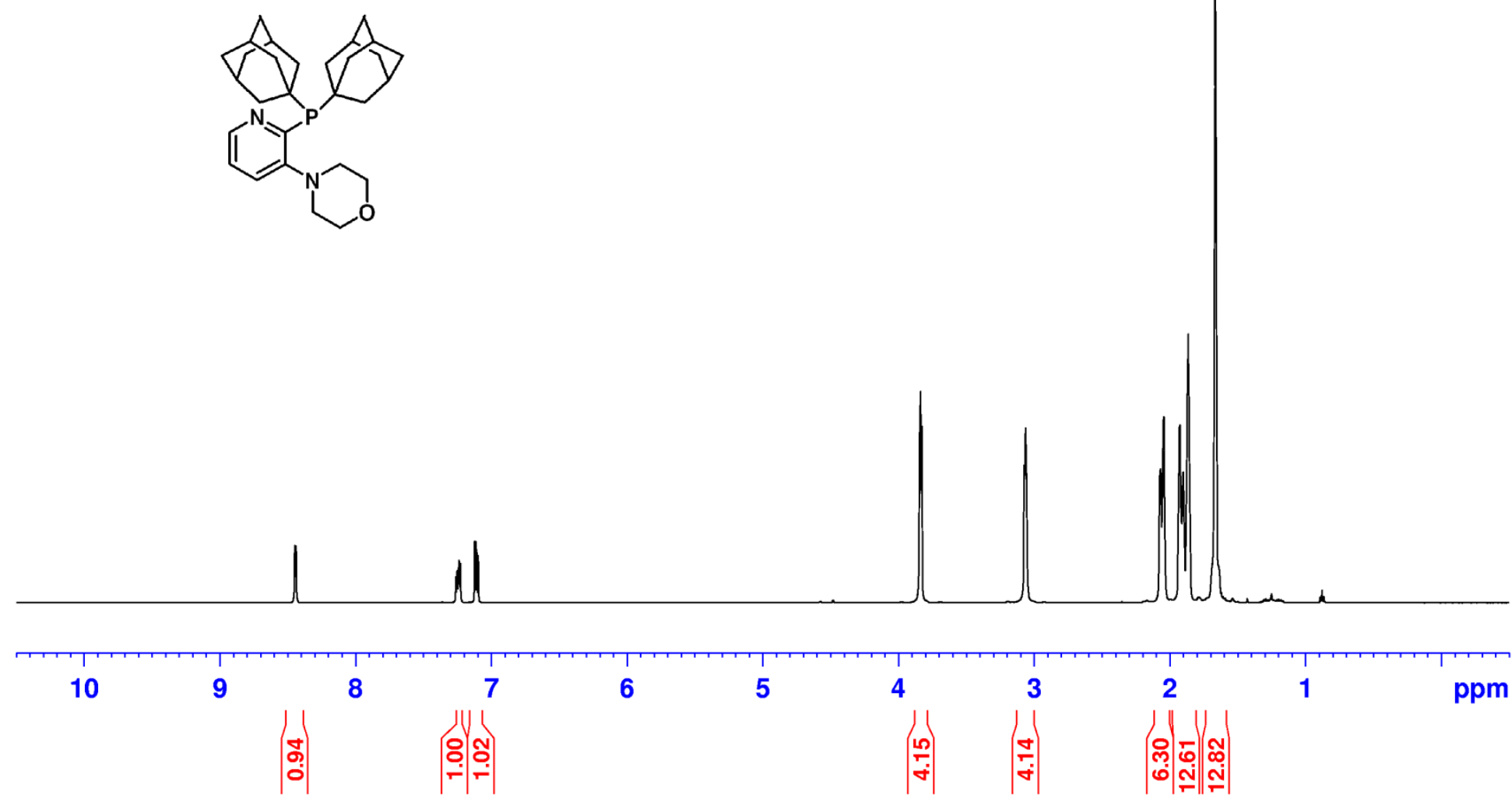
Figure S20. ${ }^{31} \mathrm{P}\left\{{ }^{1} \mathrm{H}\right\}$ NMR Spectrum of L1 (CDCl3, $\left.202.5 \mathrm{MHz}, 300 \mathrm{~K}\right)$
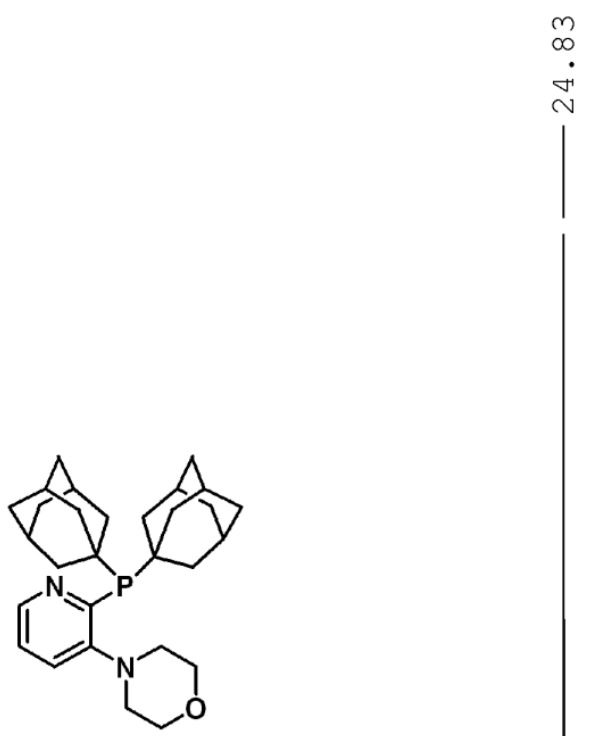
Figure S21. ${ }^{13} \mathrm{C}\left\{{ }^{1} \mathrm{H}\right\}$ NMR Spectrum of $\mathbf{L 1}\left(\mathrm{CDCl}_{3}, 125.7 \mathrm{MHz}, 300 \mathrm{~K}\right)$
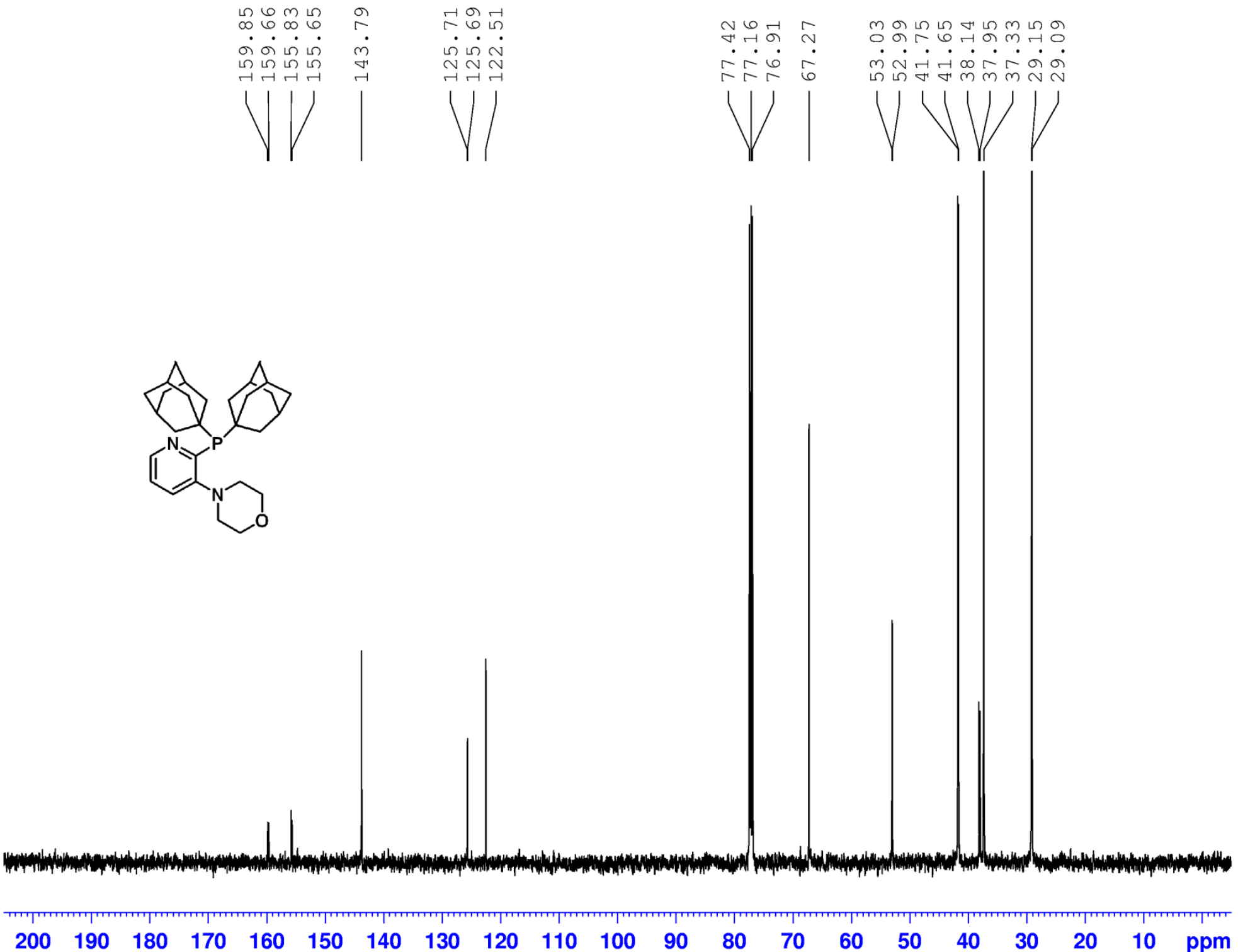
Figure S22. ${ }^{1} \mathrm{H}$ NMR Spectrum of $\mathbf{L} 2\left(\mathrm{CDCl}_{3}, 500.1 \mathrm{MHz}, 300 \mathrm{~K}\right)$
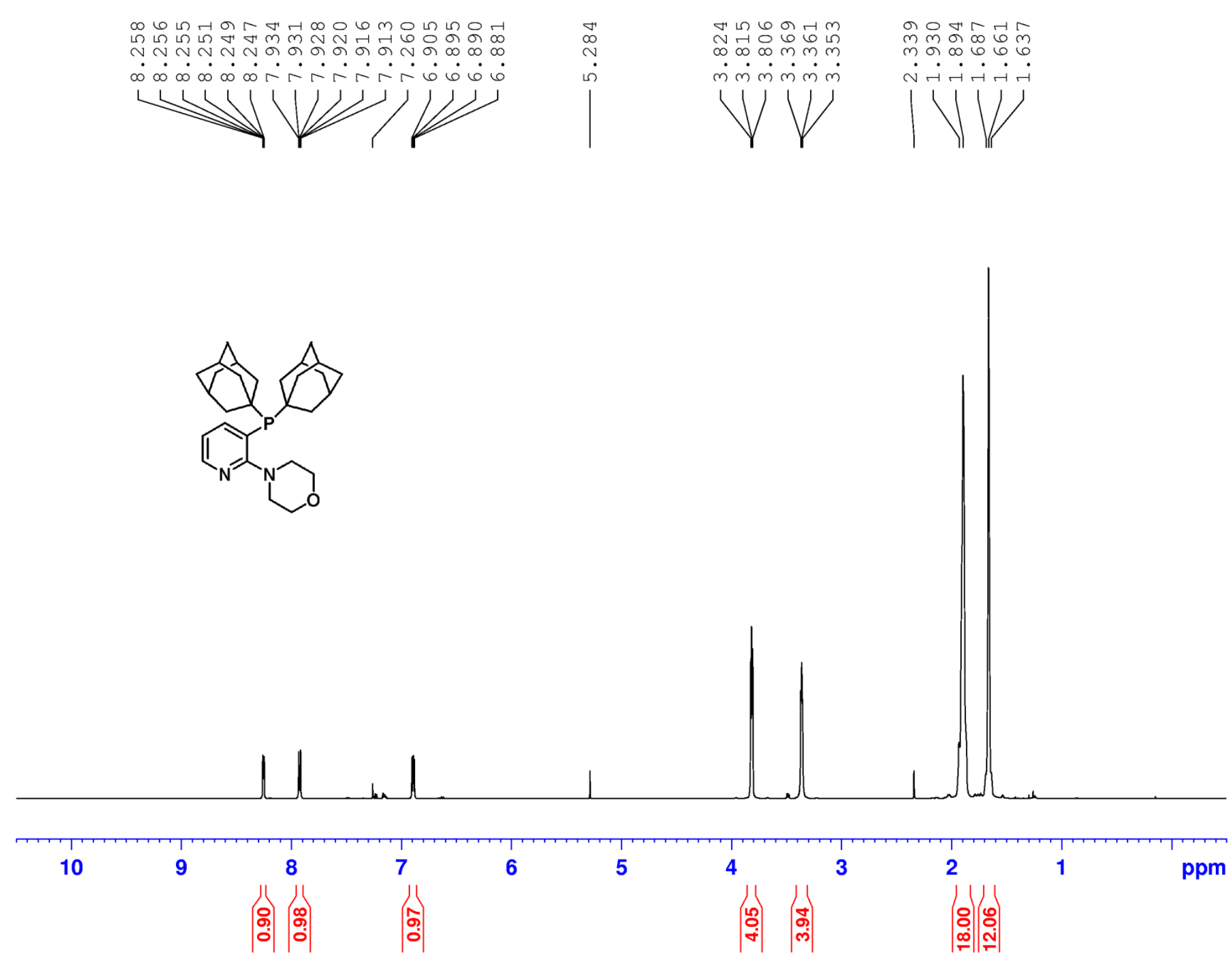
Figure S23. ${ }^{31} \mathrm{P}\left\{{ }^{1} \mathrm{H}\right\}$ NMR Spectrum of $\mathbf{L} 2(\mathrm{CDCl} 3,202.5 \mathrm{MHz}, 300 \mathrm{~K})$
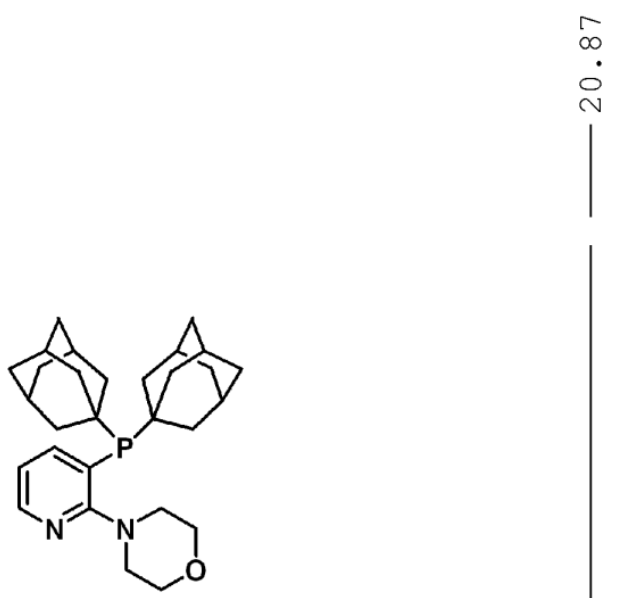
Figure S24. ${ }^{13} \mathrm{C}\left\{{ }^{1} \mathrm{H}\right\}$ NMR Spectrum of $\mathbf{L} 2\left(\mathrm{CDCl}_{3}, 125.7 \mathrm{MHz}, 300 \mathrm{~K}\right)$
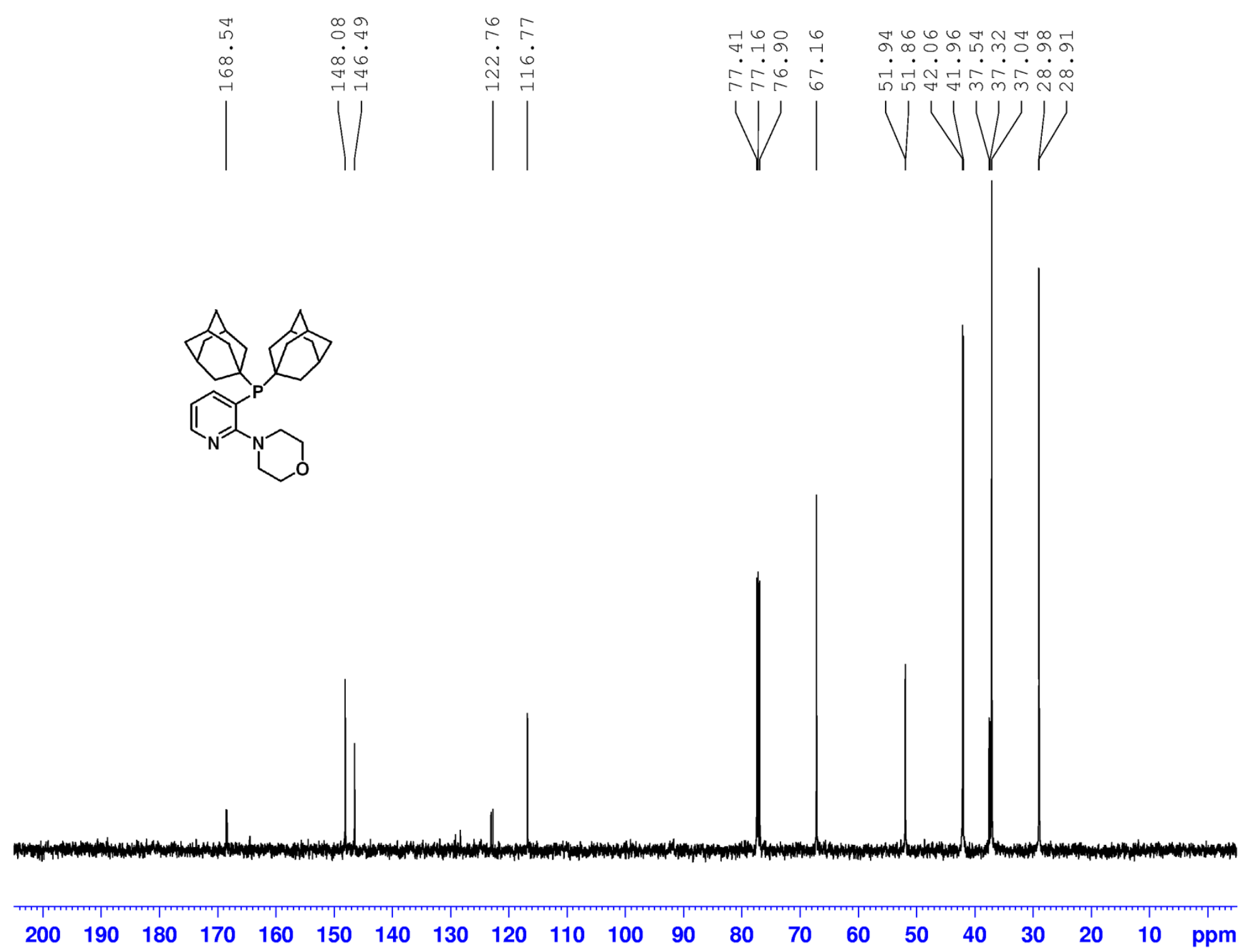
Figure S25. ${ }^{1} \mathrm{H}$ NMR Spectrum of $\mathbf{L} 3\left(\mathrm{CDCl}_{3}, 500.1 \mathrm{MHz}, 300 \mathrm{~K}\right)$
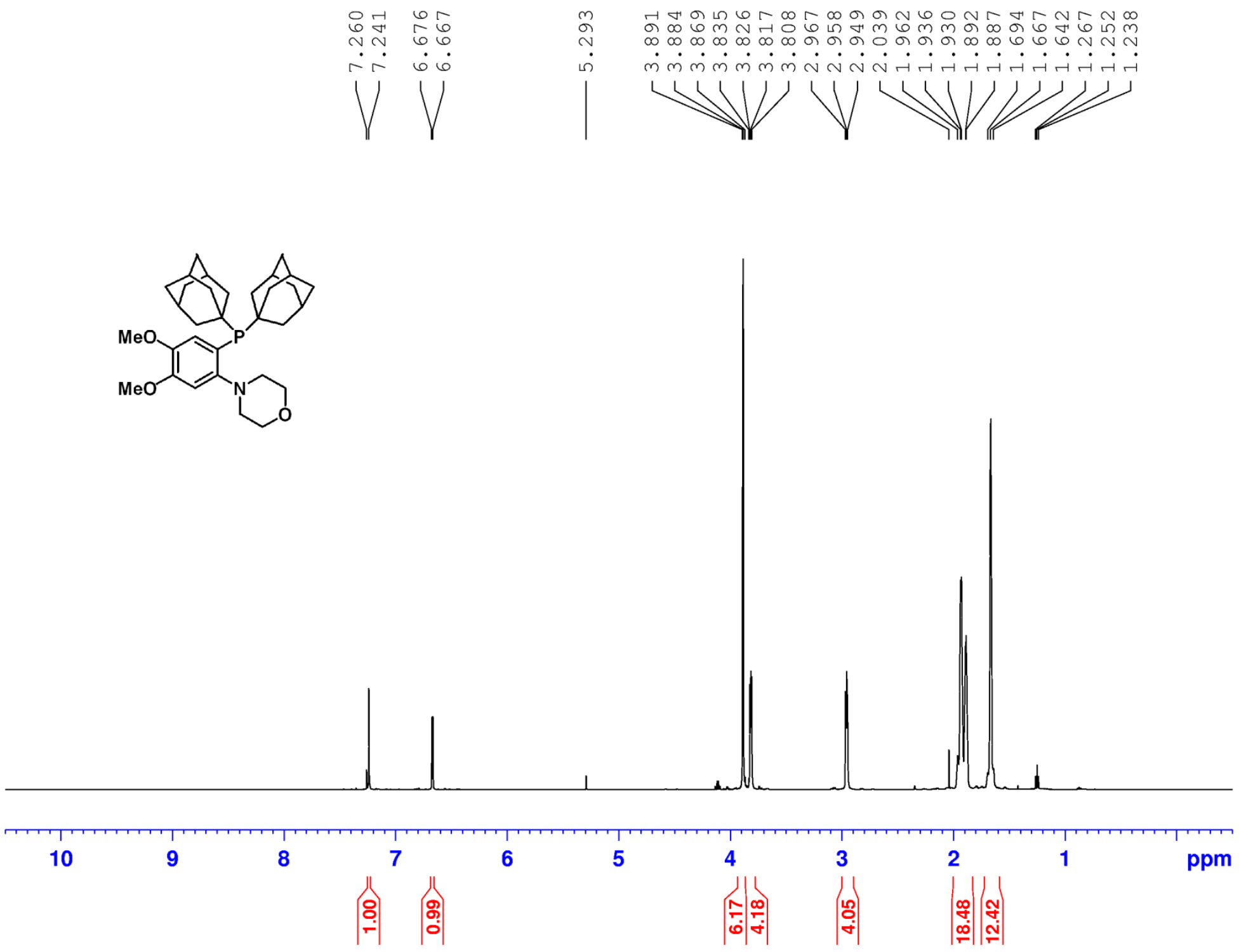
Figure S26. ${ }^{31} \mathrm{P}\left\{{ }^{1} \mathrm{H}\right\}$ NMR Spectrum of $\mathbf{L 3}(\mathrm{CDCl} 3,202.5 \mathrm{MHz}, 300 \mathrm{~K})$

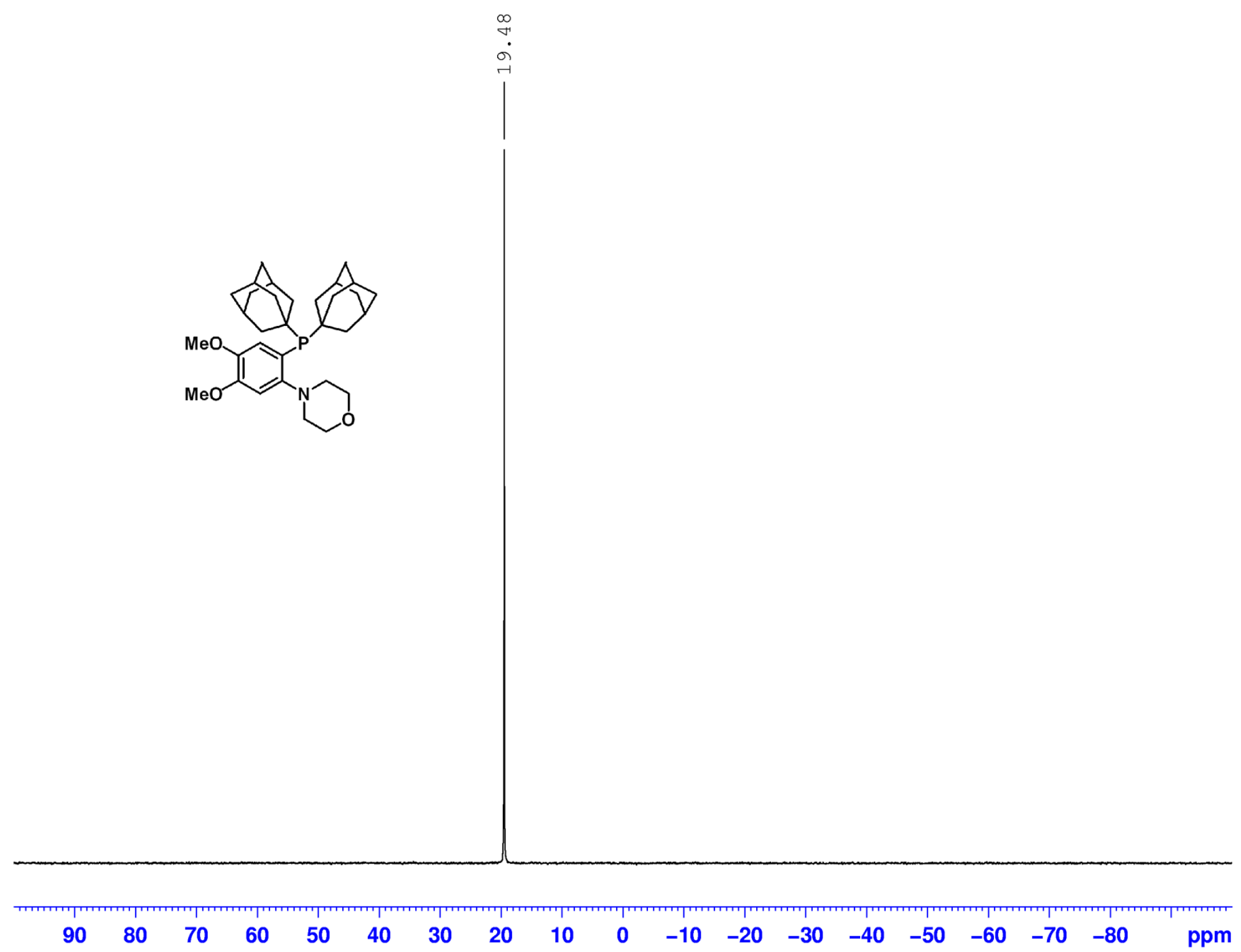


Figure S27. ${ }^{13} \mathrm{C}\left\{{ }^{1} \mathrm{H}\right\}$ NMR Spectrum of $\mathbf{L 3}\left(\mathrm{CDCl}_{3}, 125.7 \mathrm{MHz}, 300 \mathrm{~K}\right)$
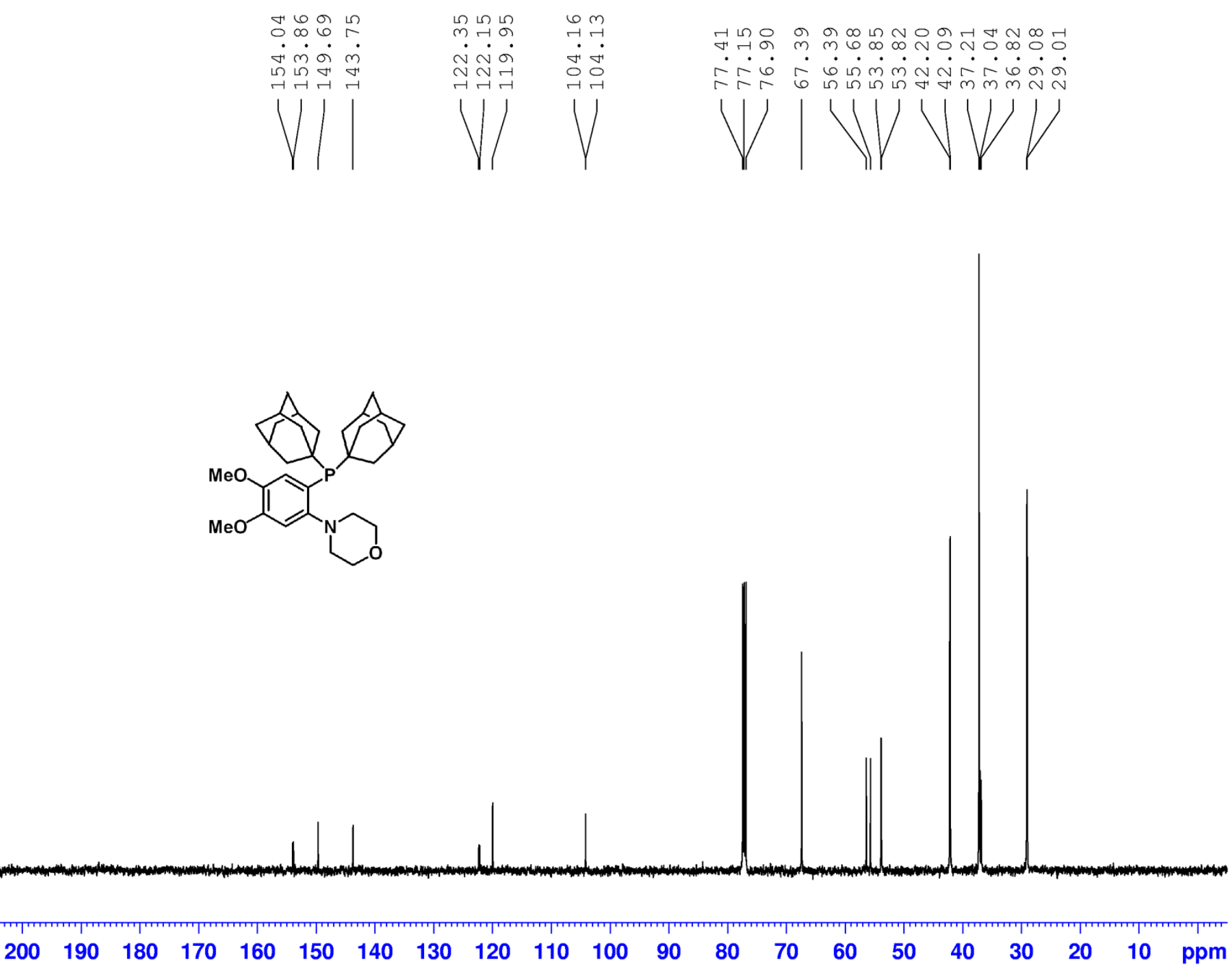
Figure S28. ${ }^{1} \mathrm{H}$ NMR Spectrum of L4 $\left(\mathrm{CDCl}_{3}, 500.1 \mathrm{MHz}, 300 \mathrm{~K}\right)$
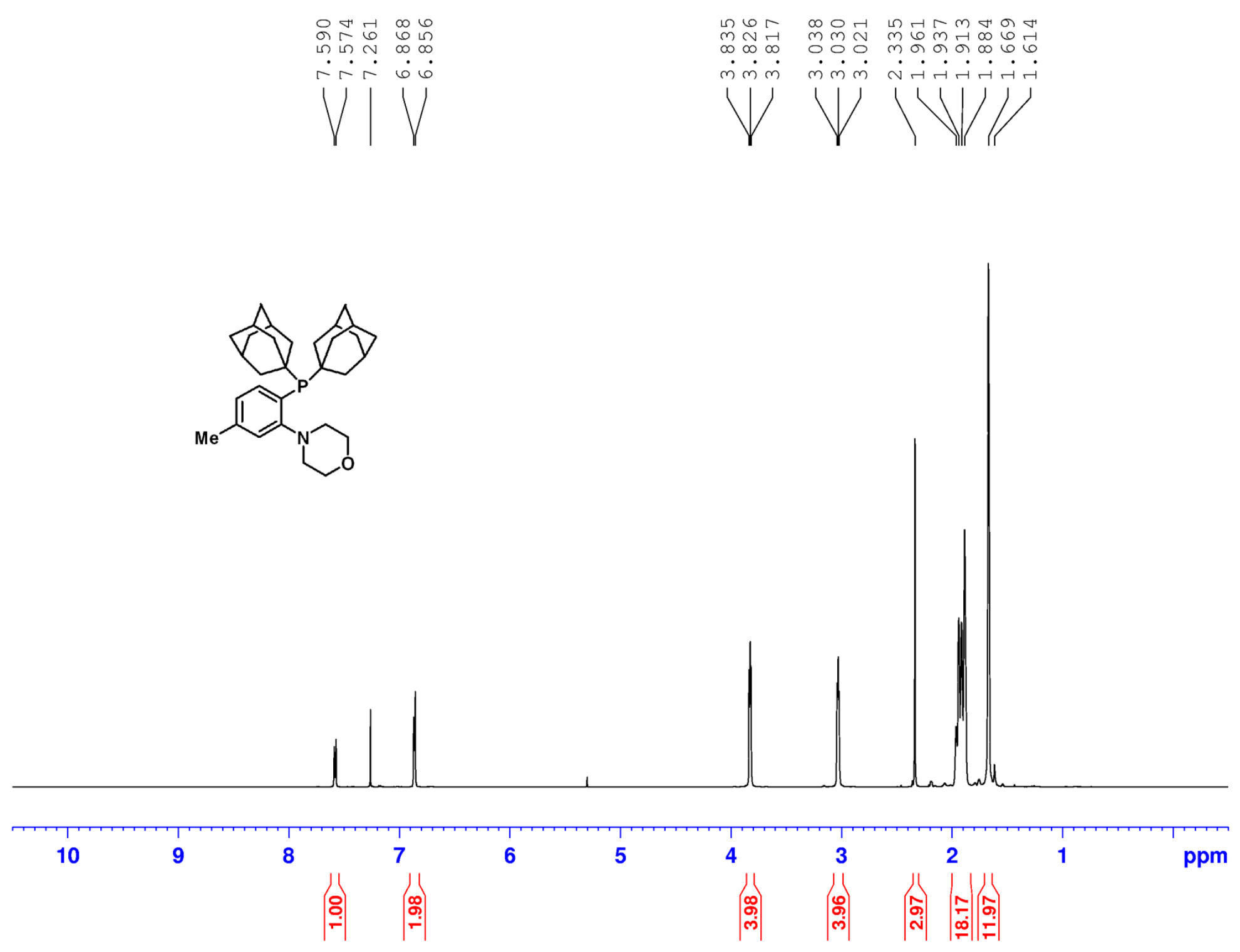
Figure S29. ${ }^{31} \mathrm{P}\left\{{ }^{1} \mathrm{H}\right\}$ NMR Spectrum of $\mathbf{L} 4(\mathrm{CDCl} 3,202.5 \mathrm{MHz}, 300 \mathrm{~K})$
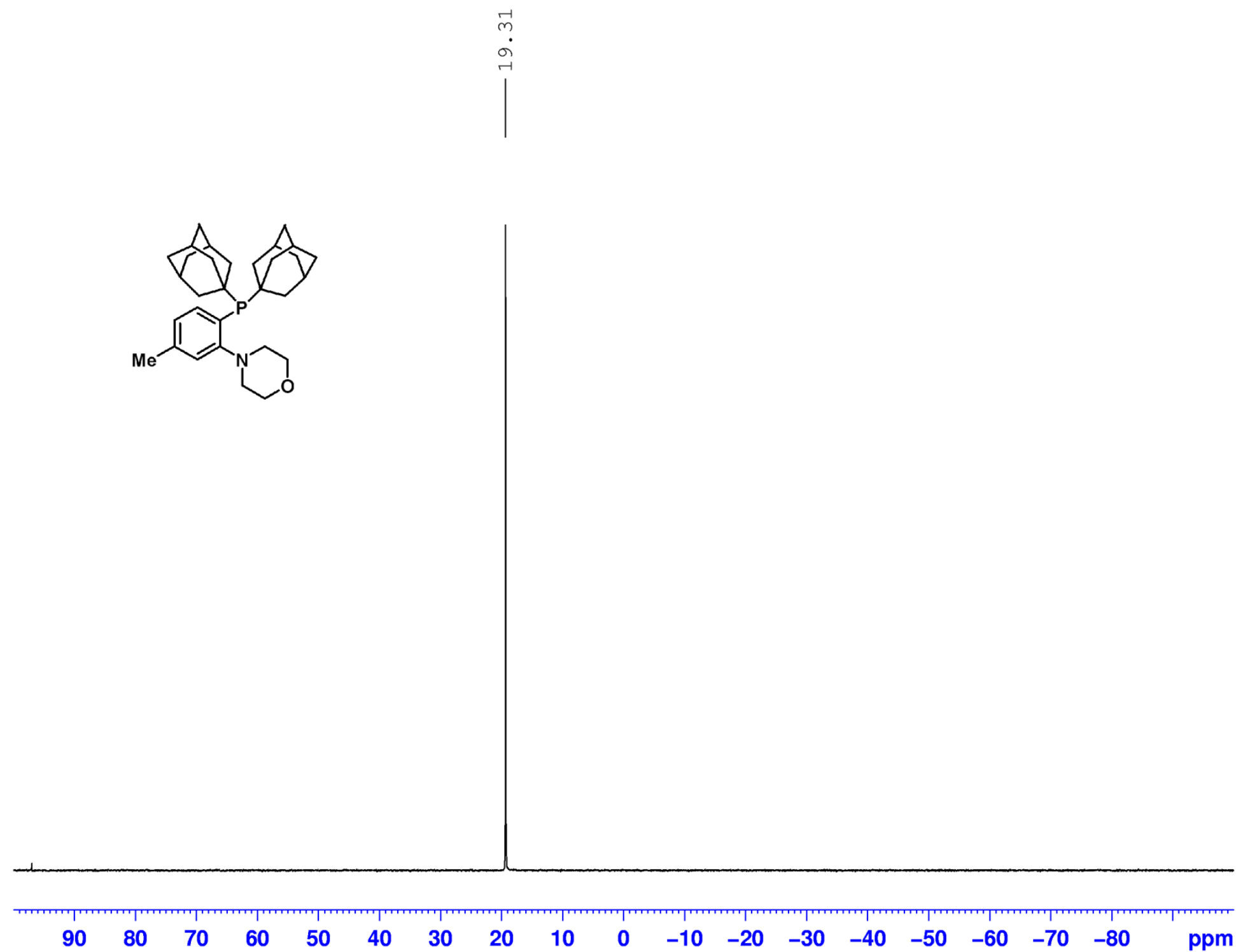
Figure S30. ${ }^{13} \mathrm{C}\left\{{ }^{1} \mathrm{H}\right\}$ NMR Spectrum of $\mathbf{L} 4\left(\mathrm{CDCl}_{3}, 125.7 \mathrm{MHz}, 300 \mathrm{~K}\right)$
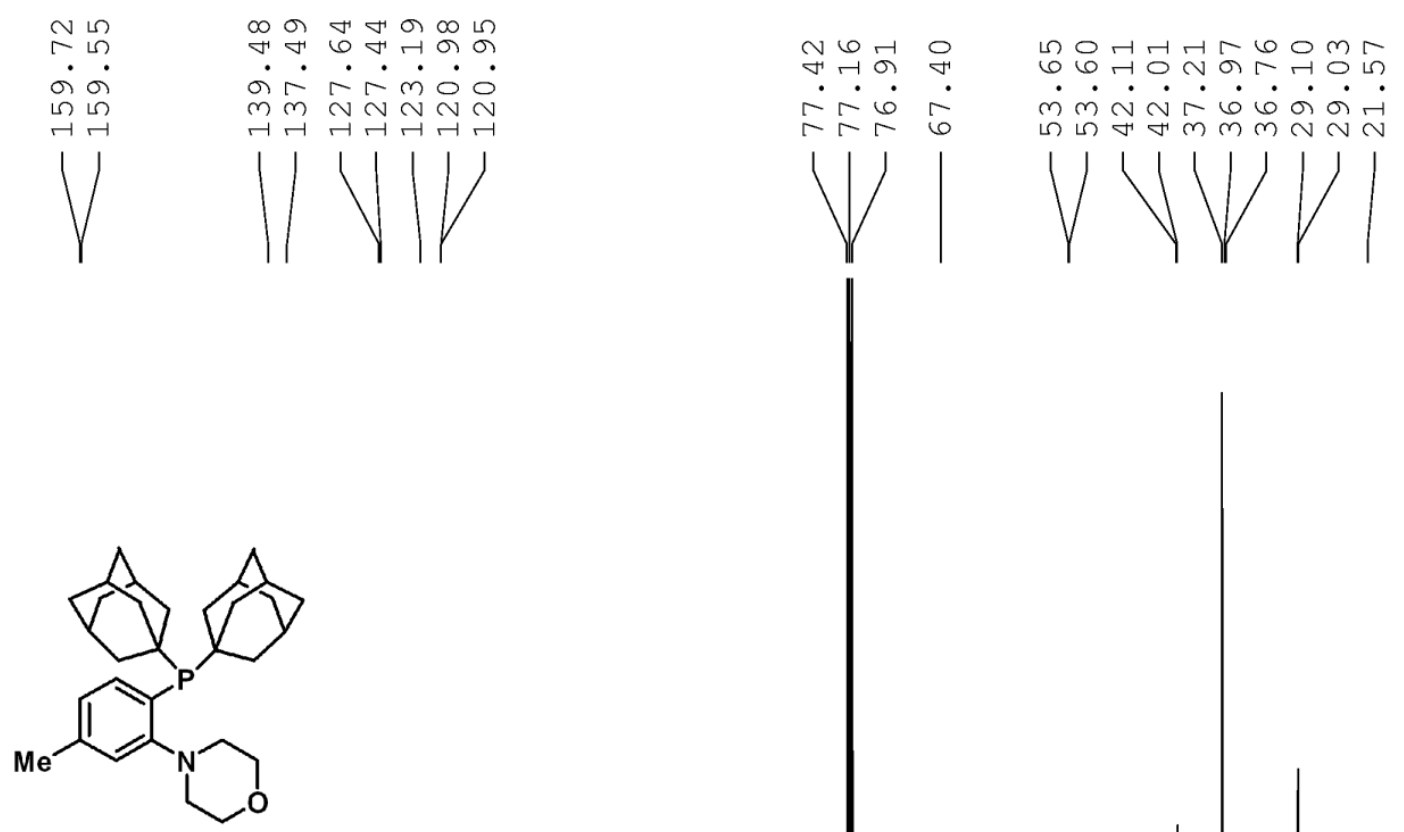
Figure S31. ${ }^{1} \mathrm{H}$ NMR Spectrum of $\mathbf{L} 5\left(\mathrm{CDCl}_{3}, 500.1 \mathrm{MHz}, 300 \mathrm{~K}\right)$

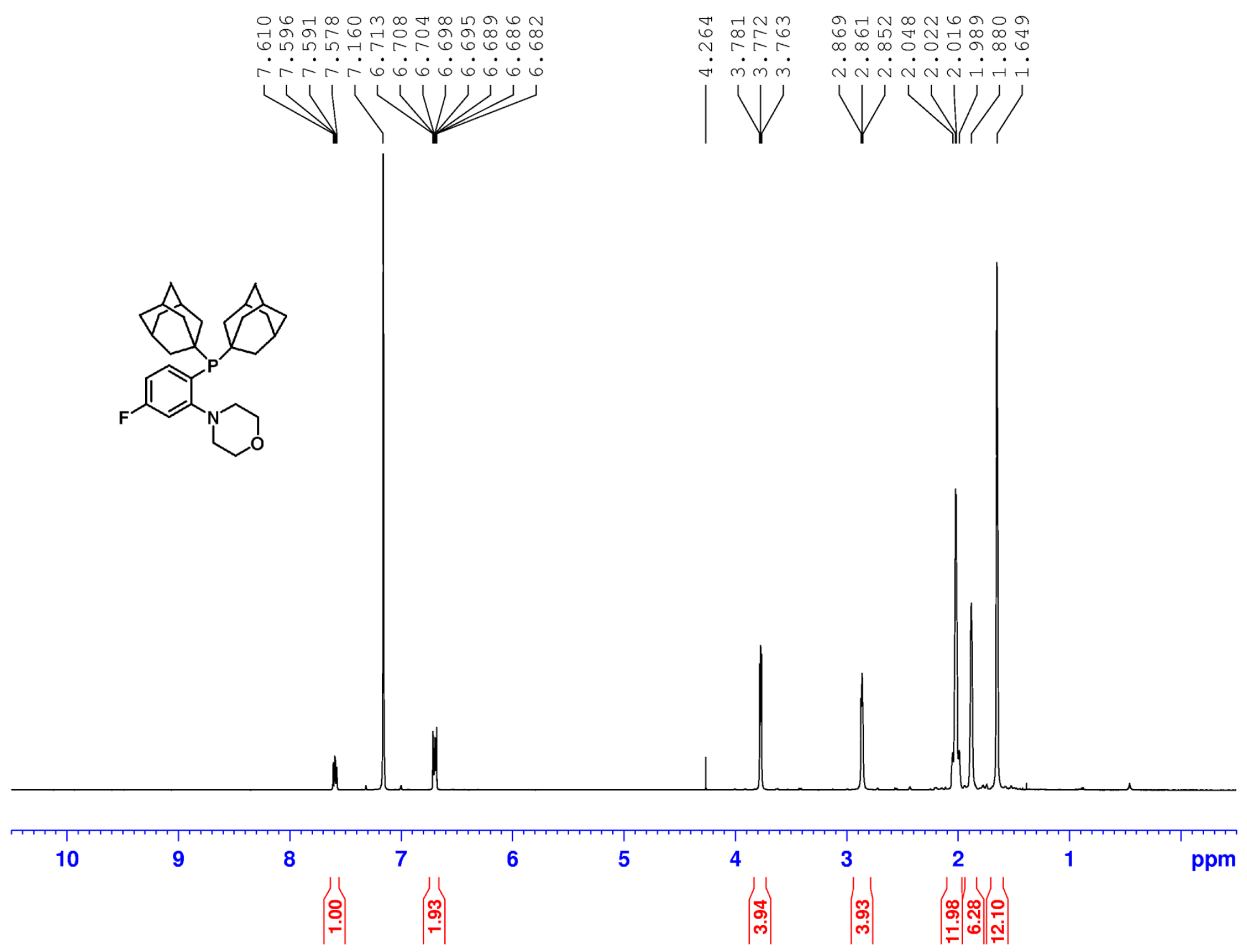


Figure S32. ${ }^{31} \mathrm{P}\left\{{ }^{1} \mathrm{H}\right\}$ NMR Spectrum of $\mathbf{L 5}(\mathrm{CDCl} 3,202.5 \mathrm{MHz}, 300 \mathrm{~K})$

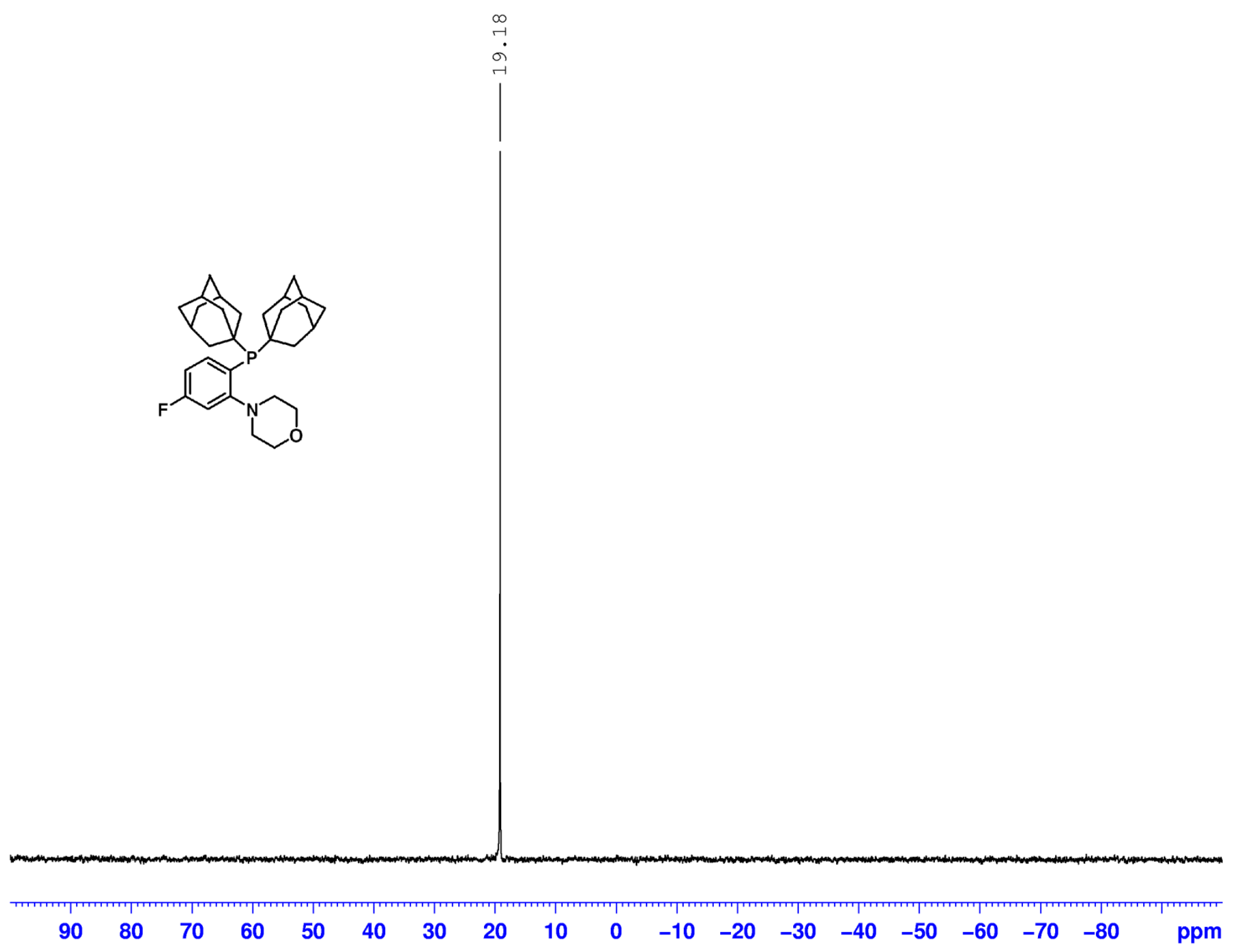


S33

Figure S33. ${ }^{13} \mathrm{C}\left\{{ }^{1} \mathrm{H}\right\}$ NMR Spectrum of $\mathbf{L 5}\left(\mathrm{CDCl}_{3}, 125.7 \mathrm{MHz}, 300 \mathrm{~K}\right)$
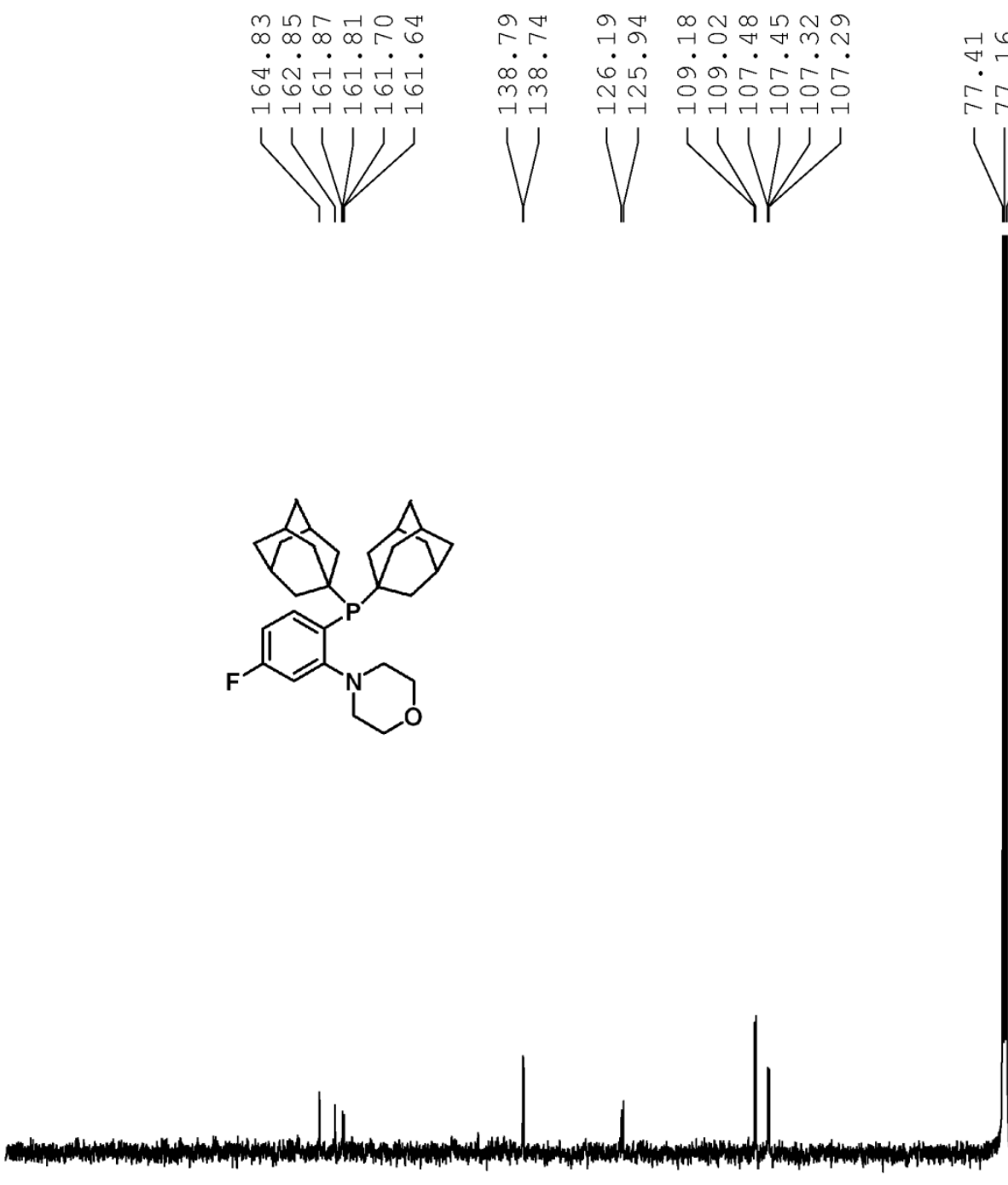

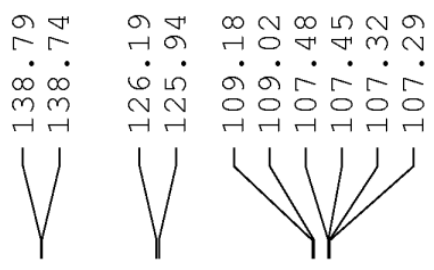

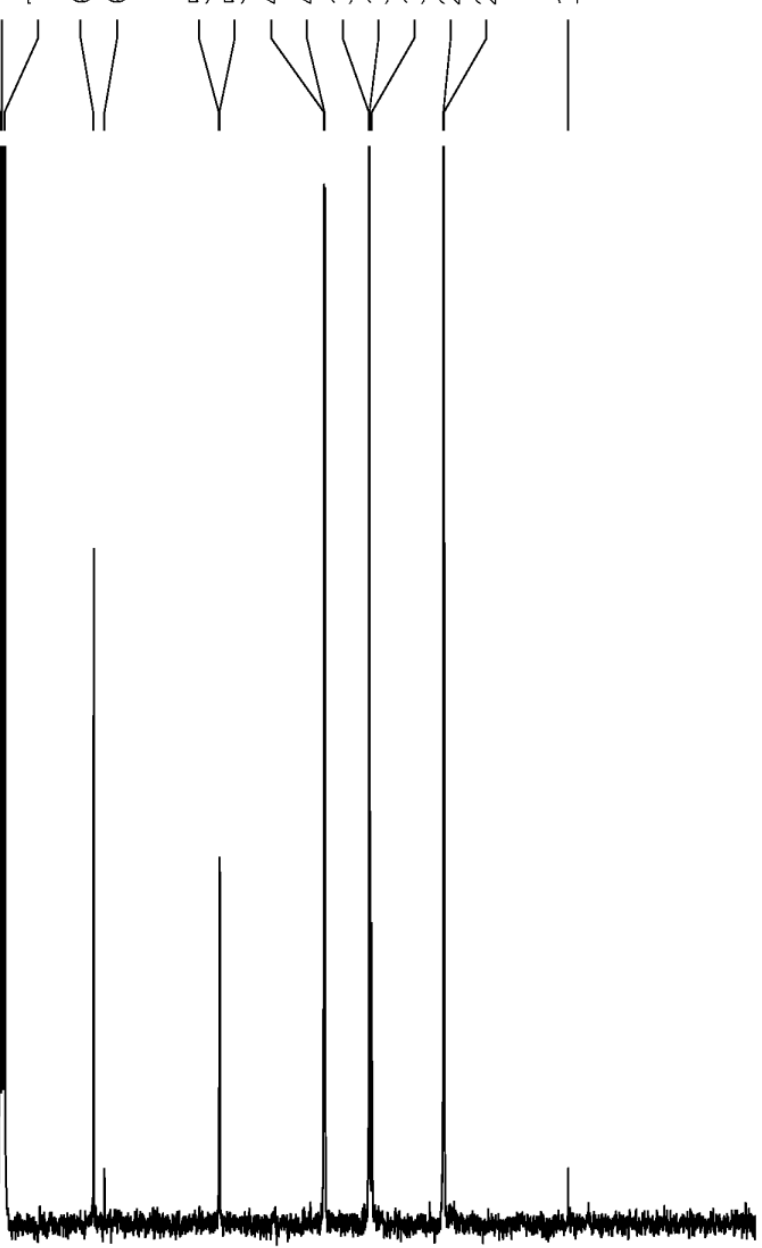

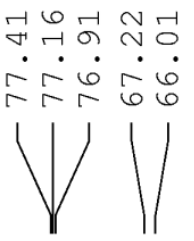

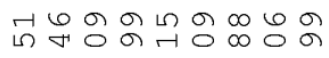

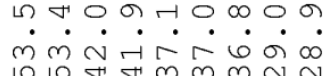

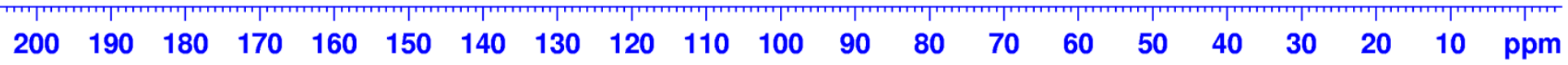


Figure S34. ${ }^{1} \mathrm{H}$ NMR Spectrum of $\mathbf{L} 6\left(\mathrm{CDCl}_{3}, 500.1 \mathrm{MHz}, 300 \mathrm{~K}\right)$
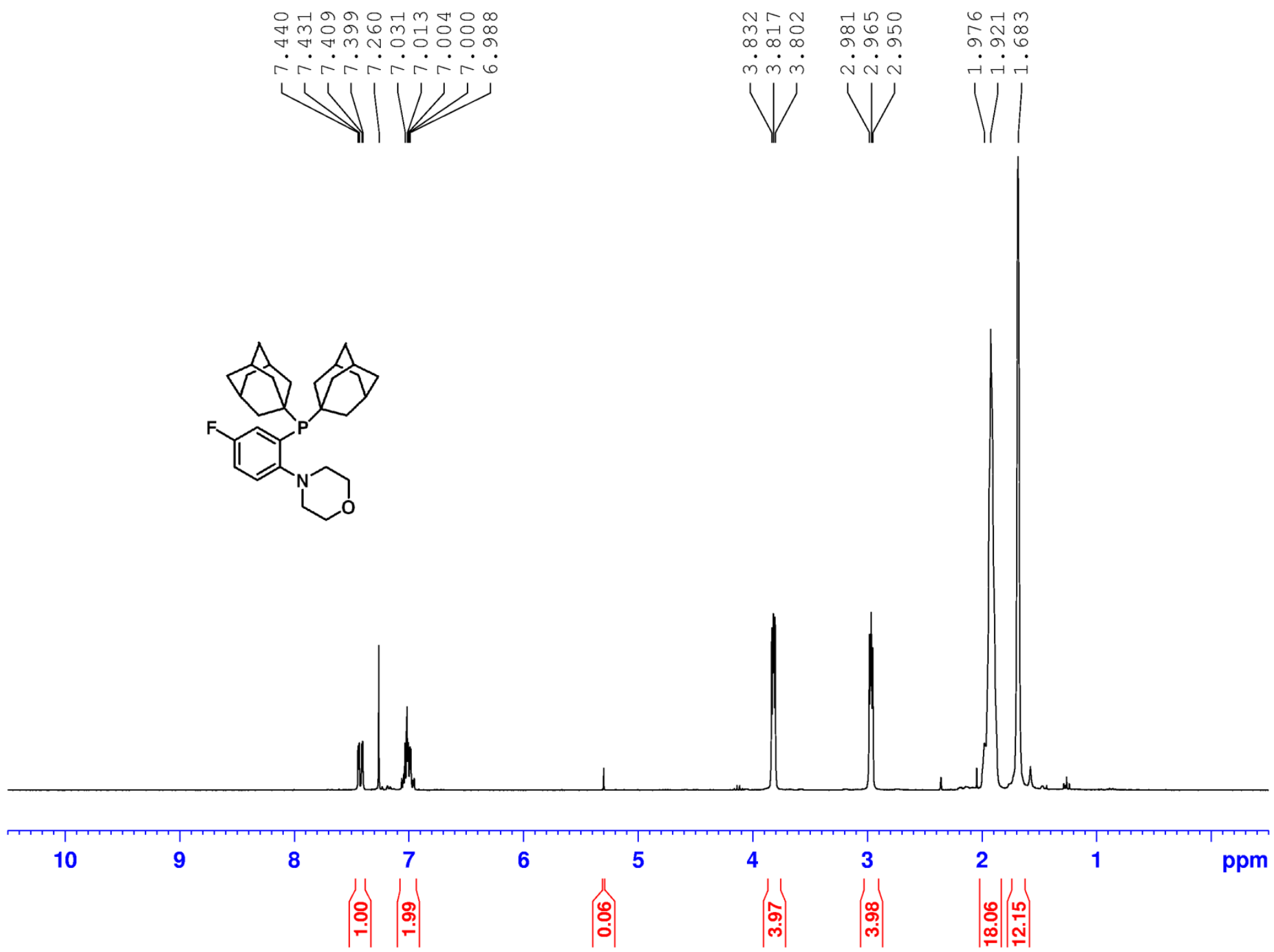
Figure S35. ${ }^{31} \mathrm{P}\left\{{ }^{1} \mathrm{H}\right\}$ NMR Spectrum of L6 (CDCl3, $\left.202.5 \mathrm{MHz}, 300 \mathrm{~K}\right)$

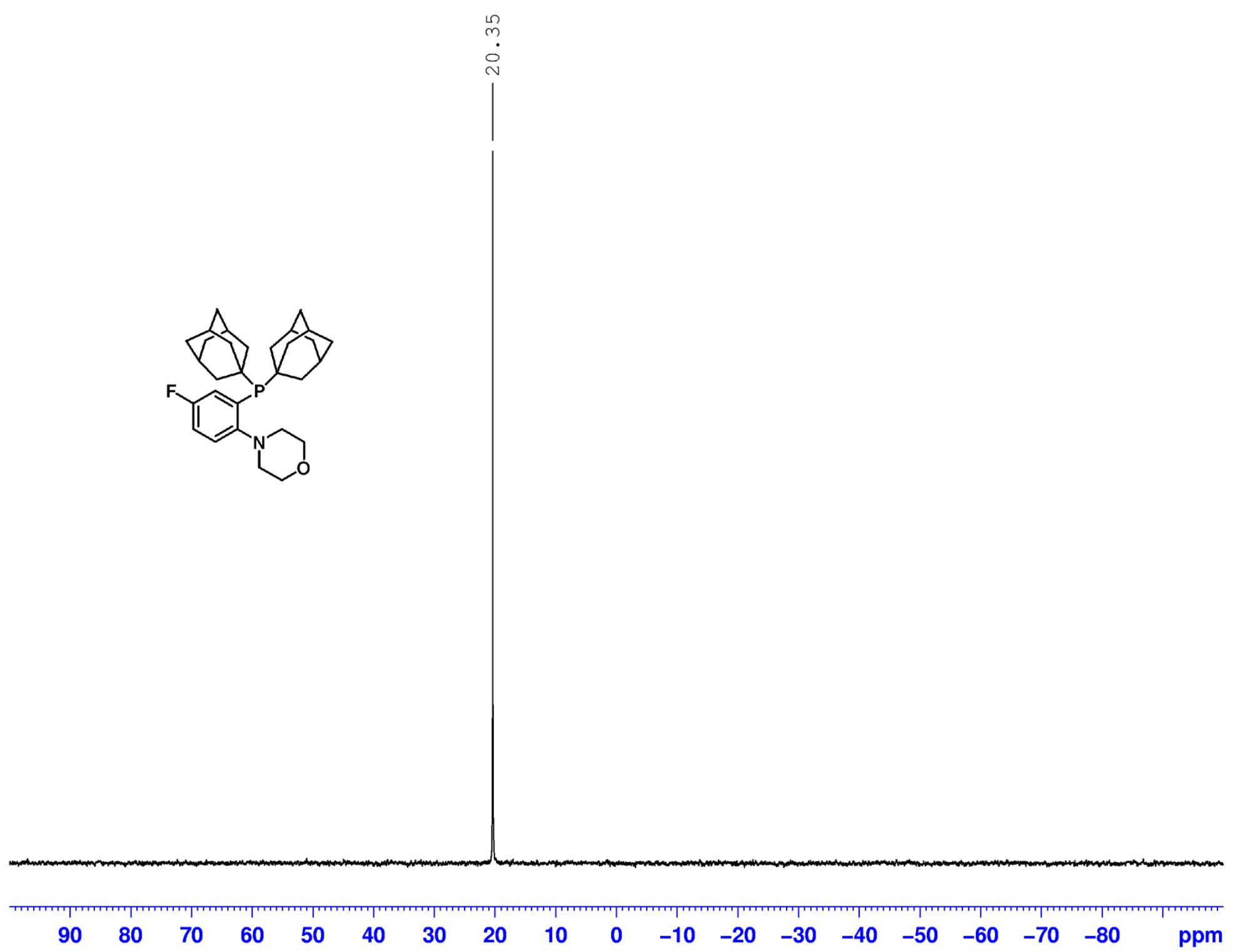


Figure S36. ${ }^{13} \mathrm{C}\left\{{ }^{1} \mathrm{H}\right\}$ NMR Spectrum of $\mathbf{L 6}\left(\mathrm{CDCl}_{3}, 125.7 \mathrm{MHz}, 300 \mathrm{~K}\right)$
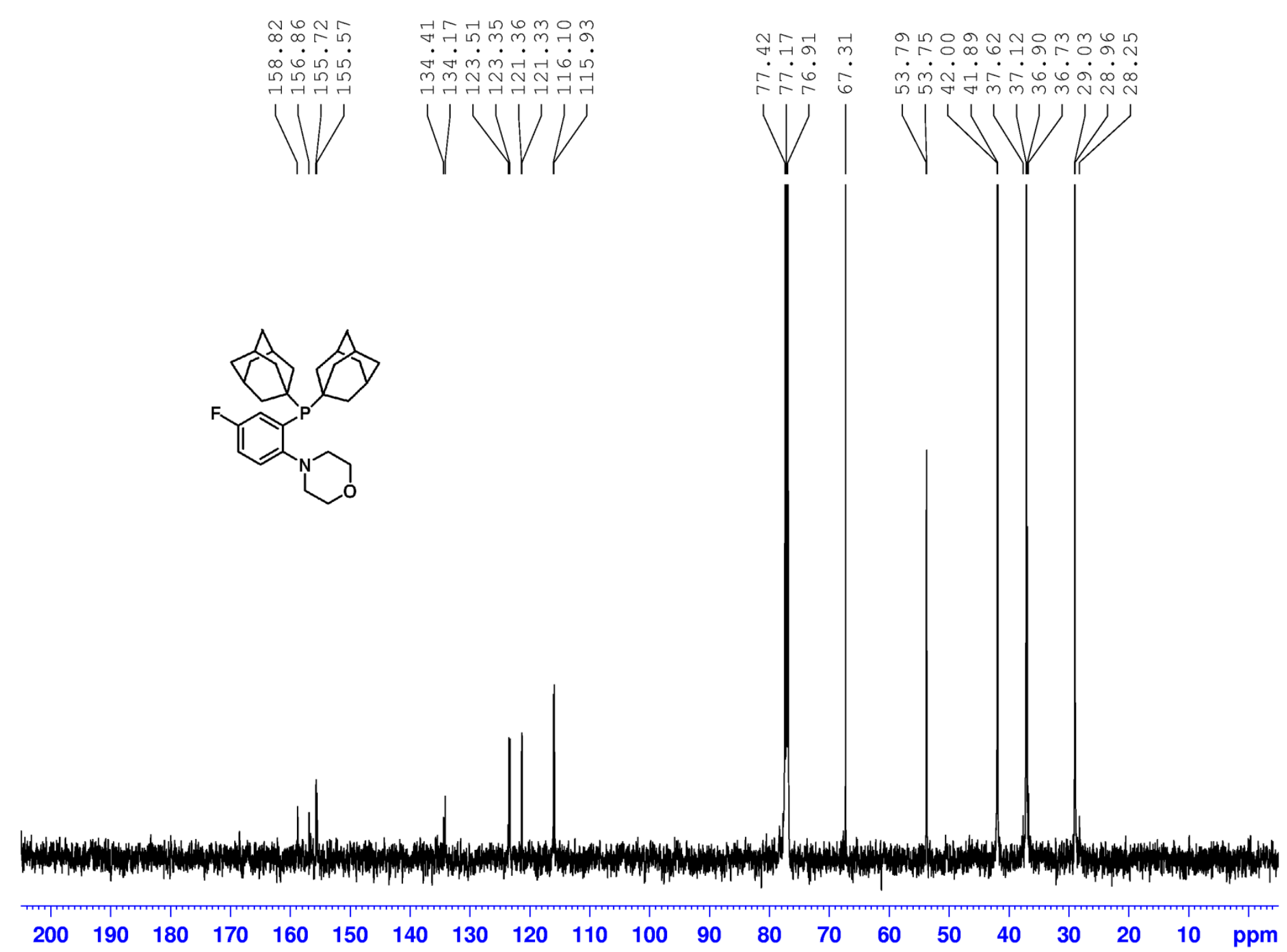
Figure S37. ${ }^{1} \mathrm{H}$ NMR Spectrum of $\mathbf{L} 7\left(\mathrm{CDCl}_{3}, 500.1 \mathrm{MHz}, 300 \mathrm{~K}\right)$
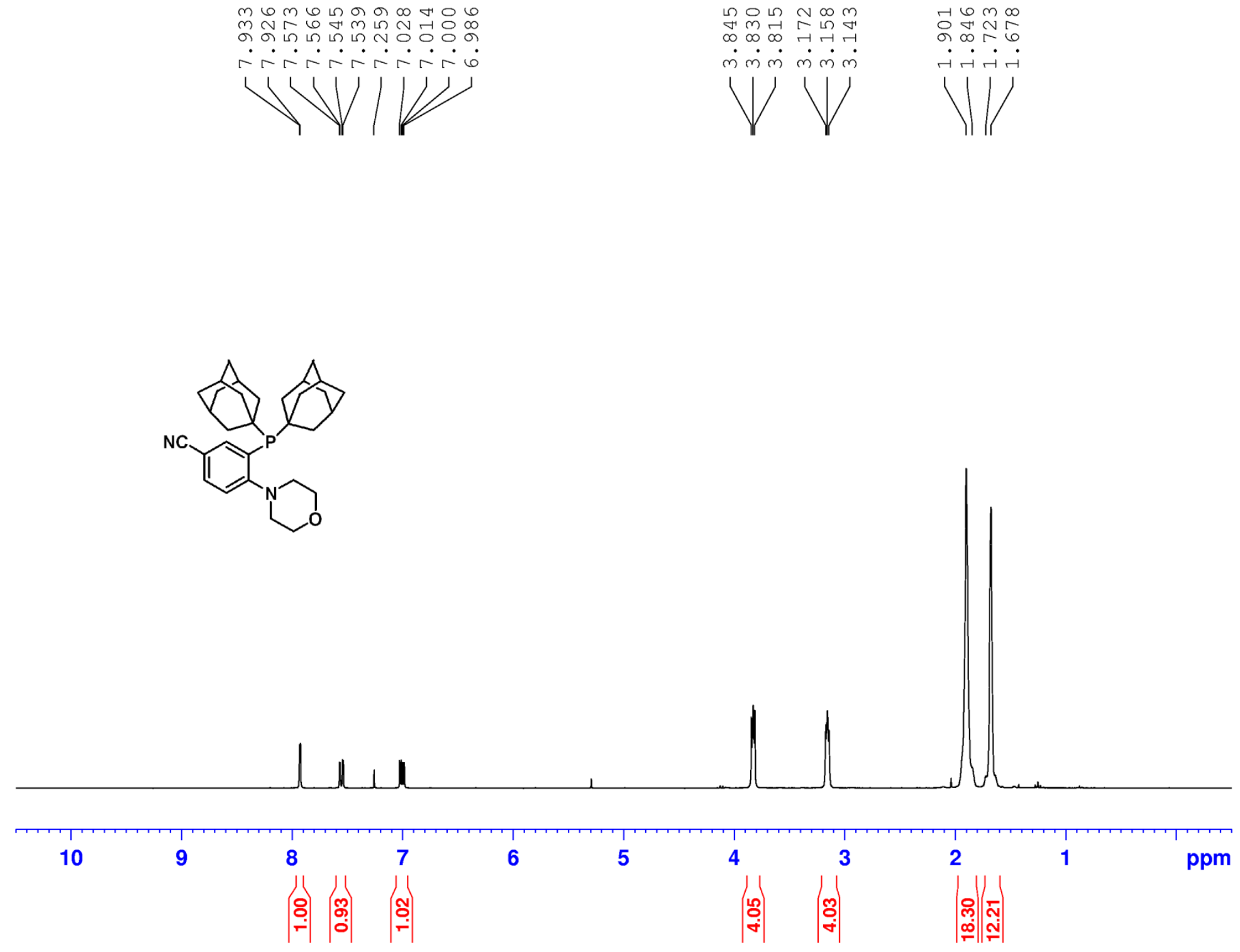
Figure S38. ${ }^{31} \mathrm{P}\left\{{ }^{1} \mathrm{H}\right\}$ NMR Spectrum of $\mathbf{L} 7(\mathrm{CDCl} 3,202.5 \mathrm{MHz}, 300 \mathrm{~K})$
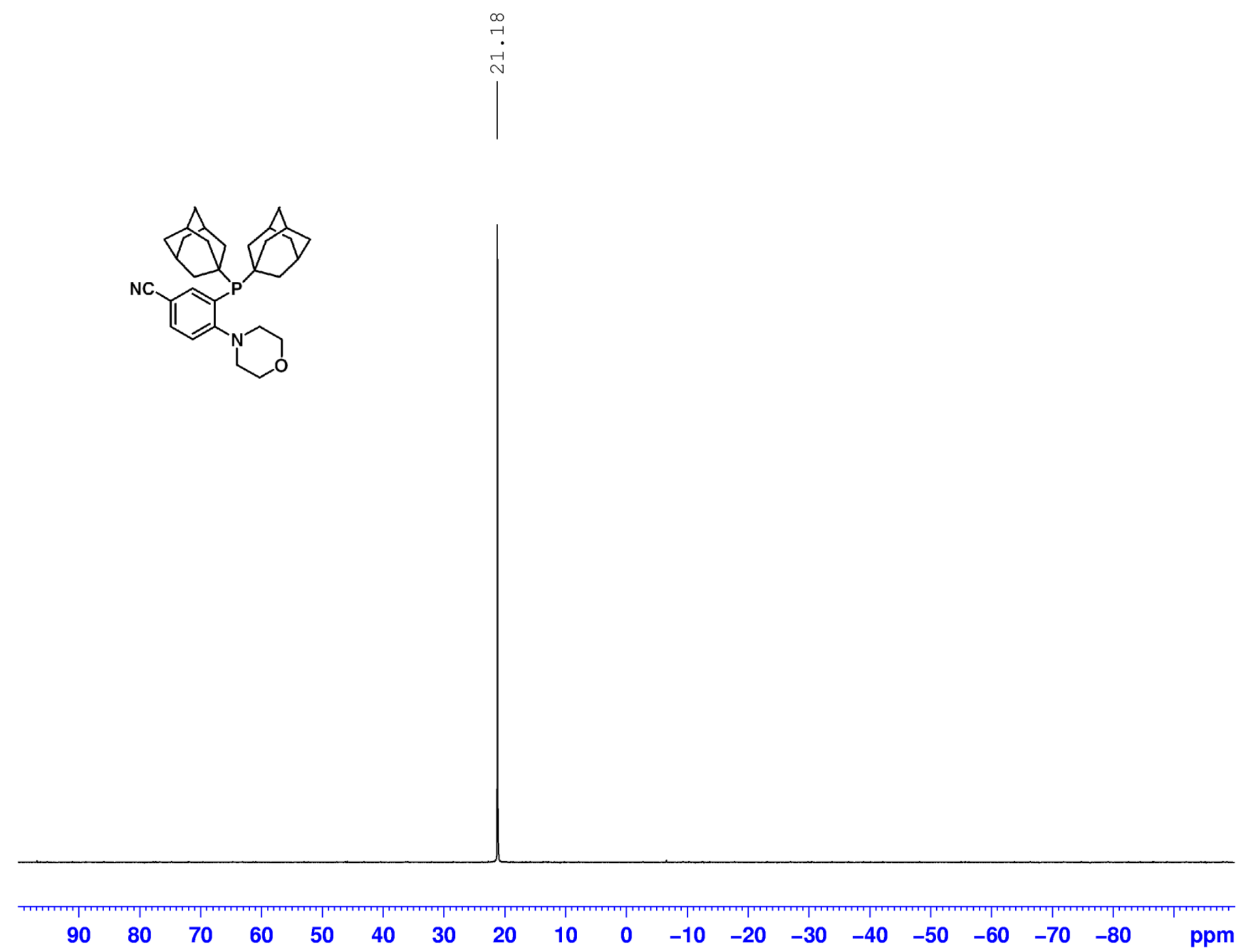
Figure S39. ${ }^{13} \mathrm{C}\left\{{ }^{1} \mathrm{H}\right\}$ NMR Spectrum of $\mathbf{L} 7\left(\mathrm{CDCl}_{3}, 125.7 \mathrm{MHz}, 300 \mathrm{~K}\right)$
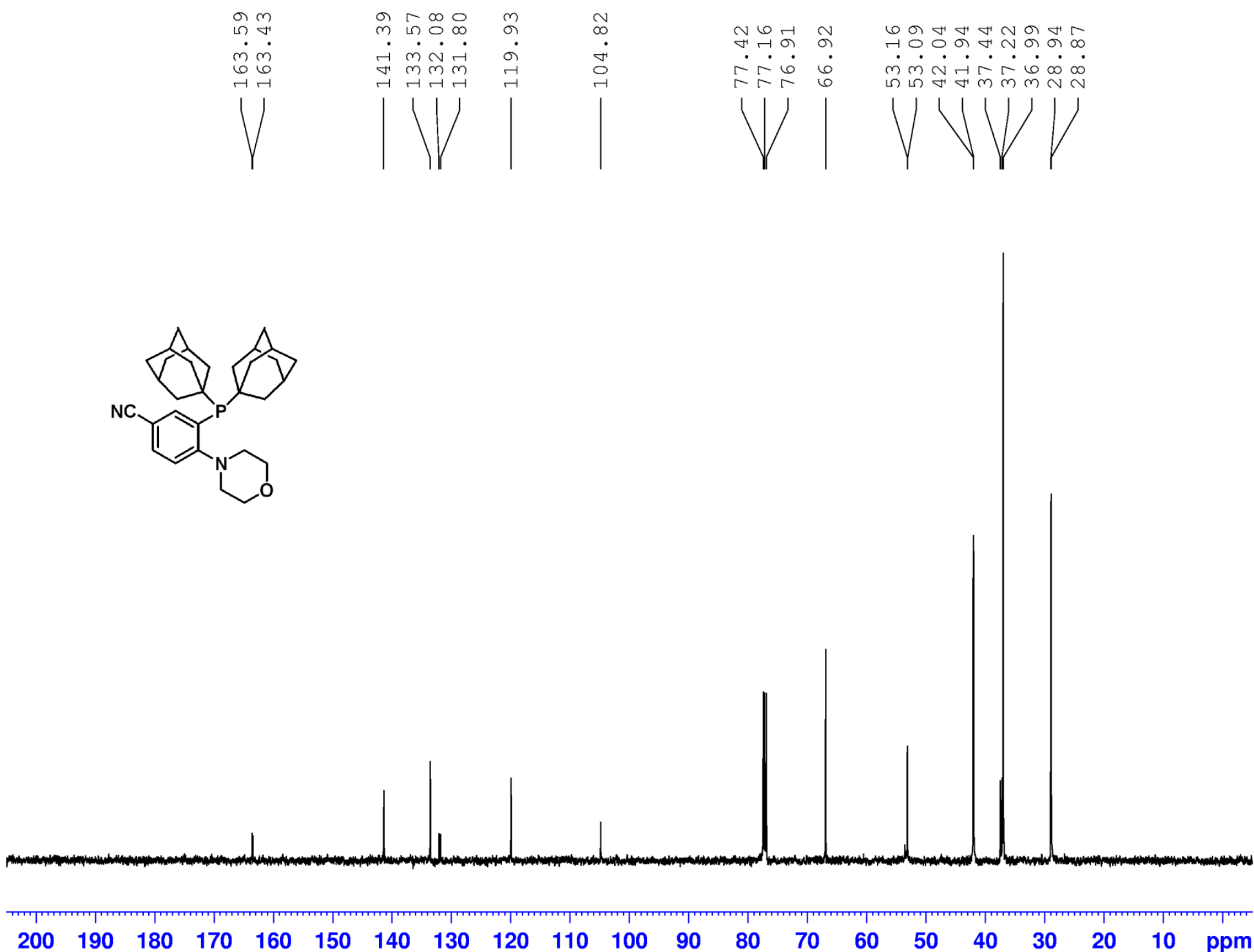
Figure S40. ${ }^{1} \mathrm{H}$ NMR Spectrum of $\mathbf{L 8}\left(\mathrm{CDCl}_{3}, 500.1 \mathrm{MHz}, 300 \mathrm{~K}\right)$
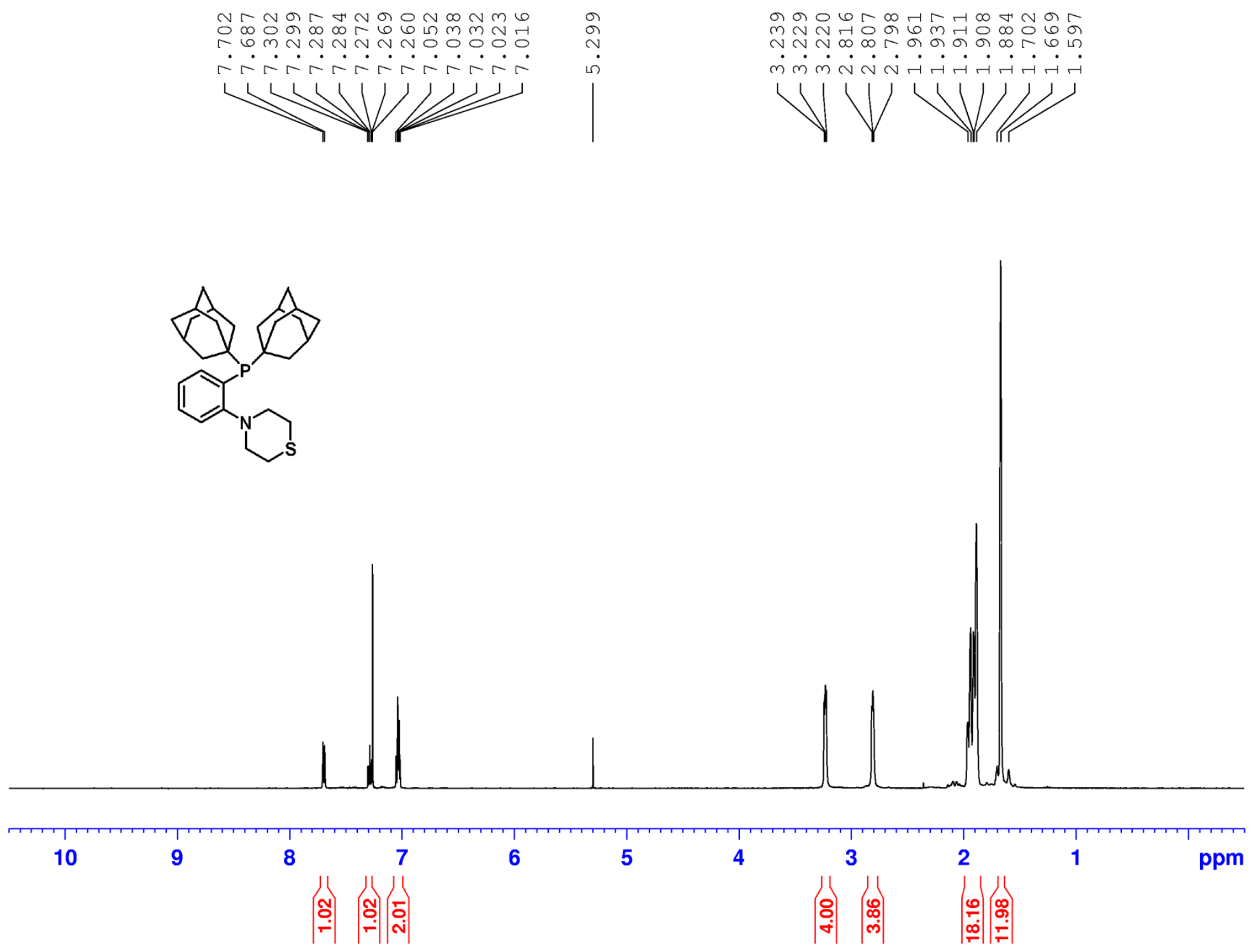
Figure S41. ${ }^{31} \mathrm{P}\left\{{ }^{1} \mathrm{H}\right\}$ NMR Spectrum of $\mathbf{L 8}(\mathrm{CDCl} 3,202.5 \mathrm{MHz}, 300 \mathrm{~K})$
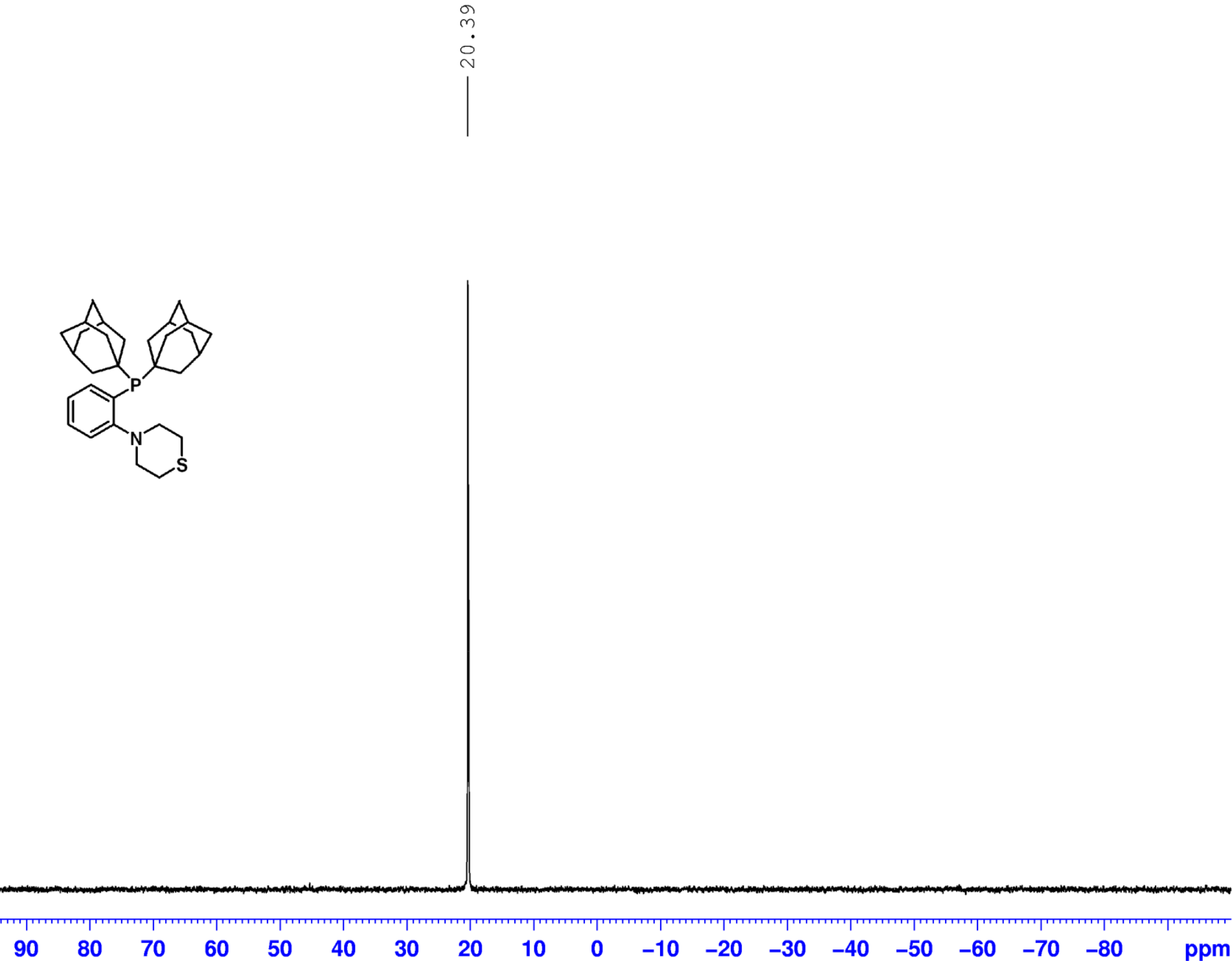
Figure S42. ${ }^{13} \mathrm{C}\left\{{ }^{1} \mathrm{H}\right\}$ NMR Spectrum of $\mathbf{L 8}\left(\mathrm{CDCl}_{3}, 125.7 \mathrm{MHz}, 300 \mathrm{~K}\right)$

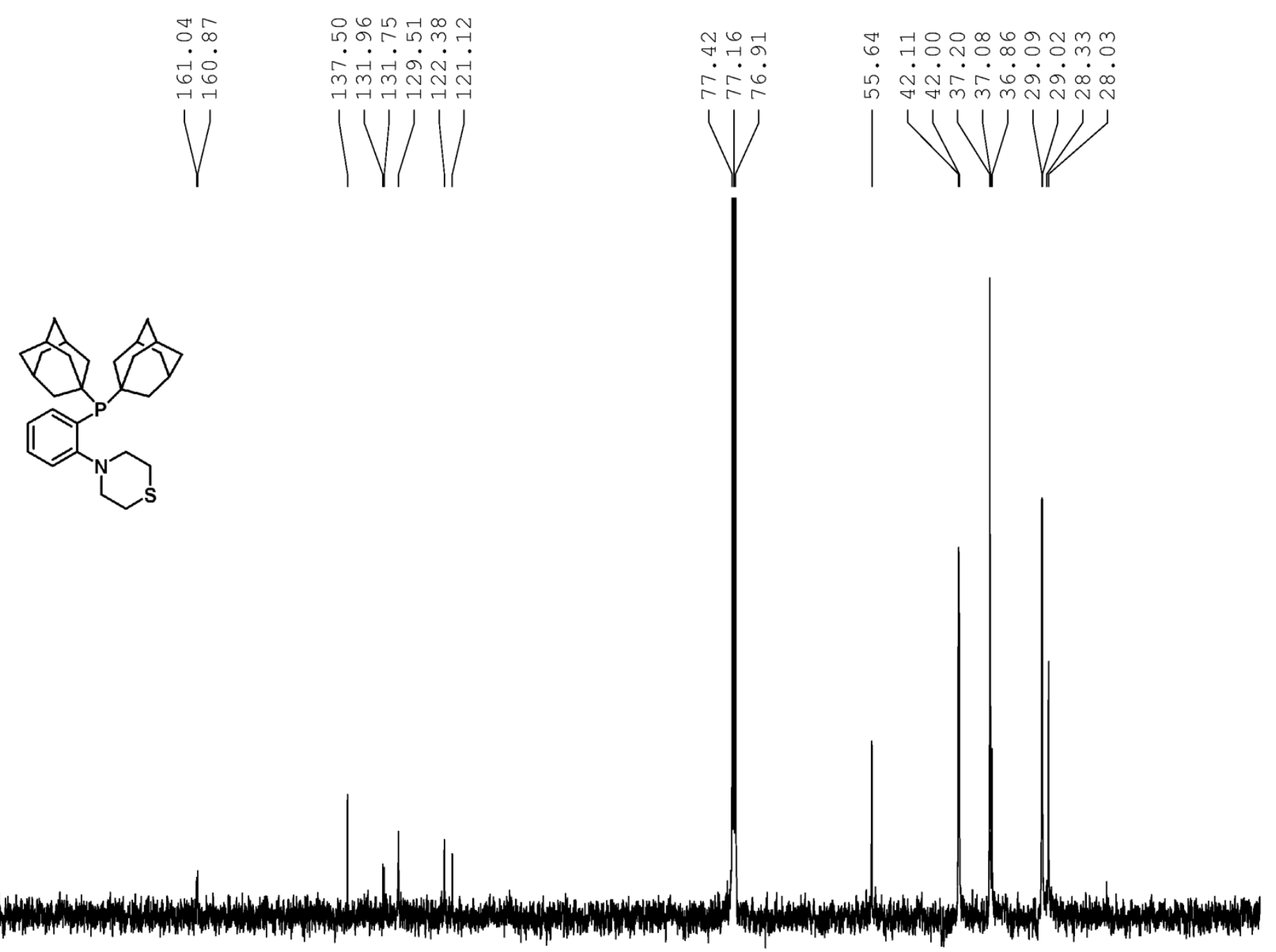


Figure S43. ${ }^{1} \mathrm{H}$ NMR Spectrum of $\mathbf{C 1}\left(\mathrm{CDCl}_{3}, 500.1 \mathrm{MHz}, 300 \mathrm{~K}\right)$
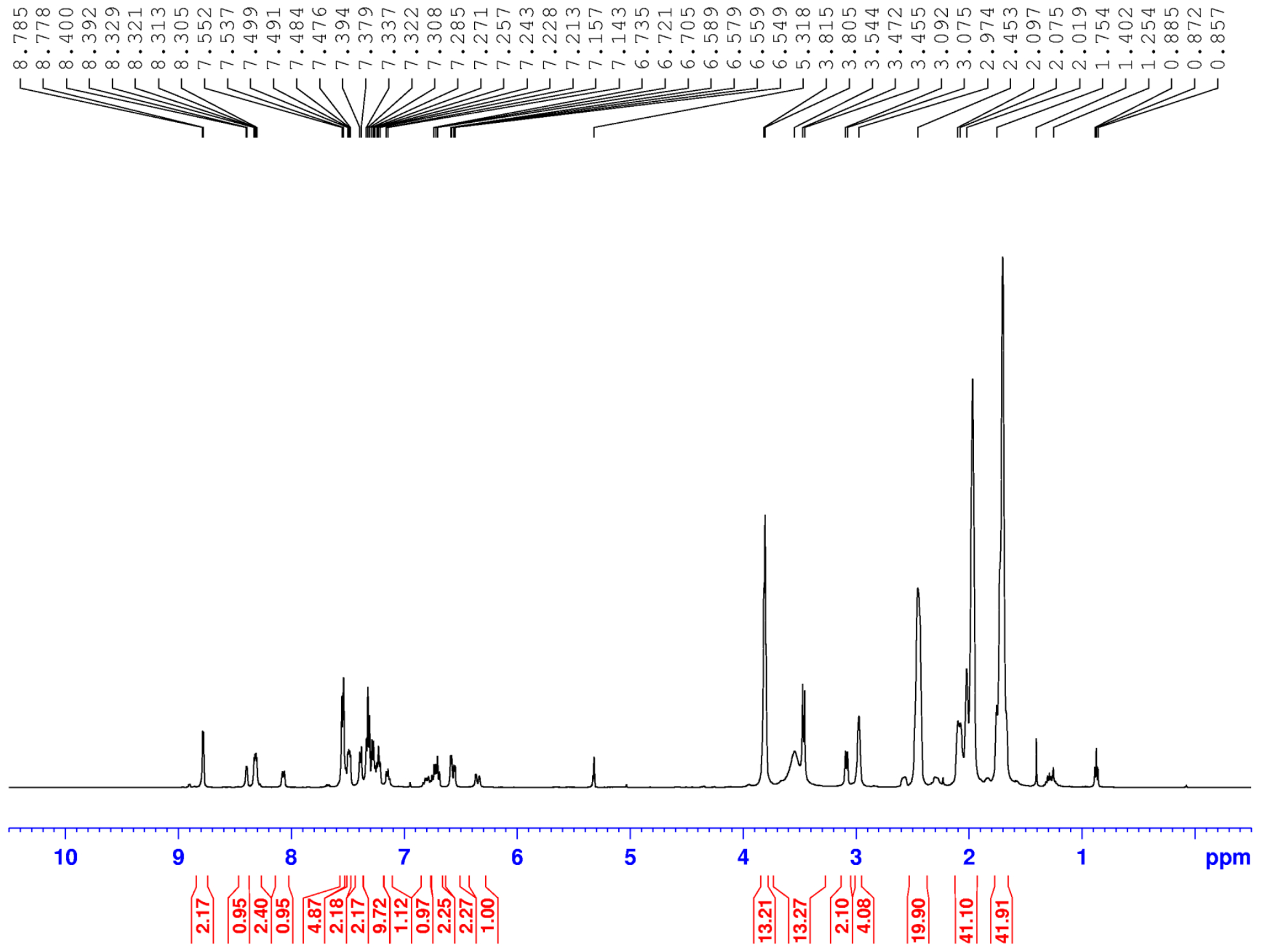
Figure S44. ${ }^{31} \mathrm{P}\left\{{ }^{1} \mathrm{H}\right\}$ NMR Spectrum of $\mathbf{C 1}\left(\mathrm{CDCl}_{3}, 202.5 \mathrm{MHz}, 300 \mathrm{~K}\right)$

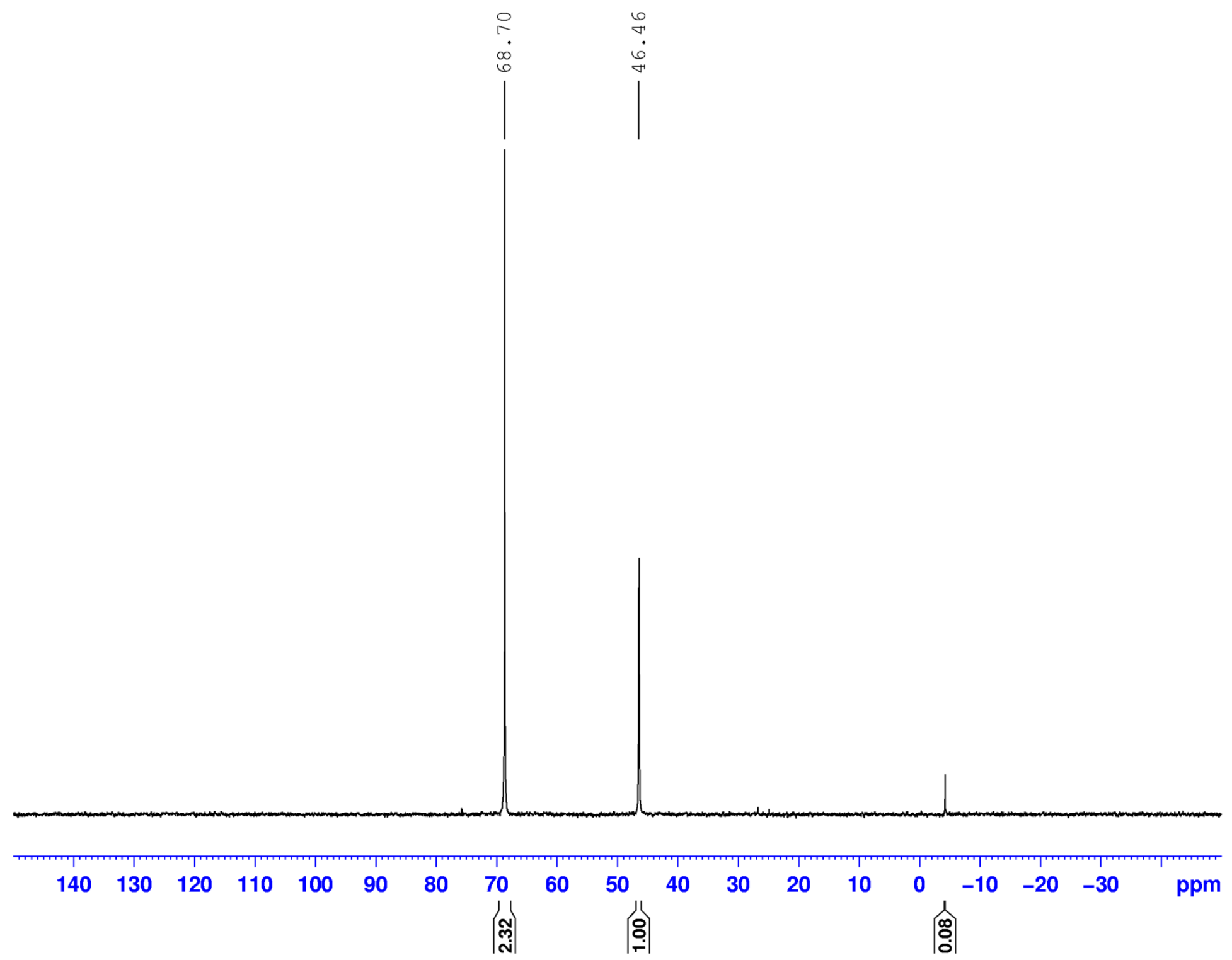


Figure S45. ${ }^{31} \mathrm{P}\left\{{ }^{1} \mathrm{H}\right\}$ NMR of C1 - Saturation Transfer Experiment $\left(\mathrm{CDCl}_{3}, 121.5 \mathrm{MHz}, 300 \mathrm{~K}\right.$; irradiation at 46.5 ppm in lower spectrum)
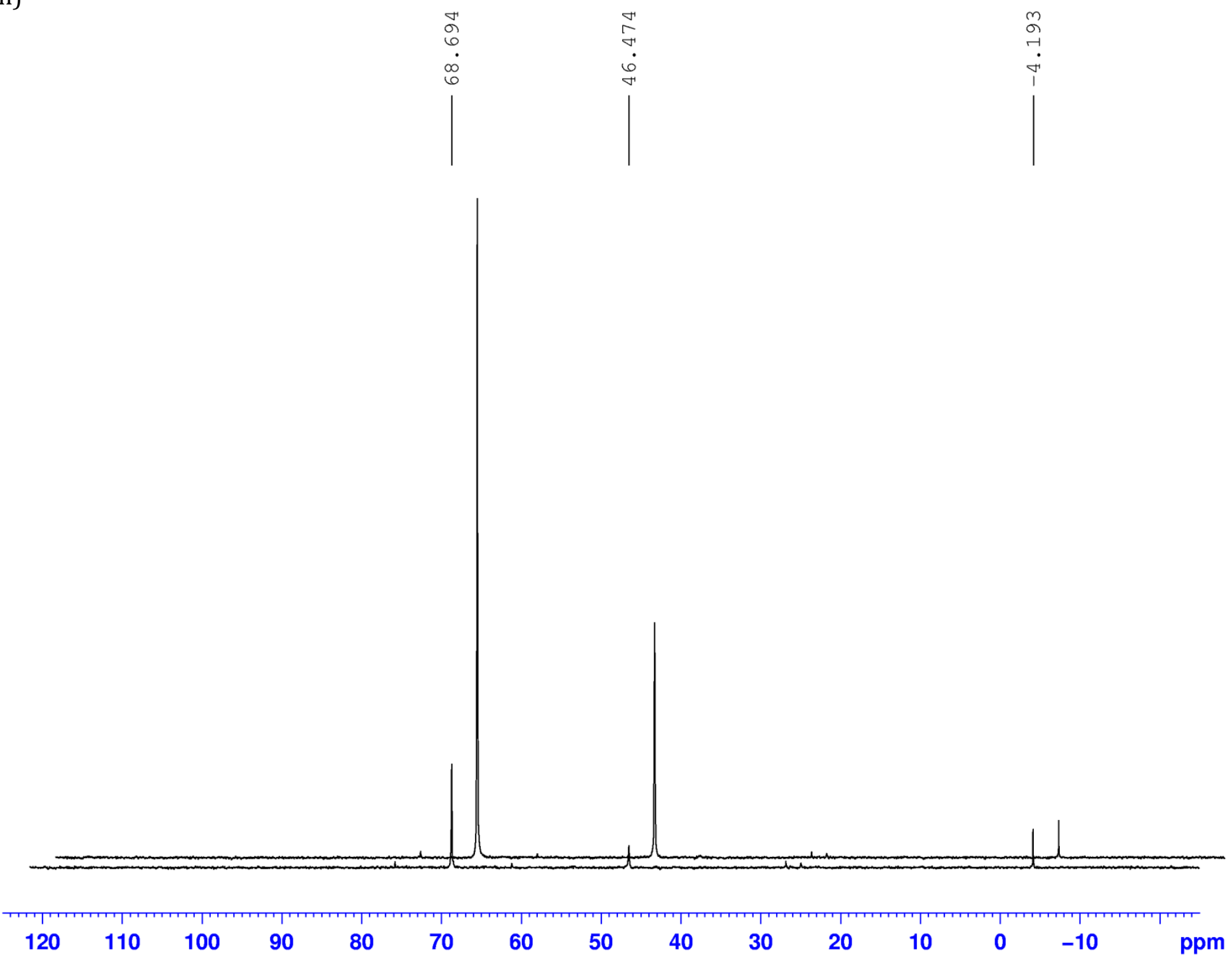
Figure S46. ${ }^{13} \mathrm{C}\left\{{ }^{1} \mathrm{H}\right\}$ NMR Spectrum of $\mathbf{C 1}\left(\mathrm{CDCl}_{3}, 125.7 \mathrm{MHz}, 300 \mathrm{~K}\right)$
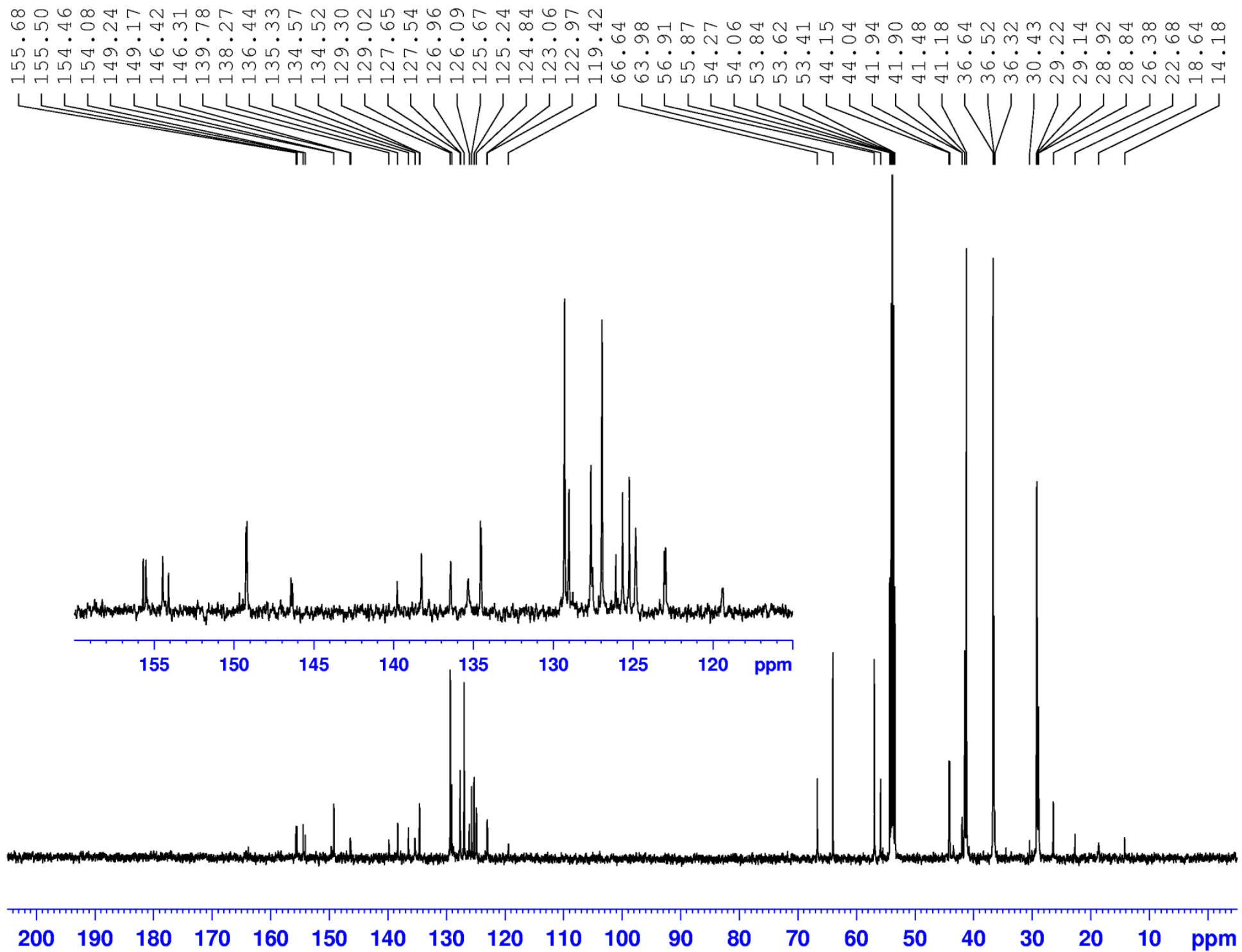
Figure S47. ${ }^{1} \mathrm{H}$ NMR Spectrum of $\mathbf{C} 2\left(\mathrm{CDCl}_{3}, 500.1 \mathrm{MHz}, 300 \mathrm{~K}\right)$

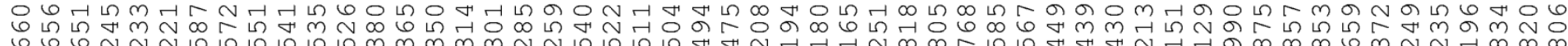

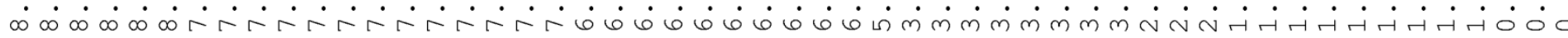

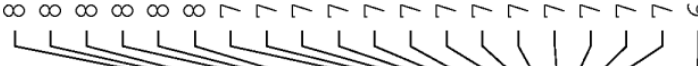
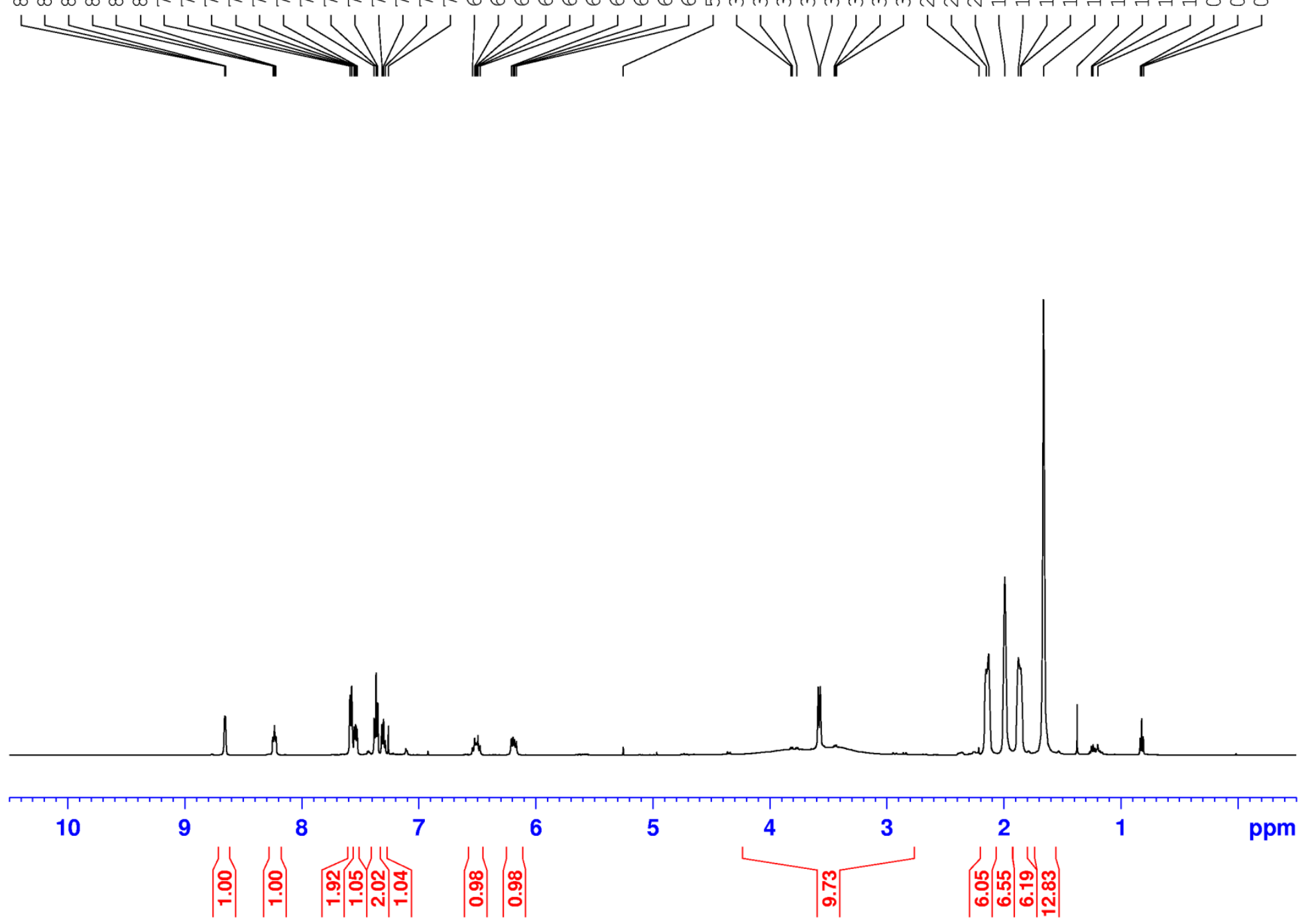
Figure S48. ${ }^{31} \mathrm{P}\left\{{ }^{1} \mathrm{H}\right\}$ NMR Spectrum of $\mathbf{C} 2(\mathrm{CDCl} 3,202.5 \mathrm{MHz}, 300 \mathrm{~K})$
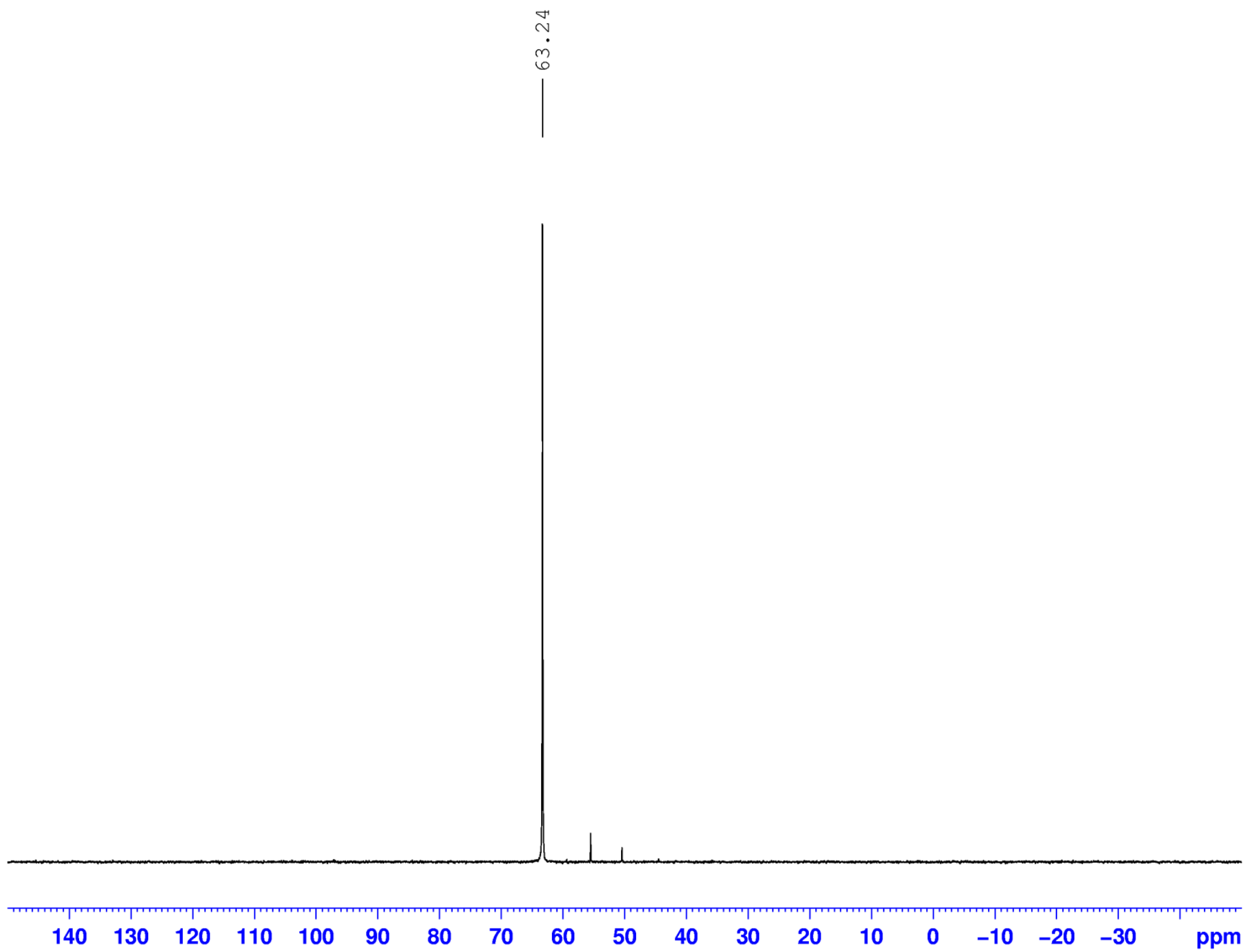
Figure S49. ${ }^{13} \mathrm{C}\left\{{ }^{1} \mathrm{H}\right\}$ NMR Spectrum of $\mathbf{C} 2\left(\mathrm{CDCl}_{3}, 125.7 \mathrm{MHz}, 300 \mathrm{~K}\right)$
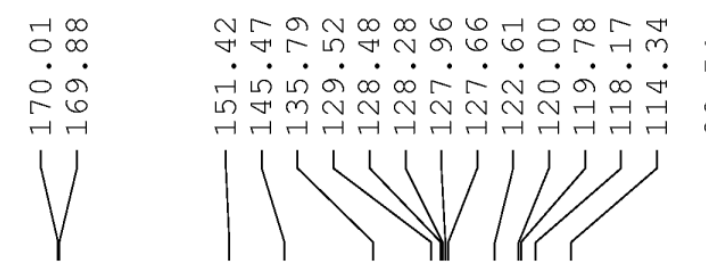

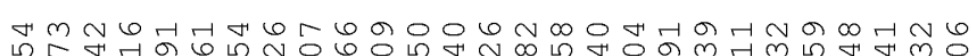

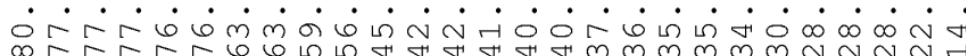

응

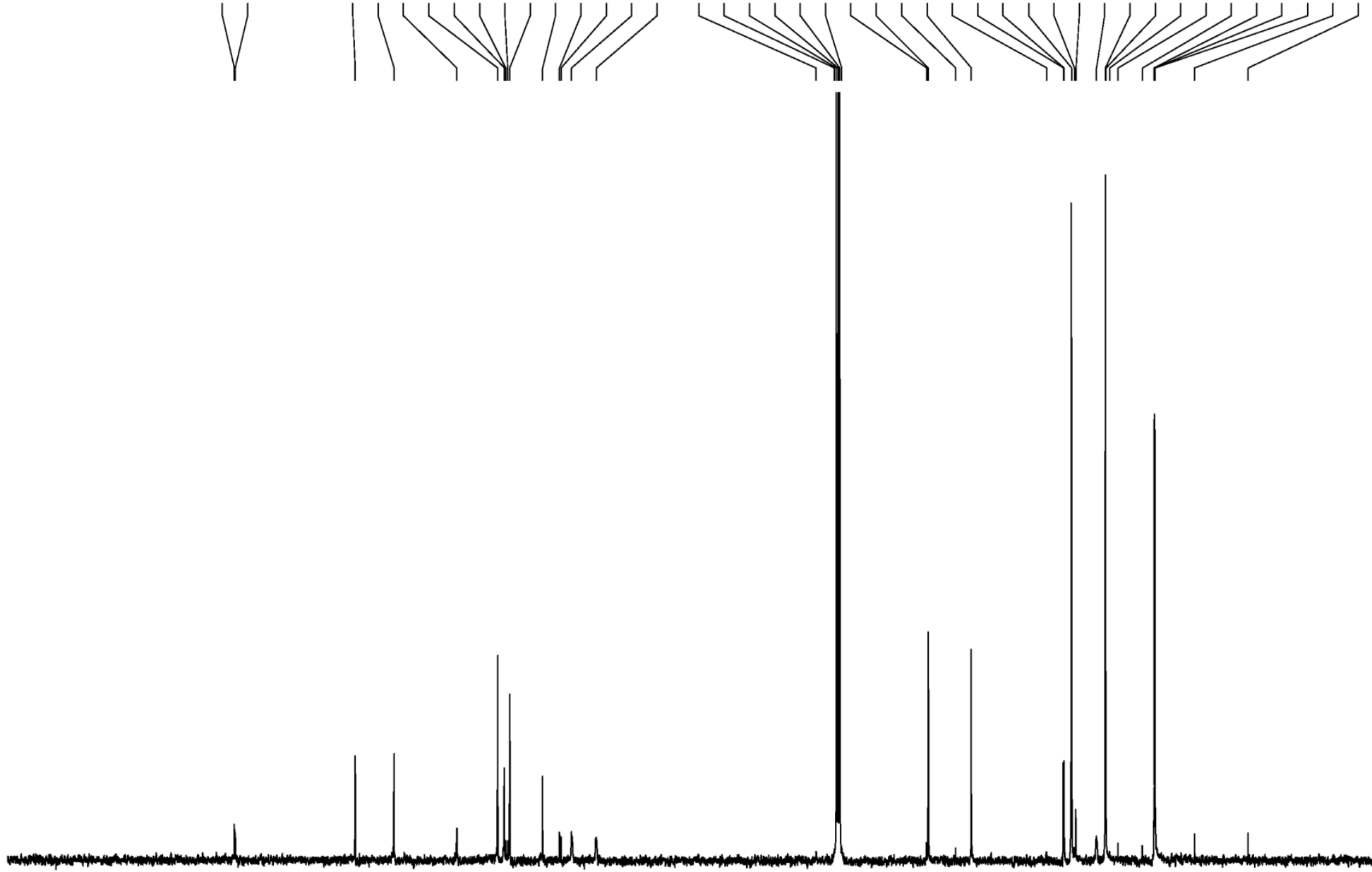


Figure S50. Variable-temperature ${ }^{1} \mathrm{H}$ NMR Spectra of $\mathbf{C 2}\left(\mathrm{CDCl}_{3}, 500.1 \mathrm{MHz}\right)$

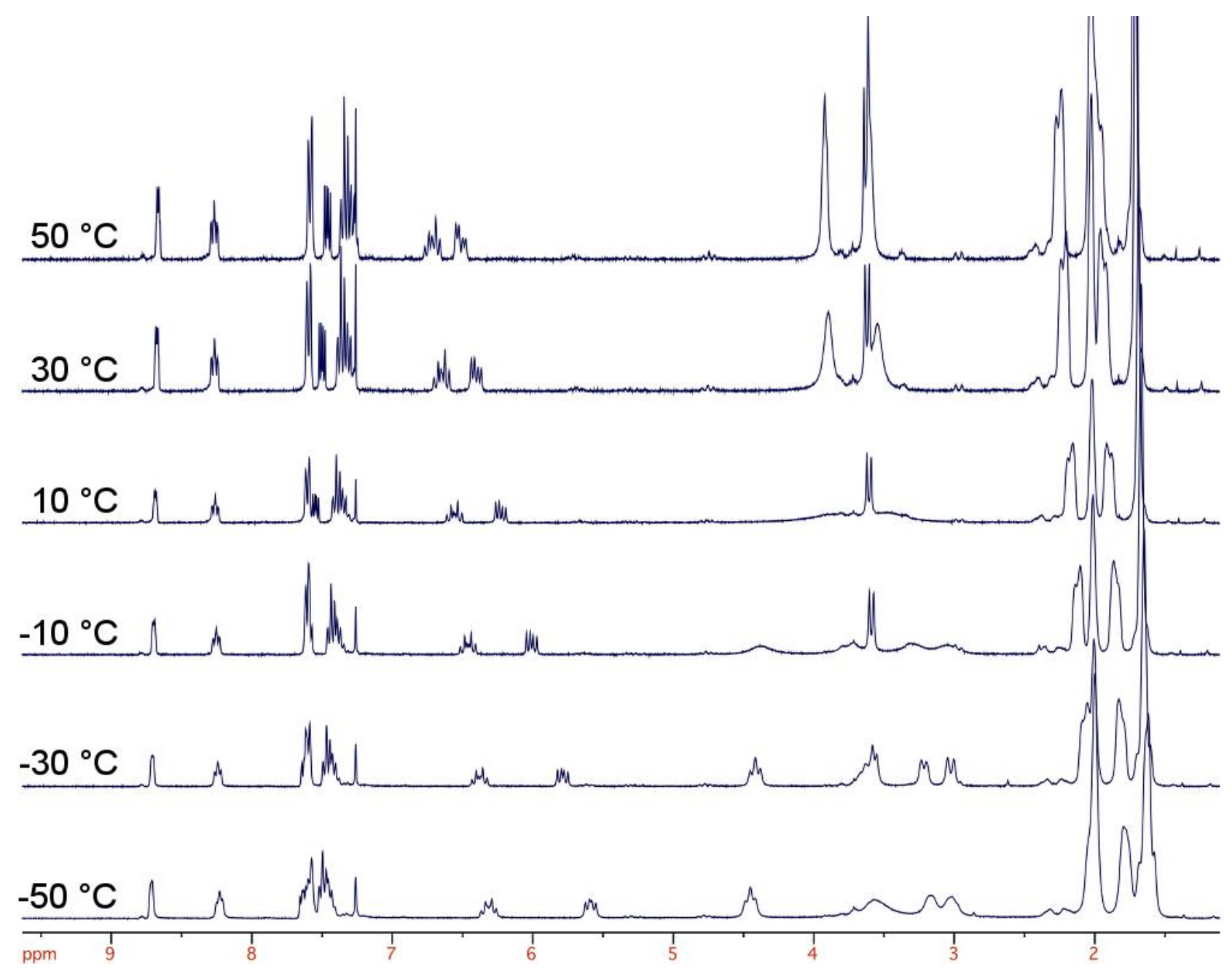


Figure S51. ${ }^{1} \mathrm{H}$ NMR Spectrum of $\mathbf{C} 3\left(\mathrm{CDCl}_{3}, 500.1 \mathrm{MHz}, 300 \mathrm{~K}\right)$
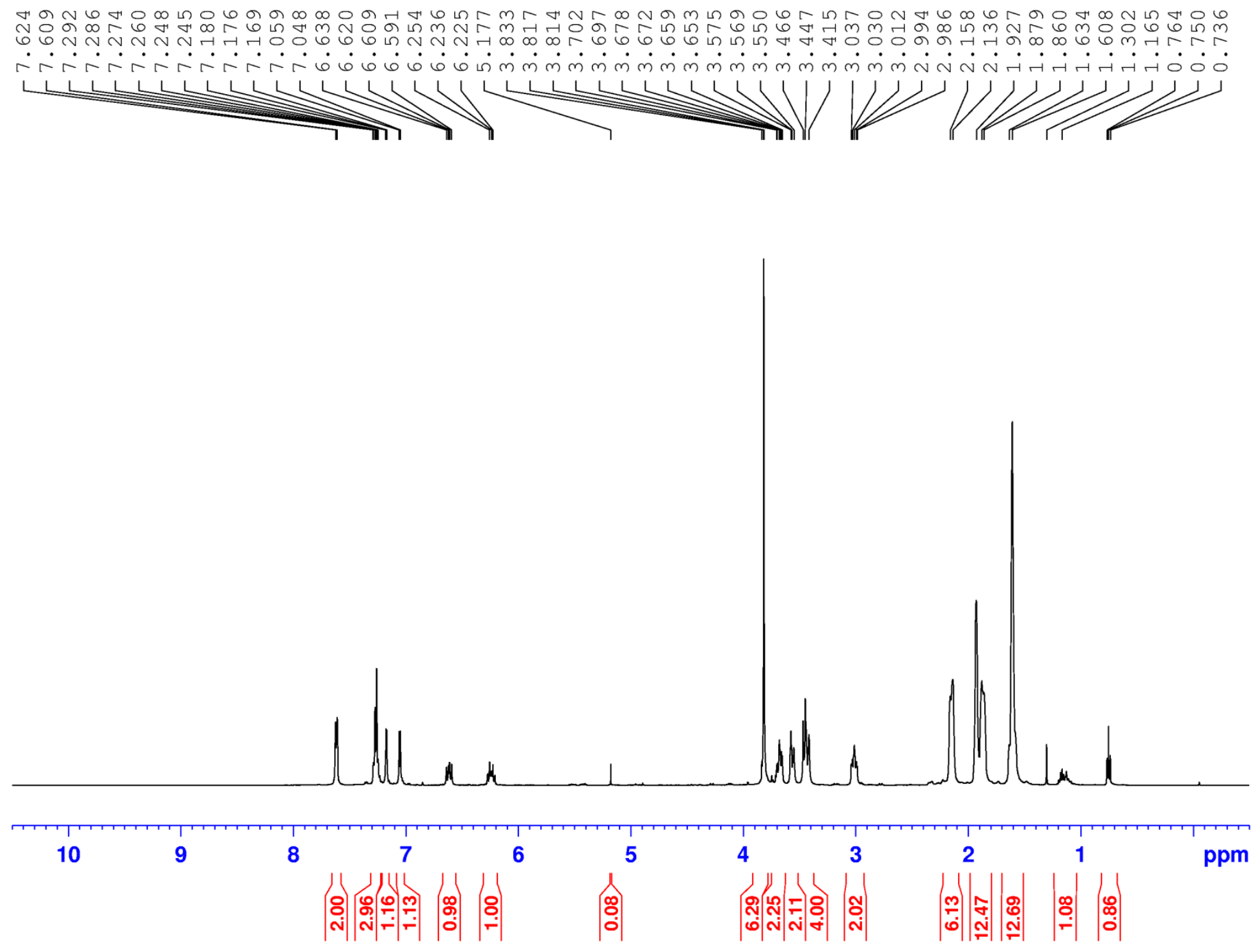
Figure S52. ${ }^{31} \mathrm{P}\left\{{ }^{1} \mathrm{H}\right\}$ NMR Spectrum of $\mathbf{C} 3(\mathrm{CDCl} 3,202.5 \mathrm{MHz}, 300 \mathrm{~K})$
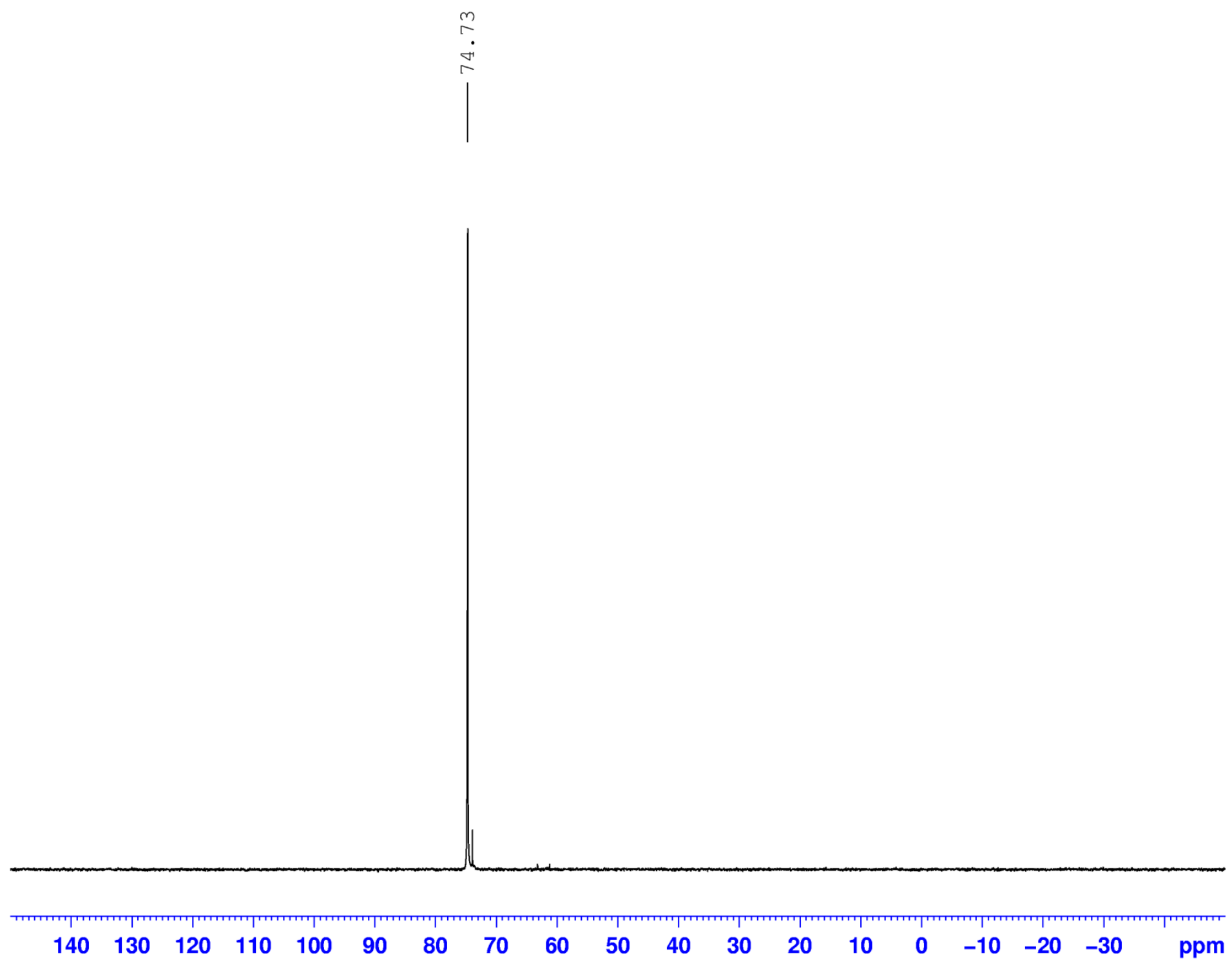
Figure S53. ${ }^{13} \mathrm{C}\left\{{ }^{1} \mathrm{H}\right\}$ NMR Spectrum of $\mathbf{C} 3\left(\mathrm{CDCl}_{3}, 125.7 \mathrm{MHz}, 300 \mathrm{~K}\right)$
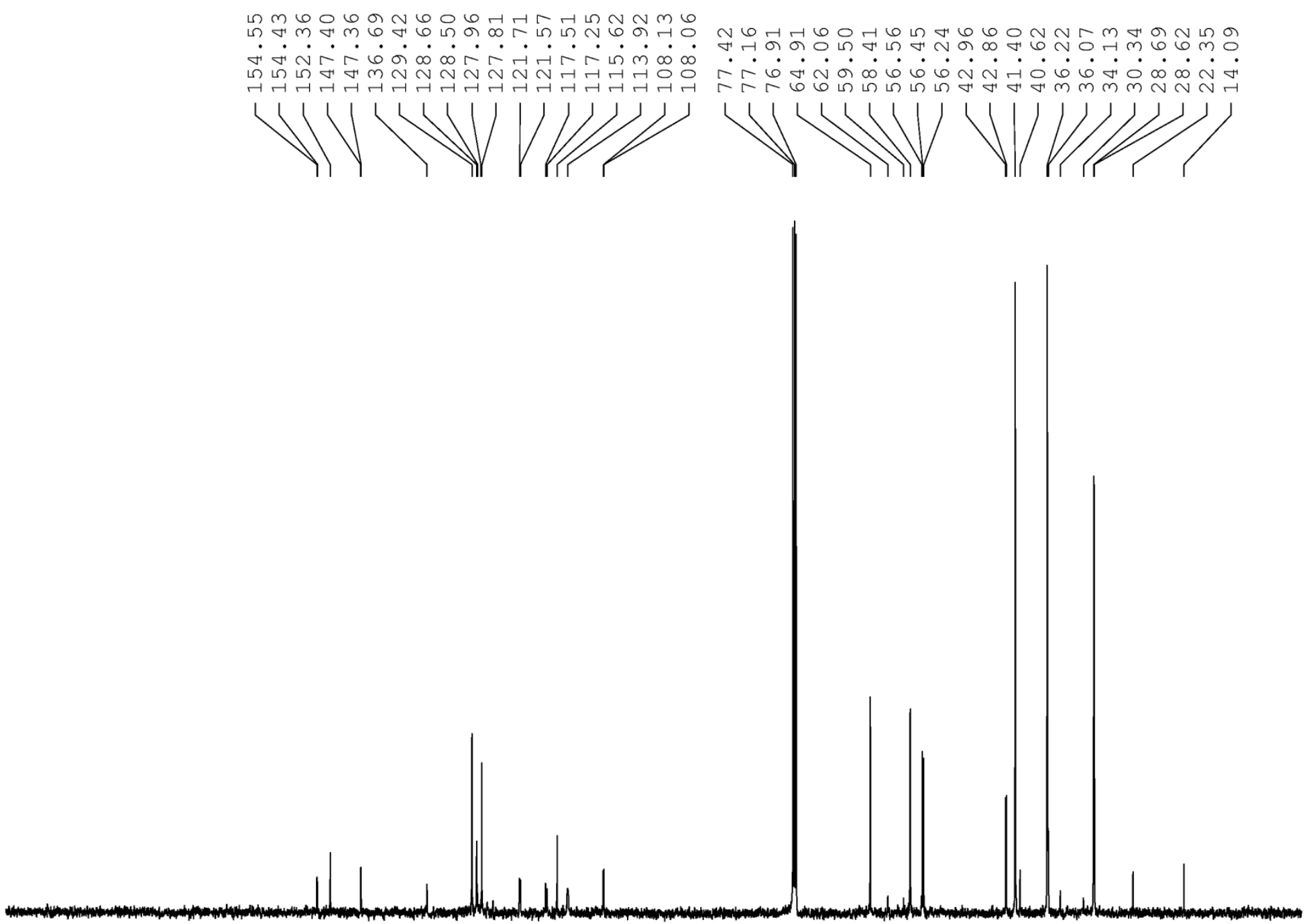
Figure S54. ${ }^{1} \mathrm{H}$ NMR Spectrum of $\mathbf{C 4}\left(\mathrm{CDCl}_{3}, 500.1 \mathrm{MHz}, 300 \mathrm{~K}\right)$

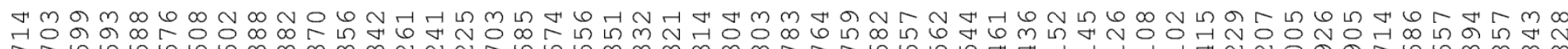

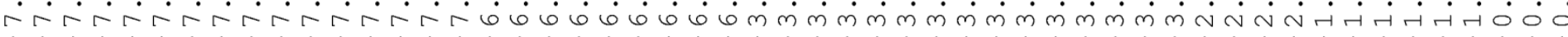
$L$ 11

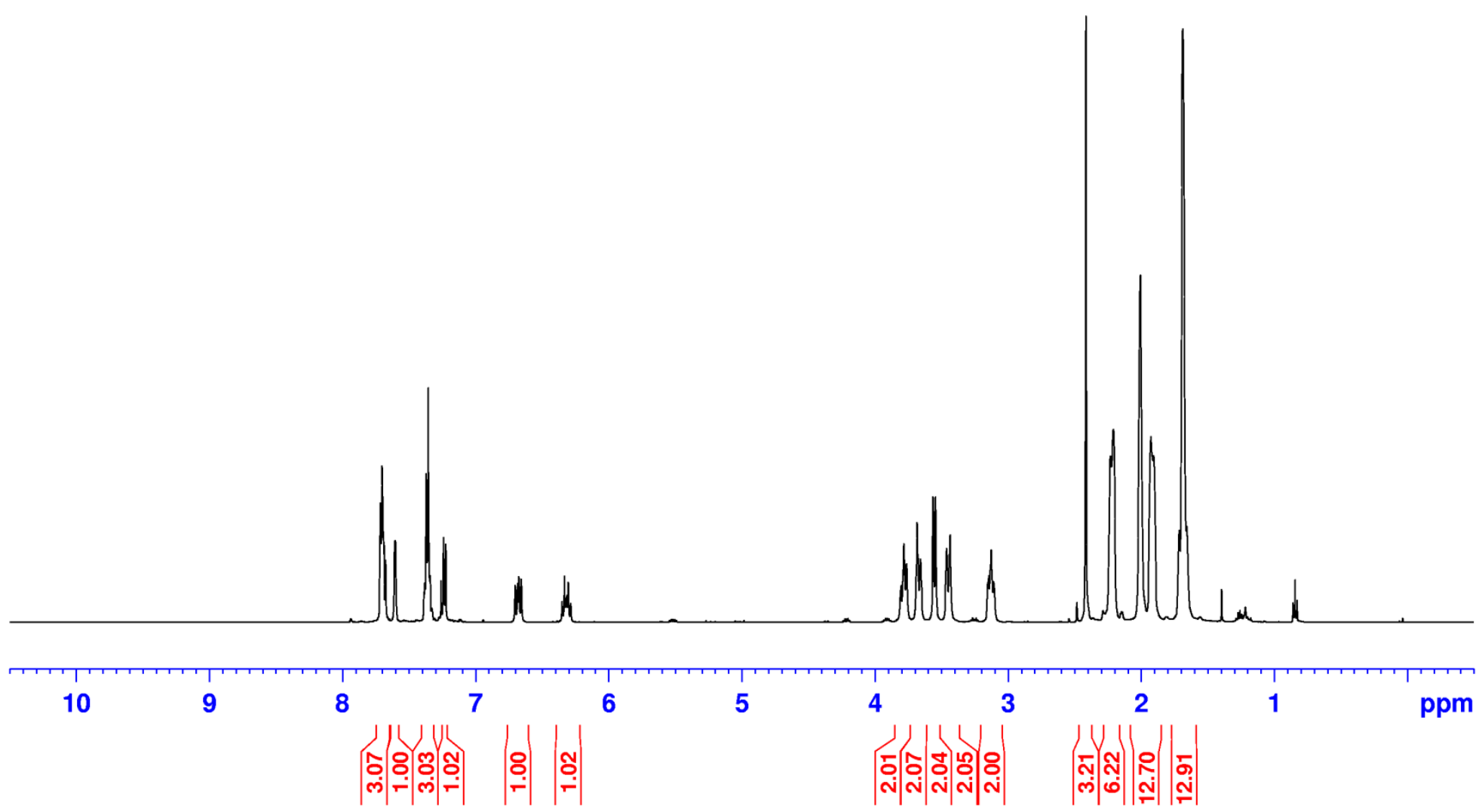


Figure S55. ${ }^{31} \mathrm{P}\left\{{ }^{1} \mathrm{H}\right\}$ NMR Spectrum of $\mathbf{C 4}(\mathrm{CDCl} 3,202.5 \mathrm{MHz}, 300 \mathrm{~K})$
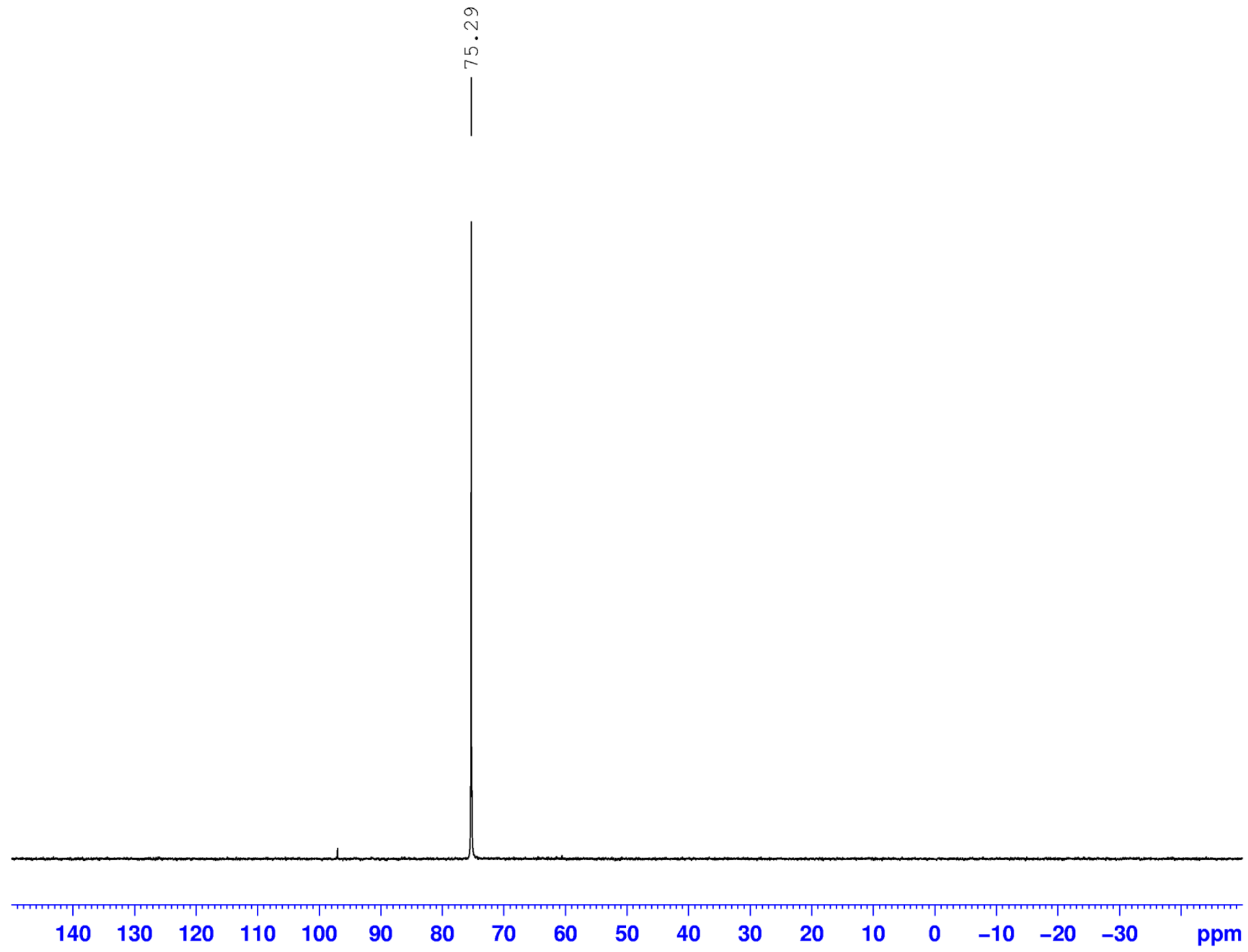
Figure S56. ${ }^{13} \mathrm{C}\left\{{ }^{1} \mathrm{H}\right\}$ NMR Spectrum of $\mathbf{C 4}\left(\mathrm{CDCl}_{3}, 125.7 \mathrm{MHz}, 300 \mathrm{~K}\right)$
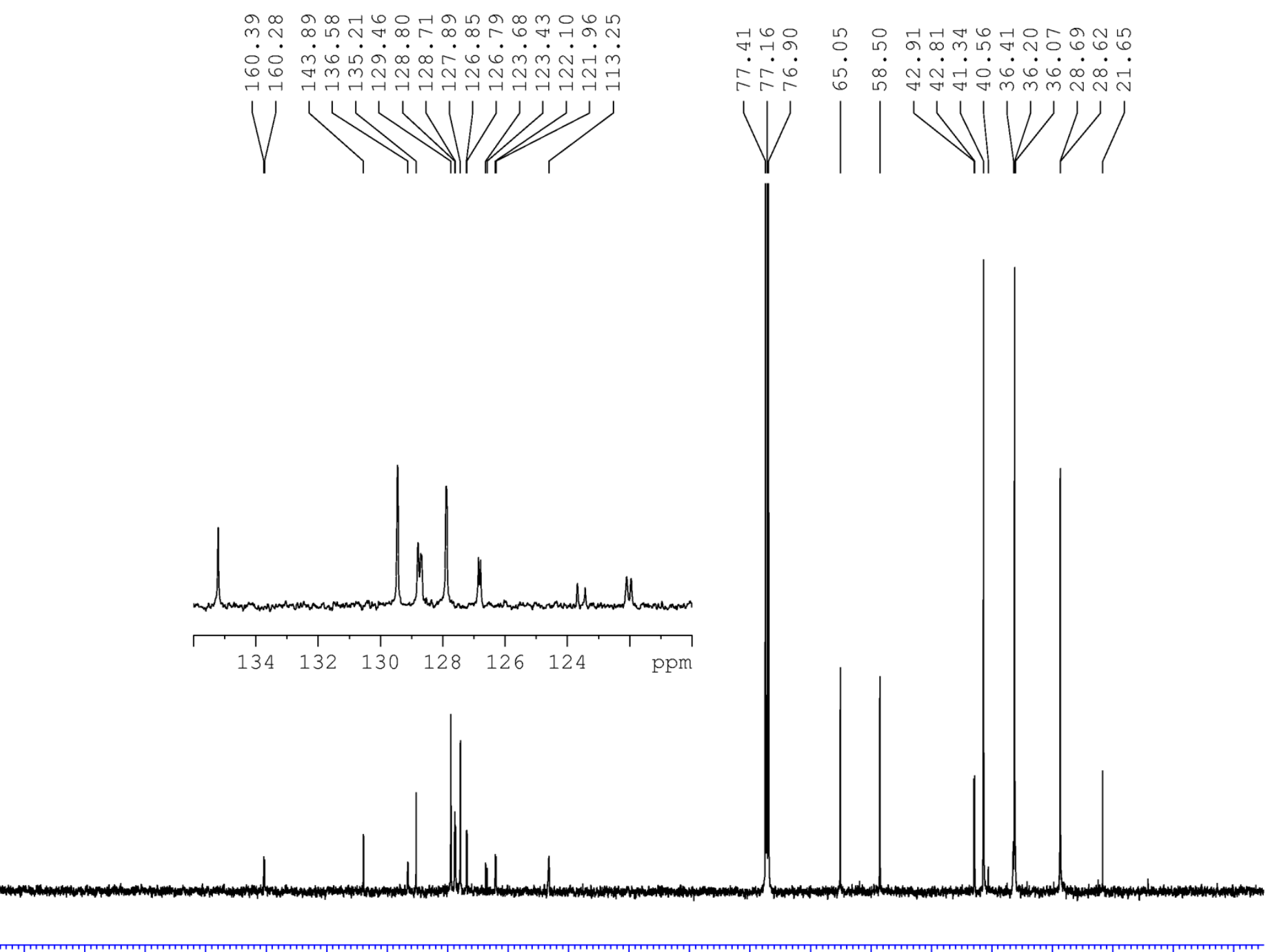

$\begin{array}{llllllllllll}200 & 190 & 180 & 170 & 160 & 150 & 140 & 130 & 120 & 110 & 100 & 90\end{array}$

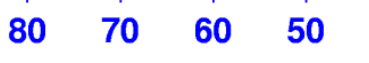

$\begin{array}{lllll}40 & 30 & 20 & 10 & \mathrm{ppm}\end{array}$ 
Figure S57. ${ }^{1} \mathrm{H}$ NMR Spectrum of $\mathbf{C 5}\left(\mathrm{CDCl}_{3}, 500.1 \mathrm{MHz}, 300 \mathrm{~K}\right)$

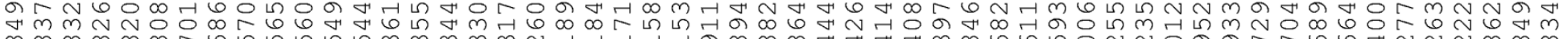

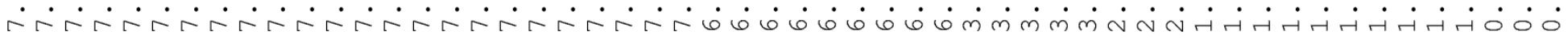
L III 1

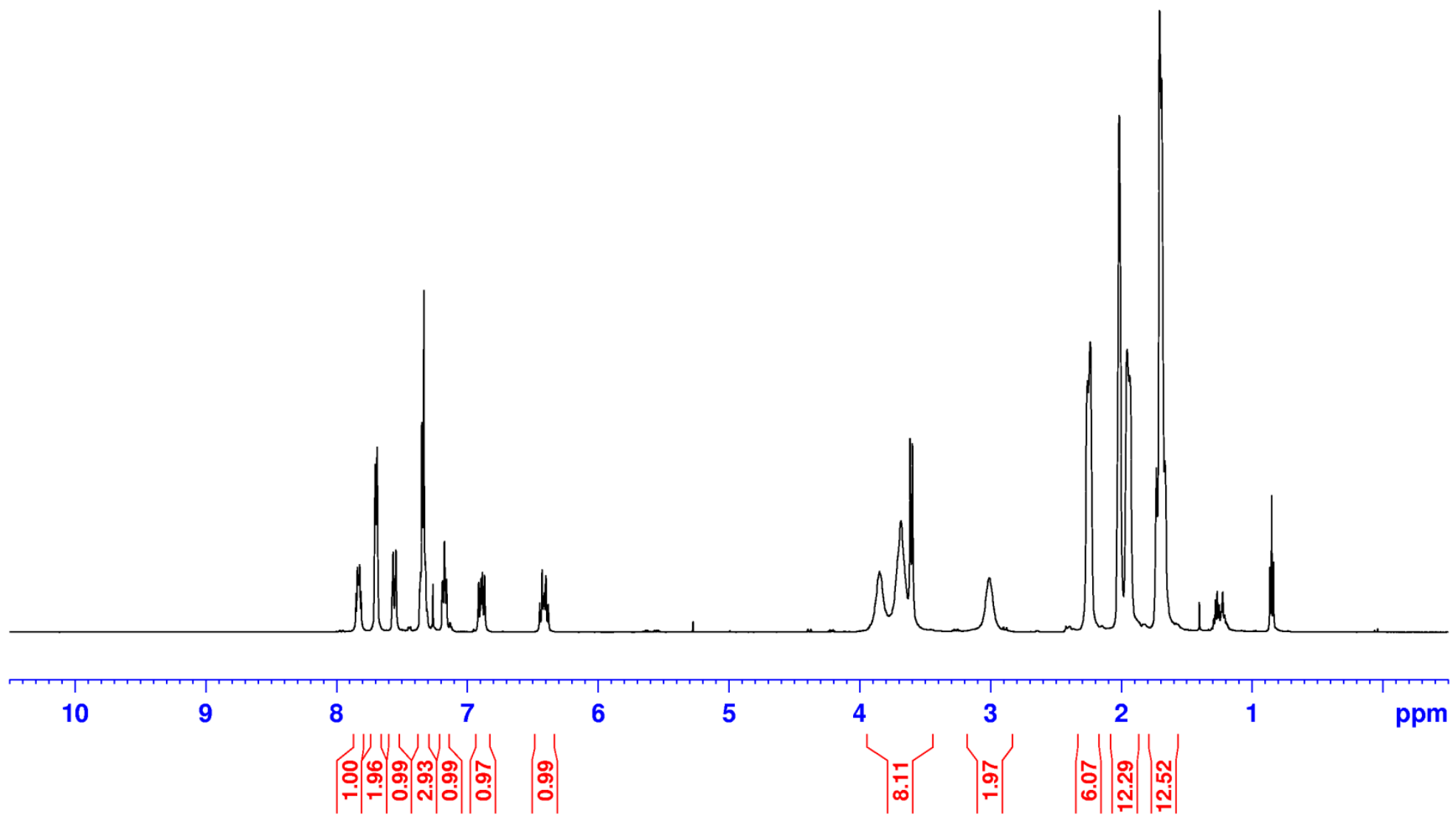


Figure S58. ${ }^{31} \mathrm{P}\left\{{ }^{1} \mathrm{H}\right\}$ NMR Spectrum of $\mathbf{C 5}(\mathrm{CDCl} 3,202.5 \mathrm{MHz}, 300 \mathrm{~K})$
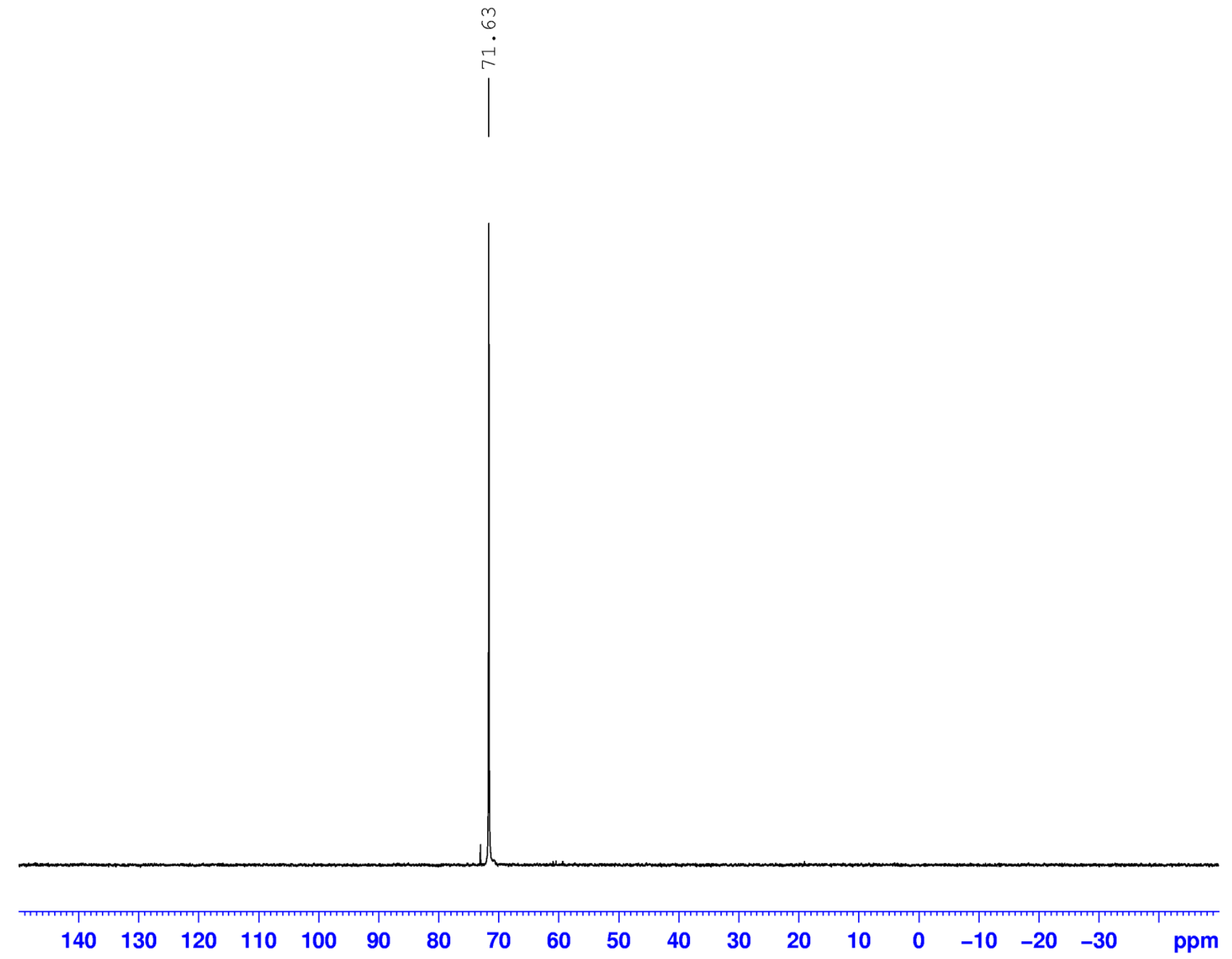
Figure S59. ${ }^{13} \mathrm{C}\left\{{ }^{1} \mathrm{H}\right\}$ NMR Spectrum of $\mathbf{C 5}\left(\mathrm{CDCl}_{3}, 125.7 \mathrm{MHz}, 300 \mathrm{~K}\right)$
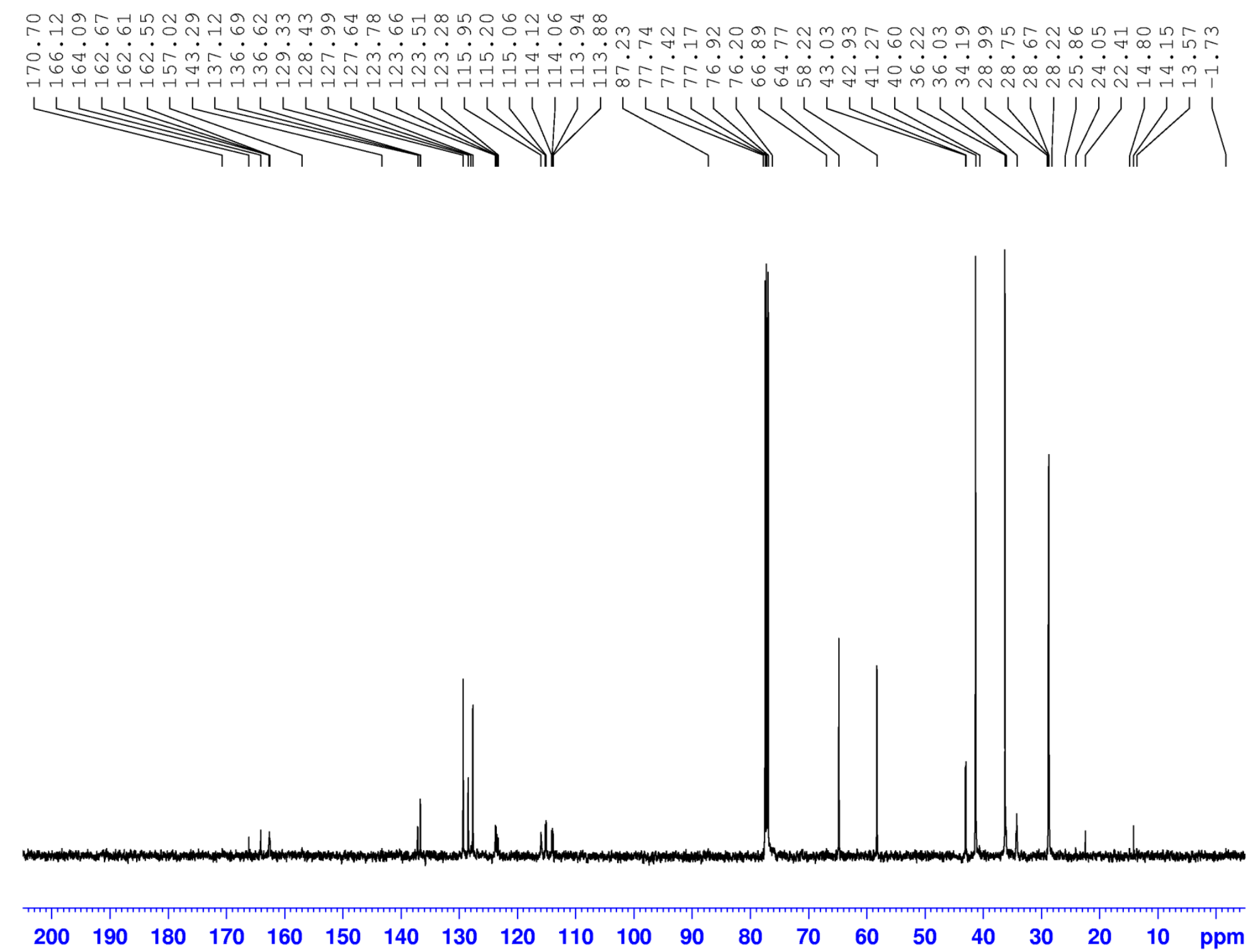
Figure S60. Variable-Temperature ${ }^{1} \mathrm{H}$ NMR Spectrum of $\mathbf{C 5}\left(\mathrm{CDCl}_{3}, 500.1 \mathrm{MHz}\right)$

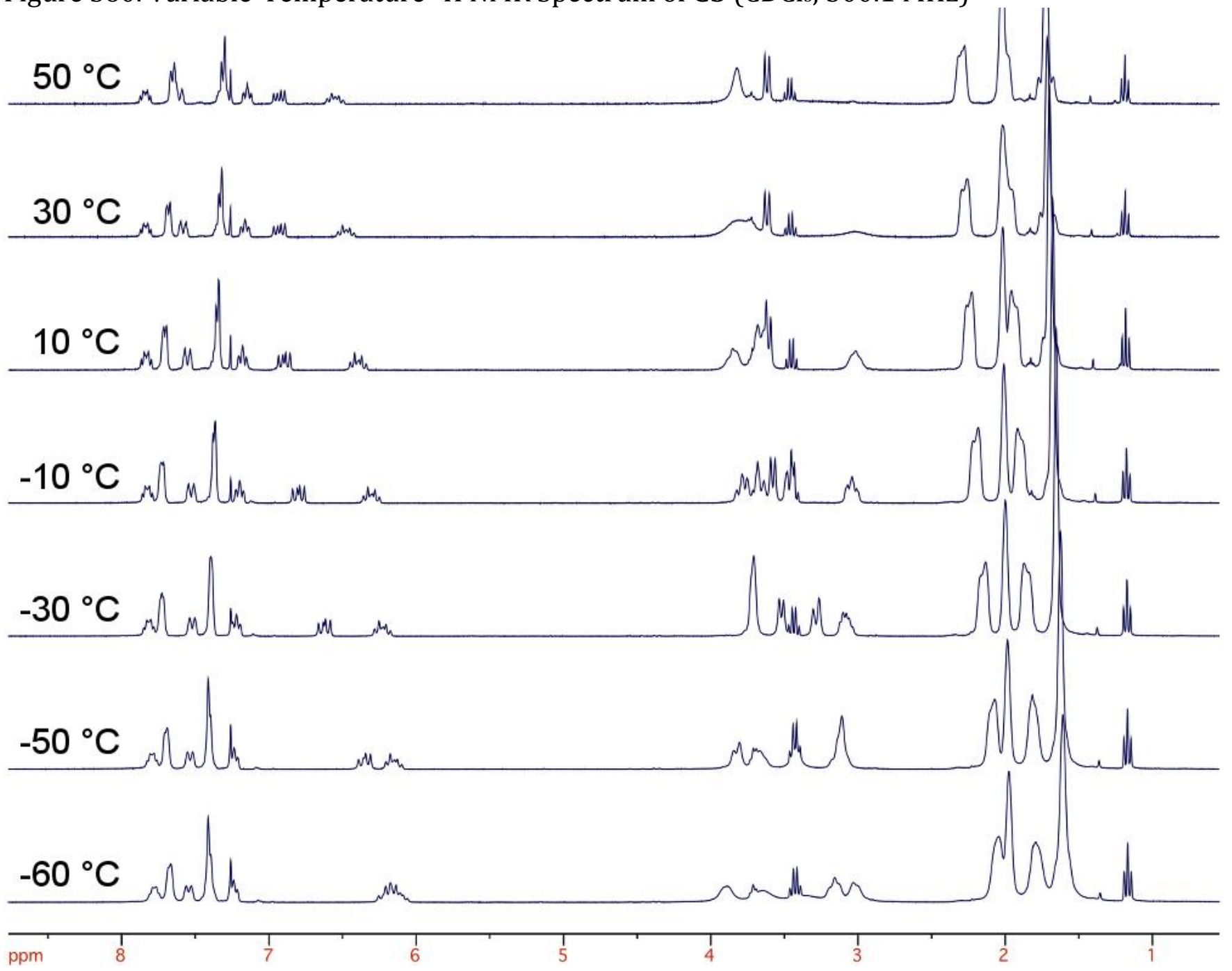


Figure S61. ${ }^{1} \mathrm{H}$ NMR Spectrum of $\mathbf{C 6}\left(\mathrm{CDCl}_{3}, 500.1 \mathrm{MHz}, 300 \mathrm{~K}\right)$
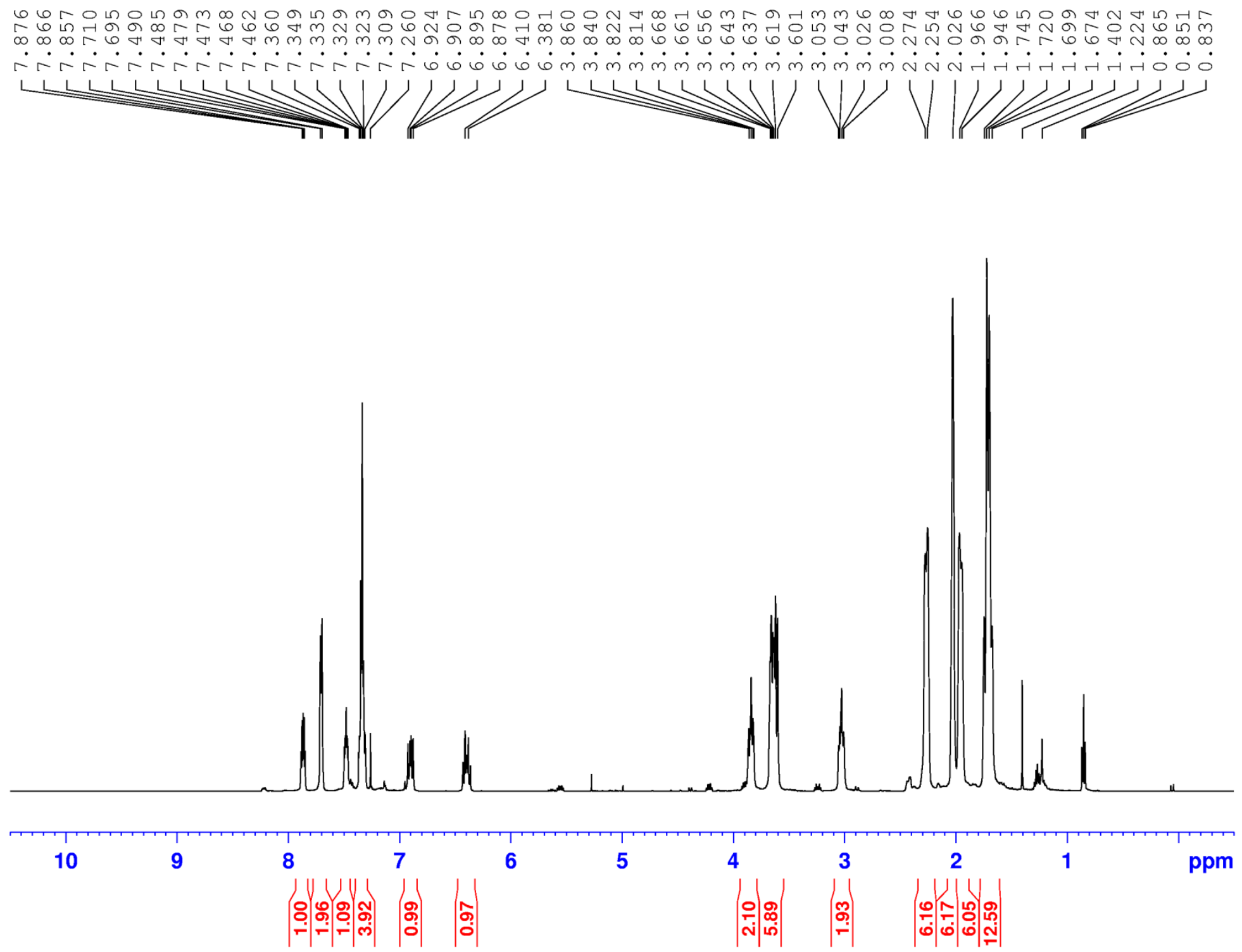
S62

Figure S62. ${ }^{11} \mathrm{P}\left\{{ }^{1} \mathrm{H}\right\}$ NMR Spectrum of $\mathbf{C 6}(\mathrm{CDCl} 3,202.5 \mathrm{MHz}, 300 \mathrm{~K})$

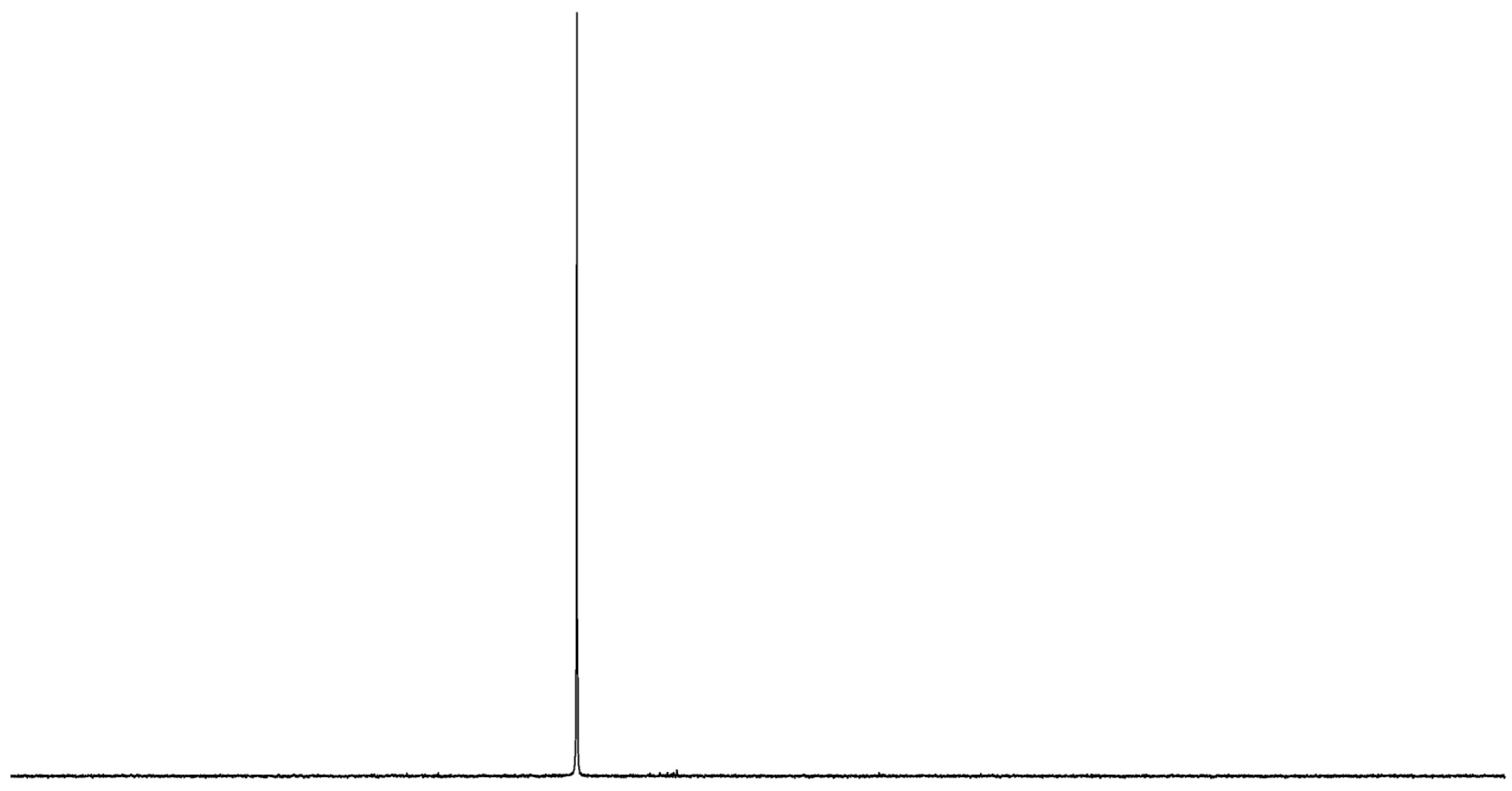

$\begin{array}{lllllllllllllllllll}140 & 130 & 120 & 110 & 100 & 90 & 80 & 70 & 60 & 50 & 40 & 30 & 20 & 10 & 0 & -10 & -20 & -30 & \text { ppm }\end{array}$ 
Figure S63. ${ }^{13} \mathrm{C}\left\{{ }^{1} \mathrm{H}\right\}$ NMR Spectrum of $\mathbf{C 6}\left(\mathrm{CDCl}_{3}, 125.7 \mathrm{MHz}, 300 \mathrm{~K}\right)$ ๙ॅळ

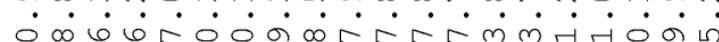

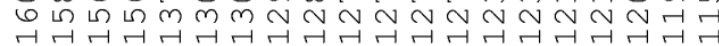

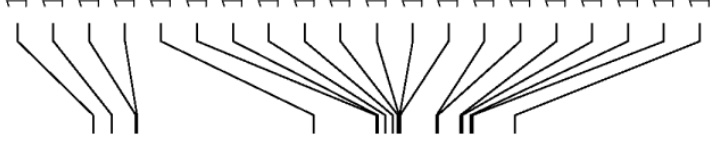

the

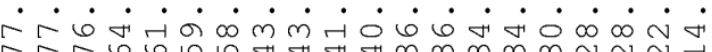
VIII)

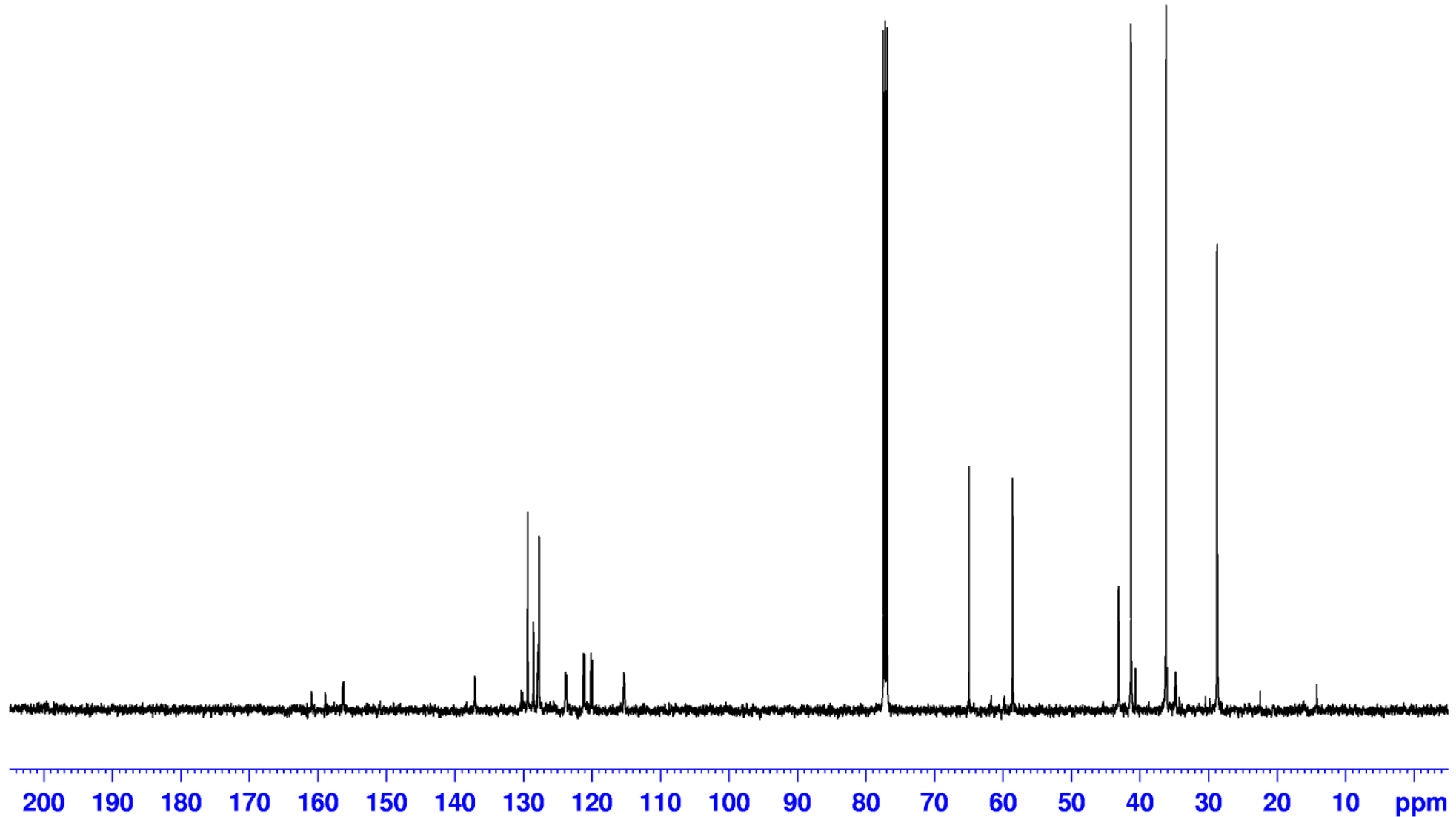


Figure S64. ${ }^{1} \mathrm{H}$ NMR Spectrum of $\mathbf{C 8}\left(\mathrm{CDCl}_{3}, 500.1 \mathrm{MHz}, 300 \mathrm{~K}\right)$
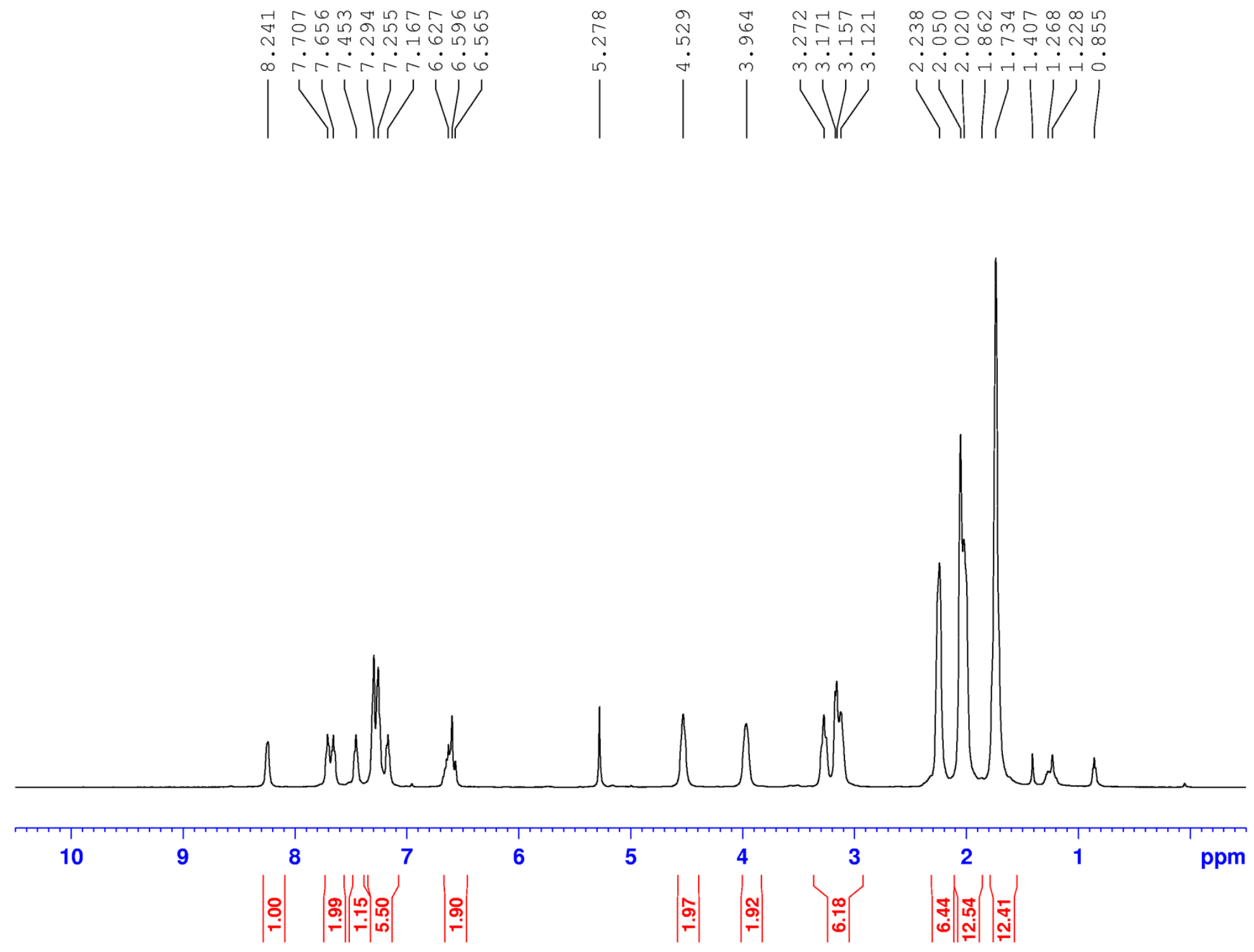
Figure S65. ${ }^{31} \mathrm{P}\left\{{ }^{1} \mathrm{H}\right\}$ NMR Spectrum of $\mathbf{C 8}(\mathrm{CDCl} 3,202.5 \mathrm{MHz}, 300 \mathrm{~K})$
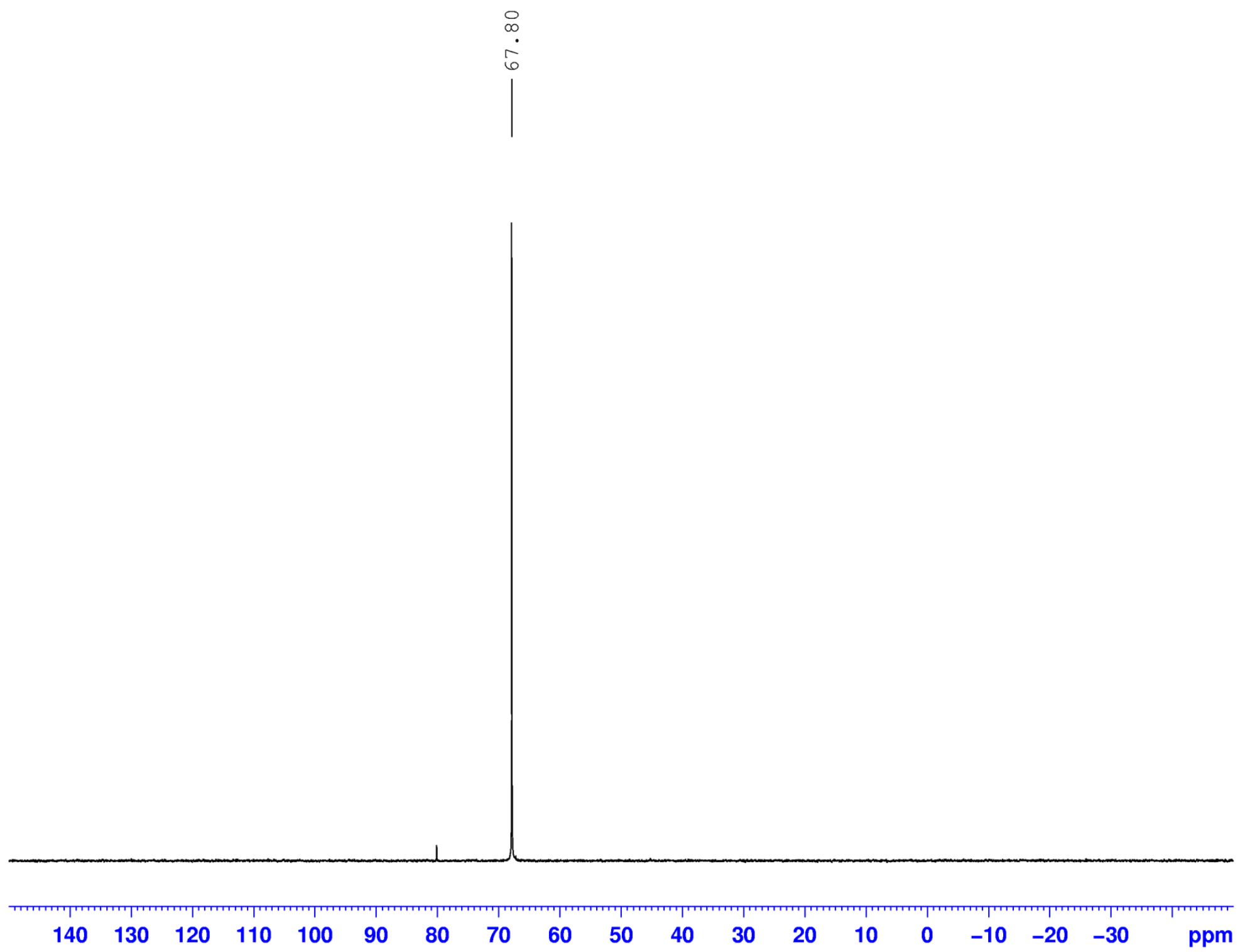
Figure S66. ${ }^{13} \mathrm{C}\left\{{ }^{1} \mathrm{H}\right\}$ NMR Spectrum of $\mathbf{C 8}\left(\mathrm{CDCl}_{3}, 125.7 \mathrm{MHz}, 300 \mathrm{~K}\right)$
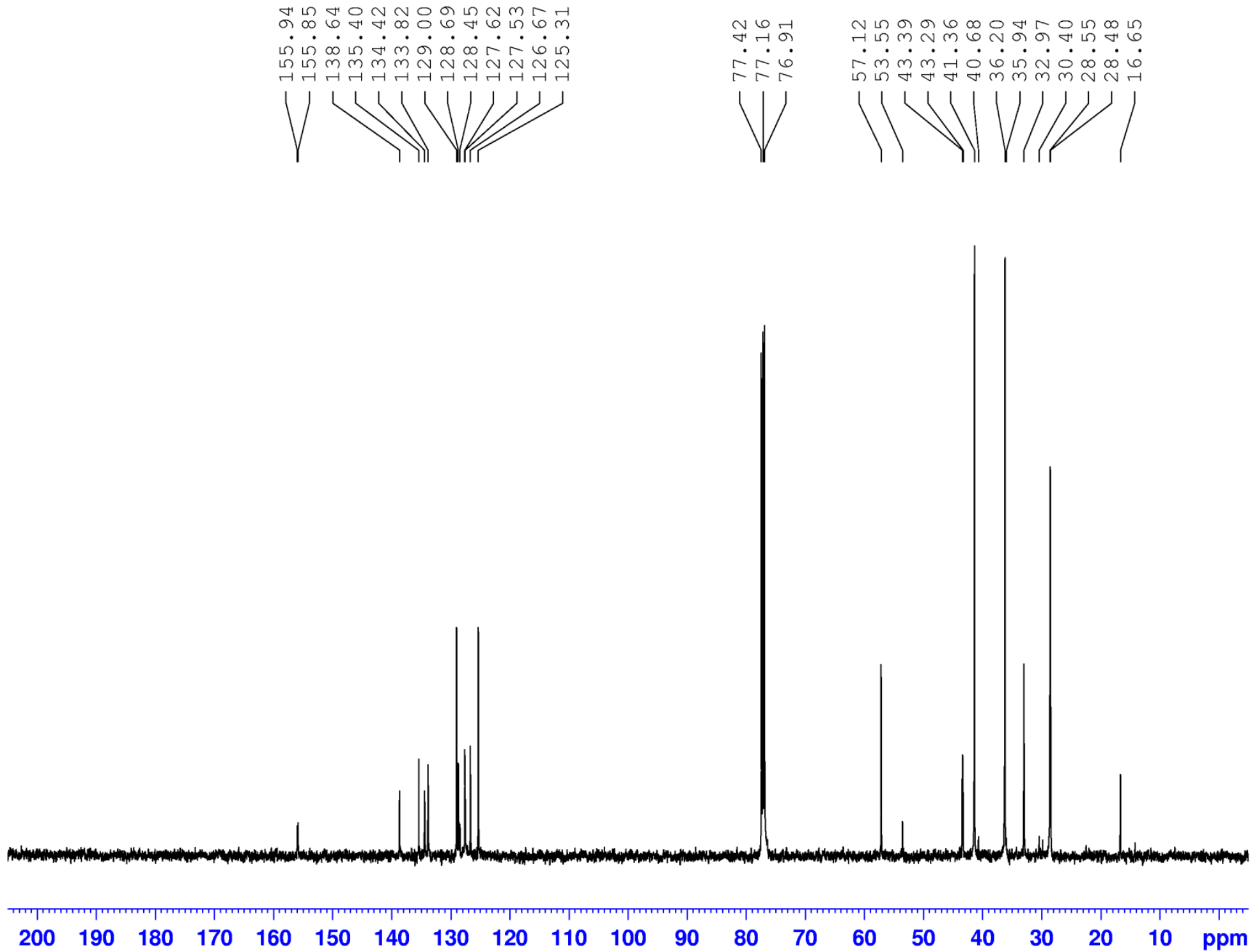
Information regarding deposited CIF data:

\section{CCDC 1582659-1582666}

Summary of Data CCDC 1582659

Compound Name:

Formula: C30 H42 N1 P1 S1

Unit Cell Parameters: a 12.205(2) b 11.509(2) c 18.079(4) P21/n

Summary of Data CCDC 1582660

\section{Compound Name:}

Formula: C30 H41 F1 N1 01 P1

Unit Cell Parameters: a 7.9191(2) b 15.0686(4) c 21.0847(6) P212121

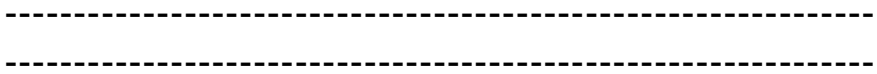

Summary of Data CCDC 1582661

\section{Compound Name:}

Formula: C29 H41 N2 01 P1

Unit Cell Parameters: a 7.9957(4) b 14.9383(7) c 20.8422(10) P212121

\section{Summary of Data CCDC 1582662}

Compound Name:

Formula: C32 H46 N1 03 P1

Unit Cell Parameters: a 10.4270(5) b 11.0705(6) c 12.8635(7) P-1 
Summary of Data CCDC 1582663

Compound Name:

Formula: C39 H51 N1 P1 Pd1 S1 1+,C1 H2 Cl2,Cl1 1-

Unit Cell Parameters: a 18.6330(8) b 10.4416(4) c 19.3804(8) P21/n

Summary of Data CCDC 1582664

Compound Name:

Formula: C39 H50 Cl1 F1 N1 01 P1 Pd1

Unit Cell Parameters: a 10.3503(4) b 18.5899(8) c 17.4546(7) P21/n

Summary of Data CCDC 1582665

Compound Name:

Formula: C40 H53 N1 01 P1 Pd1 1+,Cl1 1-

Unit Cell Parameters: a 10.0961(4) b 12.3233(5) c 18.9808(8) P-1

Summary of Data CCDC 1582666

Compound Name:

Formula: C29 H41 N2 01 P1

Unit Cell Parameters: a 9.9701(5) b 16.9174(8) c 15.3331(7) P21/c 